INSTITUTO DE PESQUISAS ENERGÉTICAS E NUCLEARES Autarquia Associada à Universidade de São Paulo

OBTENÇÃO E AVALIAÇÃO DO COMPORTAMENTO À FADIGA DE COMPÓSITOS DE MATRIZ DE ALUMÍNIO SUBMETIDOS A DIFERENTES TRATAMENTOS SUPERFICIAIS MECÂNICOS

EDSON SOUZA DE JESUS FILHO

Dissertação apresentada como parte dos requisitos para obtenção do grau de Mestre em Ciências na Área de Tecnologia Nuclear - Materiais.

Orientador:

Dr. Jesualdo Luiz Rossi

São Paulo 
À memória de minha mãe

eu dedico este trabalho.

"Para quem deu tudo de sí sem nada pedir, meu profundo amor e eterna gratidão.

Obrigado mamãe." 
Agradecimentos

À Deus pela presença constante.

Ao meu orientador Dr. Jesualdo Luiz Rossi por ter confiado e acreditado no meu trabalho e pela participação valiosa e exaustiva em todas as etapas do mesmo.

Ao Dr. Luis Filipe C. P. de Lima pelo apoio e pelas orientações sempre pertinentes e feitas de maneira simpática.

Ao Dr. Arnaldo H. P. de Andrade, pelas discussões e sugestões construtivas e constantes ao longo do trabalho.

Ao meu irmão MSc. Eng. Edilson Rosa Barbosa de Jesus pela presença e ajuda em tempo integral.

Aos colegas do MM e IEO que direta ou indiretamente participaram da elaboração deste trabalho, em especial ao Célio Miguel.

Ao Laboratório de Caracterização Mecânica do IPT, na pessoa do Dr. Marcelo Gonçalves pela utilização da extrusora na etapa de produção dos materiais.

Ao Laboratório de Ensaios do Departamento de Engenharia Civil da Escola Politécnica da USP, nas pessoas do Sr. Reginaldo Mariano da Silva e Srta. Patrícia Rodrigues de Freitas, pela cessão do equipamento utilizado na compactação dos pós. Ao Departamento de Engenharia Metalúrgica e de Materiais da Escola Politécnica da USP, nas pessoas do Dr. André Paulo Tschiptschin e do Dr. Hélio Goldenstein, da qual fui aluno na fase inicial deste trabalho.

Ao Laboratório de Metalografia do Departamento de Engenharia Metalúrgica e de Materiais da Escola Politécnica da USP, na pessoa da Srta. Márcia Ribeiro pela utilização de equipamentos e auxílio na preparação de amostras e da Srta. Maria Leonora de Castro pela ajuda com o polimento das amostras de Al/SiC.

A todo o pessoal da biblioteca do IPEN e à Sra. Clélia Megherditchian e Srta. Cláudia F. de Lima da biblioteca do Departamento de Engenharia Metalúrgica e de Materiais da Escola Politécnica da USP, pela colaboração e paciência imensurável.

À Universidade Santa Cecília dos Bandeirantes pela cessão do rugosímetro analógico.

Aos queridos amigos Hamilta de Oliveira Santos, Edson Garcia Gomes, Edmara Marques Rodrigues da Silva, Sérgio Luis de Jesus, Cristiane Dias, Wagner Soares dos Santos e Gui Schroer pelo companheirismo e colaboração de diversas maneiras.

A todos os demais colegas.

Aos meus irmãos e familiares. 


\title{
OBTENÇÃO E AVALIAÇÃO DO COMPORTAMENTO À FADIGA DE COMPÓSITOS DE MATRIZ DE ALUMÍNIO SUBMETIDOS A DIFERENTES TRATAMENTOS SUPERFICIAIS MECÂNICOS
}

\author{
Edson Souza de Jesus Filho
}

\begin{abstract}
RESUMO
O objetivo deste trabalho foi a avaliação do comportamento à fadiga de materiais compósitos de matriz metálica (CMM) obtidos pela rota da metalurgia do pó, tendo como variáveis a fração volumétrica de reforços e o tipo de tratamento superficial mecânico utilizado. Foram obtidos materiais compósitos com matriz de alumínio AA 1100 reforçados com partículas de carboneto de silício (SiC) nas frações volumétricas de 5, 10 e 15\%. Uma quantidade de material de controle, constituído unicamente pelo material da matriz também foi produzido para fins de comparação. Os materiais obtidos foram caracterizados física, mecânica e microestruturalmente. Os resultados mostraram, de maneira geral, uma distribuição homogênea das partículas de reforço e melhoria do limite de resistência dos compósitos com relação ao material de controle. Entretanto, alguns defeitos como porosidades e veios de alumínio puro foram detectados esporadicamente. Em outra etapa, foram realizados ensaios de fadiga do tipo axial nos materiais em modo tensão-tensão, com razão de tensões $R=0,1$ e frequência de $15 \mathrm{~Hz}$. Os tipos de tratamentos superficiais utilizados na confecção dos corpos de prova de fadiga foram: usinagem e jateamento. As variáveis de usinagem foram: taxa de avanço e tipo de ferramenta. Os materiais jateados não apresentaram melhorias significativas de vida à fadiga com relação ao material de controle. Os usinados grosseiramente apresentaram a pior vida em fadiga e as marcas de usinagem, nestes casos, funcionaram como fortes concentradores de tensão. Os reforçados com 5\% de $\mathrm{SiC}$, diferentemente daqueles reforçados com 10 e 15\%, apresentaram vida à fadiga inferior à do material de controle, ou por causa do menor limite de escoamento ou devido à menor fração volumétrica de reforços. Os materiais usinados com metal duro (MD) não apresentaram diferenças de vida à fadiga com relação aos usinados com $\mathrm{PCD}$, provavelmente devido à classe do metal duro utilizado. Os materiais reforçados com $5 \%$ de SiC e jateados apresentaram resultados de fadiga com os maiores desvios padrões. Os materiais reforçados com $5 \%$ de SiC apresentaram as menores sensibilidades à fadiga com a variação da carga.
\end{abstract}




\title{
OBTENTION AND EVALUATION OF THE FATIGUE BEHAVIOUR OF ALUMINIUM MATRIX COMPOSITES SUBJECT TO DIFFERENT MECHANICAL SURFACE TREATMENTS
}

\author{
Edson Souza de Jesus Filho
}

\begin{abstract}
The objective of this work was the evaluation of the fatigue behaviour of aluminium metal matrix composites (MMC) obtained by powder metallurgy. The testing variables were the volumetric fraction of reinforcements and the type of mechanical surface treatment used. Initially, the composite materials were obtained from aluminium AA 1100 matrix, reinforced with silicon carbide ( $\mathrm{SiC}$ ) particles in the volumetric fraction of 5,10 and 15\%. An amount of control material (unreinforced) was produced for comparison purposes. The obtained materials were physically, mechanically and microstructurally characterised. The results showed a homogeneous distribution of the reinforcement particles and an improvement of the ultimate tensile strength of the composites with relation to the control material. However, some defects such as porosity and streaks of pure aluminium were detected. In a second stage, the fatigue tests of the composites were accomplished. The types of surface treatments used in the fabrication of the fatigue test specimens were machining and shot peening. For machining the variables were feed rate and tool type. The shot peened materials did not present a significant fatigue life improvement when compared to the control material. The coarse machined materials presented the worst fatigue life and the machining marks worked as strong stress concentrators. The material reinforced with $5 \%$ of SiC, differently of those reinforced with 10 and $15 \%$ showed inferior fatigue life when compared to the control material, probably because of a lower yielding strength, or lower reinforcement volumetric fraction. The material machined with hard metal (MD) did not present differences of fatigue life with relation to the machined with PCD, probably due to the class of the hard metal used. The material reinforced with $5 \%$ of $\mathrm{SiC}$ and shot peened, presented fatigue results with the largest standard deviations. The materials reinforced with $5 \%$ of SiC presented the smallest fatigue sensibility with the load variation.
\end{abstract}


ÍNDICE

Assunto

Pág.

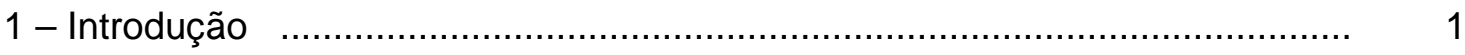

1.1 - Prefácio $\quad$.................................................................................... 1

1.2 - Relevância do assunto $\quad$............................................................ 2

1.3 - Objetivos, abrangência e delimitação da abordagem $\quad$.................... 4

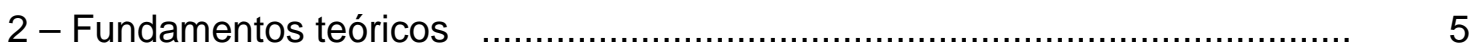

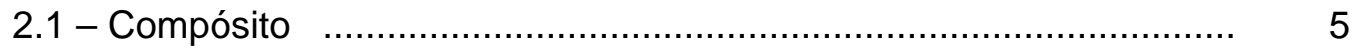

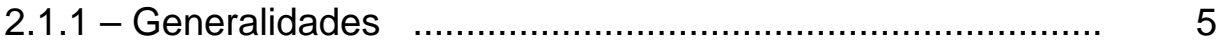

2.1 .2 - Tipos de compósitos .................................................... 6

2.1.3 - Compósitos de matriz metálica (CMM) …...................... 8

2.1.4 - Métodos de produção de CMM …................................ 9

2.1.4.1 - Produção de CMM via metalurgia do pó $\quad$.......... 11

2.1 .5 - Aplicações de CMM ….............................................. 13

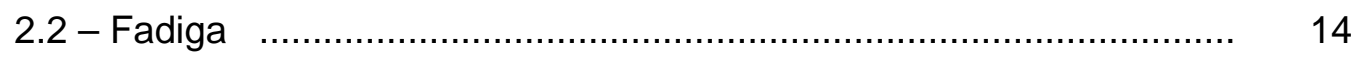

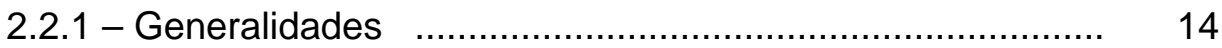

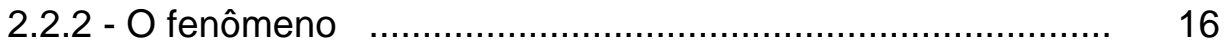

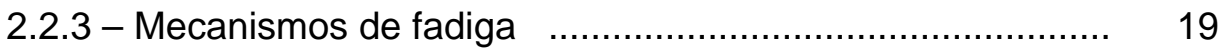

2.2.4 - Métodos de determinação da fadiga $\quad$.............................. 21

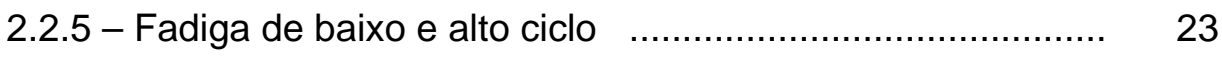

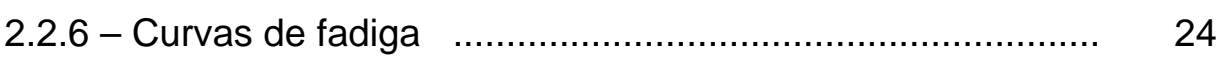

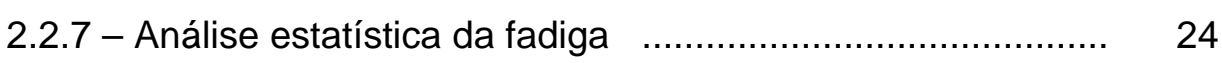

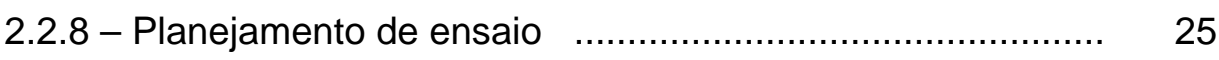

2.2 .9 - Fadiga em CMM ....................................................... 26

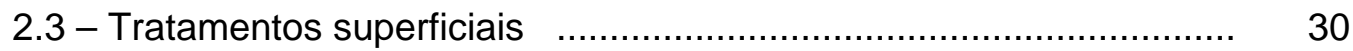

2.3.1 - Generalidades ................................................... $\quad 30$

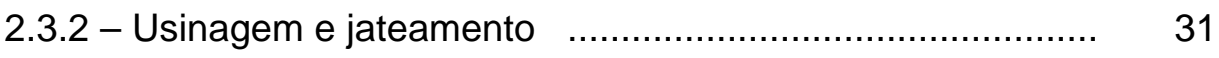

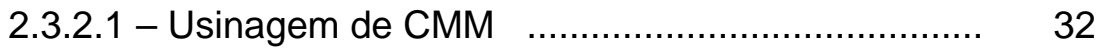

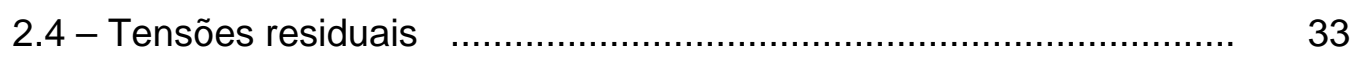

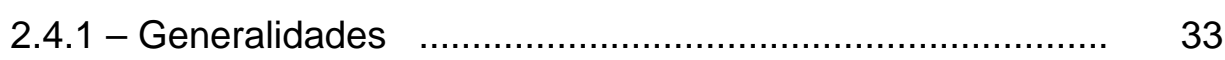

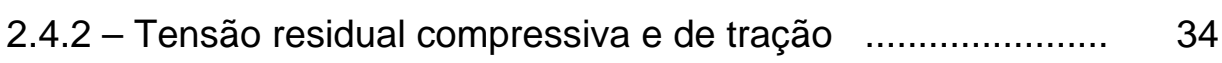

2.5 - Rugosidade $\quad$............................................................................ 35

2.5 .1 - Generalidades $\quad$....................................................... 35

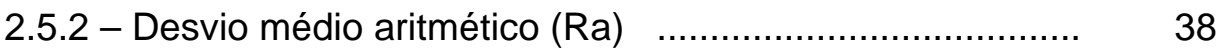




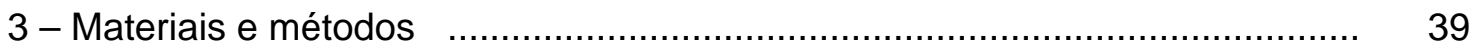

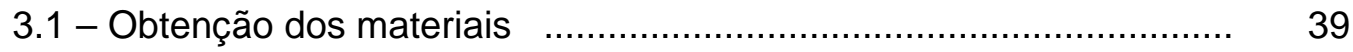

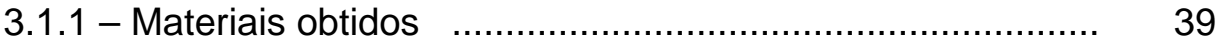

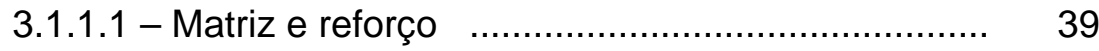

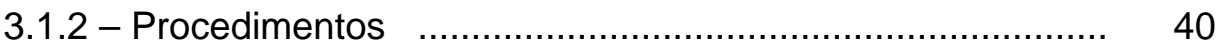

3.1.2.1 - Detalhamento das etapas de obtenção dos materiais

3.1.3 - Caracterização física, mecânica e microestrutural dos materiais obtidos

3.1.3.1 - Dureza e resistência mecânica

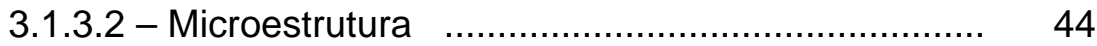

3.1.3.3 - Densidade ............................................... 45

3.2 - Confecção dos corpos de prova para os ensaios de fadiga $\quad$.......... 46

3.2.1 - Definição das condições de preparação $\quad$.......................... 46

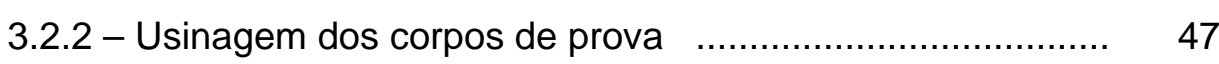

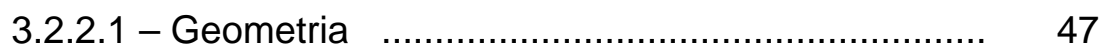

3.2.2.2 - Preparação e pré usinagem …......................... 48

3.2.2.3 - Usinagem final dos corpos de prova $\quad . . . . . . . . . . . . . \quad 49$

3.2.2.4 - Jateamento ............................................. 51

3.2.2.5 - Dimensão e rugosidade dos corpos de prova .. 51

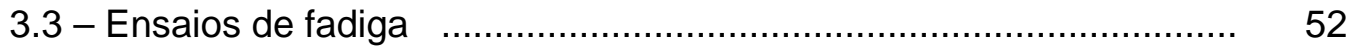

3.3.1 - Definição dos parâmetros de ensaio ............................. 52

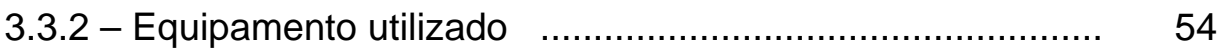

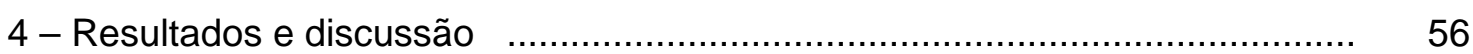

4.1 - Caracterização mecânica, física e microestrutural ....................... 56

4.1 .1 - Caracterização mecânica $\quad$............................................ 56

4.1.1.1 - Fractografias - ensaios de tração .................. 58

4.1.2 - Caracterização física $\quad$................................................... 59

4.1 .3 - Microestrutura $\quad$....................................................... 61

4.1.4 - Rugosidade e dimensões dos corpos de prova $\quad$.............. $\quad 65$

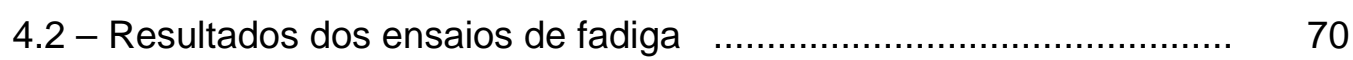

4.2.1 - Curvas de fadiga individuais das condições de ensaio

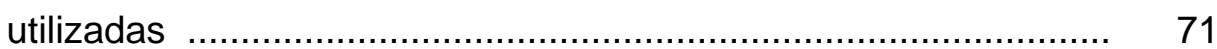

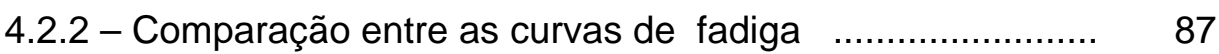

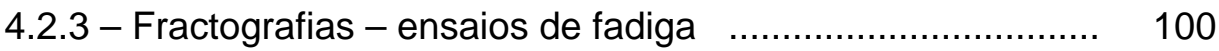




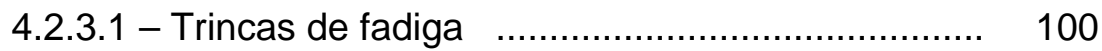

4.2.3.2 - Superfícies de fratura ................................... 105

4.2.3.3 - Aspecto transversal das fraturas de fadiga $\ldots . . . \quad 109$

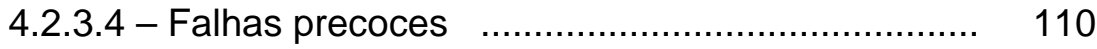

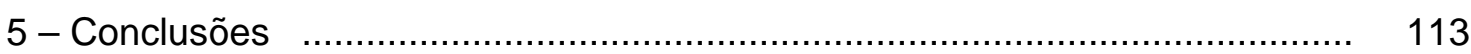

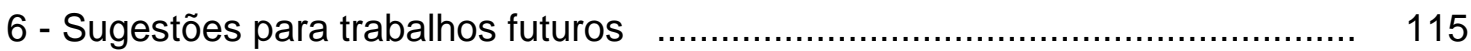

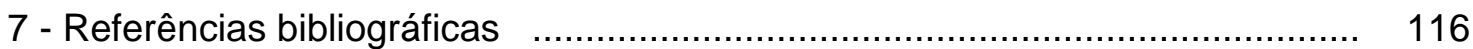

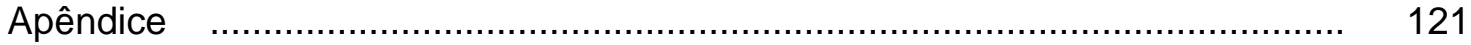




\section{INTRODUÇÃO}

\section{1 - Prefácio}

Dentre os diversos motivos pelos quais pesquisadores da área de materiais e indústrias de manufatura do mundo inteiro têm dedicado grande atenção e investido tempo e dinheiro em pesquisas, dois deles têm importância fundamental. O primeiro está associado com o comportamento dos materiais quando submetidos a carregamentos de natureza cíclica, que podem levar um componente mecânico à falha mesmo com níveis de carga situados abaixo do limite de escoamento. Este fenômeno, intitulado fadiga, já há muito tempo é conhecido, entretanto, ainda hoje é objeto de intensa pesquisa devido à sua grande complexidade e número de variáveis envolvidas.

O segundo motivo diz respeito a uma nova classe de materiais que vêm se destacando nos últimos anos em diversos campos de aplicação. Chamados comumente de compósitos, caracterizam-se por serem constituídos de dois ou mais componentes com propriedades mecânicas e/ou físicas bastante distintas. Quando unidos, entretanto, mesclam suas propriedades de tal forma, que tem sido possível por exemplo, obter materiais de alta resistência mecânica e baixo peso específico, entre outras características interessantes.

O emprego destes materiais de maneira mais ampla requer que um interessante desafio seja vencido, e que consiste basicamente em se conhecer com maior profundidade o comportamento dos mesmos quando se confrontam com o fenômeno da fadiga. Se a fadiga já é complexa e de difícil tratamento em materiais monolíticos, há de se esperar que sua compreensão seja mais difícil quando presente em materiais compósitos.

Desta forma, o presente trabalho pretende somar-se ao que já existe sobre o assunto, para promover uma melhor compreensão do fenômeno de fadiga em 
materiais desta natureza. Com isso, espera-se possibilitar uma melhor aplicação, com racionalidade e segurança, destes materiais.

\section{2 - Relevância do assunto}

MATTHEWS E RAWLINGS [1] e KUMAI, KING e KNOTT [2] alertam para o fato de que as falhas em materiais compósitos de matriz metálica (CMM), sujeitos a flutuações ou tensões cíclicas não têm sido investigadas com a mesma extensão como no caso das propriedades obtidas sob carregamentos estáticos.

Segundo OMAM, LU, LIEURADE e FLAVENOT [3], os resultados disponíveis até então sobre fadiga desta classe de materiais ainda são bastante contraditórios, e citam como exemplo, os resultados obtidos por KUMAI et al. [2] quando estudaram compósitos com matriz de alumínio 6061 reforçados com partículas ou whiskers de SiC sujeitos a carregamentos cíclicos em regimes de alto e baixo ciclo. Eles verificaram que os materiais reforçados (compósitos) não apresentaram melhorias de vida à fadiga com relação ao material não reforçado, quando solicitados em regime de baixo ciclo; entretanto, para o regime de alto ciclo a vida à fadiga se mostrou superior.

HARRIS [4] estudou dois tipos de alumínio (AA-1100 e 2618A) reforçados com $20 \%$ em volume de fibras de $\mathrm{Al}_{2} \mathrm{O}_{3}$ em regime de alto ciclo e verificou melhorias de vida à fadiga com relação ao material não reforçado apenas para o compósito com matriz de alumínio AA-1100. O outro compósito apresentou comportamento à fadiga inferior ao correspondente material não reforçado.

Estas contradições podem ser devidas a diferentes aspectos, que vão desde a estrutura do material, passando pelas condições de obtenção (processamento e manufatura), chegando até o nível e a natureza das solicitações impostas $[3,5]$. 
Conforme BONNEN, ALLISON e JONES [5], muitas das aplicações para as quais estes materiais podem ser considerados, envolvem carregamento cíclico, e portanto as propriedades à fadiga são de grande interesse.

Outro aspecto importante, por afetar de maneira bastante direta a vida à fadiga dos materiais, é a condição superficial dos mesmos. HABEL, CHRISTENSON, ALLISON e JONES [6] afirmam que o processo de falha por fadiga é afetado por uma variedade de fatores, entre eles, a condição de superfície. QUIGLEY, MONAGHAN e O'REILLY [7] também concordam que defeitos superficiais influenciam no comportamento à fratura dos $\mathrm{CMM}$, e que portanto o acabamento superficial é importante.

STUCKY e RICHARD [8], SHARP, CLAYTON e CLARK [9], TAYLOR e CLANCY [10] e JESUS FILHO e ROSSI [11], de maneira geral, também associam a performance dos materiais às solicitações que lhe são impostas (sobretudo aquelas de natureza dinâmica) ao estado de superfície dos mesmos, mostrando que este fator deve ser observado com rigor nas etapas de processamento e manufatura de componentes. O Metals Handbook [12] no capítulo que aborda falha, análise e prevenção, retrata a influência das práticas de manufatura sobre a resistência à fadiga dos materiais monolíticos, enfatizando a introdução ou remoção de tensões residuais, bem como de irregularidades superficiais, que agem como concentradores de tensão e pontos críticos para o surgimento e crescimento de trincas de fadiga.

Todos os aspectos comentados e considerados anteriormente, realçam a relevância e a importância das propriedades dinâmicas dos CMM, associadas ao estado de superfície dos mesmos, tornando assim, este assunto tema extensivo do presente trabalho. 


\section{3 - Objetivos, abrangência e delimitação da abordagem}

O trabalho em questão é composto basicamente por duas etapas. A primeira consistiu na obtenção dos materiais de estudo e a segunda visou avaliar o comportamento à fadiga destes materiais sob certas condições de tratamentos superficiais bem definidas.

A elaboração do presente estudo está centrada nas seguintes abordagens:

-Conhecer a sensibilidade destes materiais à fadiga, quando submetidos a diferentes tipos de tratamentos superficiais mecânicos, visto que, independentemente do processo adotado para manufaturá-los, haverá sempre um grau de acabamento superficial e de tensão residual associados que, poderão influenciar nas propriedades mecânicas do componente final, sobretudo, naquelas associadas a carregamentos de natureza dinâmica [11,13].

-Estudar o comportamento à fadiga de materiais compósitos de matriz metálica constituídos por uma matriz de alumínio comercialmente puro. Embora esta matriz não proporcione ao compósito propriedades de resistência mecânica extraordinárias, ela pode ser interessante em aplicações que requeiram moderada resistência mecânica, aliada a boas características de estabilidade térmica, resistência ao desgaste, resistência à fadiga e resistência a ambientes corrosivos [14].

-Avaliar o comportamento à fadiga destes materiais com a variação da fração volumétrica de reforço dos mesmos.

Desta forma, este estudo torna-se importante, na medida em que fornece informações sobre a vida à fadiga destes materiais sob certas condições bem definidas de tratamento superficial, contribuindo assim para que as indústrias, não só possam definir a melhor aplicação para estes materiais, como também, possam selecionar o processo mais adequado para sua manufatura, tanto do ponto de vista econômico quanto qualitativo. 


\section{FUNDAMENTAÇÃO TEÓRICA}

\section{1 - Compósito}

\subsection{1 - Generalidades}

Compósito é basicamente uma mistura de dois ou mais constituintes ou fases distintas. Entretanto, para MATTHEWS e RAWLINGS [1], esta definição não é suficiente e três outros critérios devem ser satisfeitos antes que um material possa ser denominado compósito:

- Ambos os constituintes devem estar presentes em proporções razoáveis na mistura, ou seja, maior do que $5 \%$;

- As fases constituintes devem possuir propriedades individuais diferentes, e então, proporcionarem ao compósito propriedades visivelmente diferentes delas;

- Um compósito artificial é usualmente produzido pela combinação e mistura íntima dos seus constituintes através de vários métodos. Assim, uma liga que possua uma microestrutura de duas fases que é produzida durante a solidificação de uma fusão homogênea, por exemplo, não é normalmente classificada como um compósito.

TAYA e ARSENAUT [15] acrescentam ainda:

- Um compósito deverá ser uma combinação de pelo menos dois materiais quimicamente diferentes;

- Os materiais constituintes do compósito deverão estar combinados tridimensionalmente.

As principais vantagens dos materiais compósitos residem no fato de apresentarem maiores valores específicos de módulo de elasticidade e de resistência, o 
que possibilita a redução de peso dos componentes, tornando-os assim candidatos interessantes para aplicação em sistemas de transporte (trens, automóveis, aviões, etc.) [1,16]. O comportamento mecânico destes materiais (tração por exemplo) apresenta resultados intermediários aos valores individuais dos materiais que os constituem (figura 1) [17].

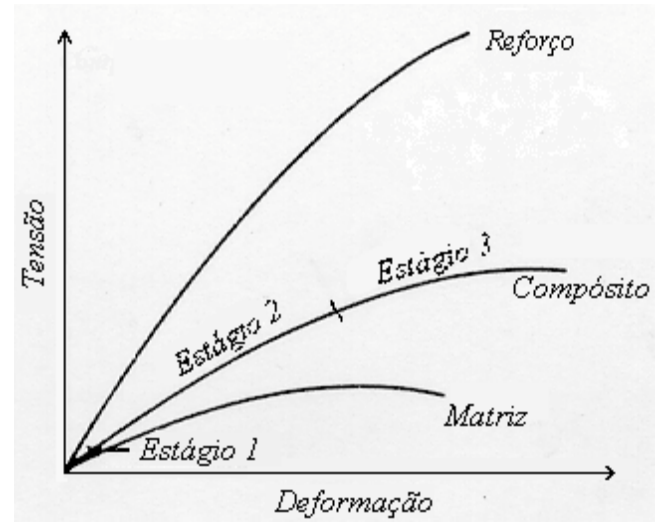

Figura 1 - Esquema clássico, mostrando as propriedades intermediárias do compósito em relação aos materiais que o compõem [17].

Os constituintes de um compósito dividem-se em dois grupos: matriz e reforço. A matriz é o constituinte que é contínuo e freqüentemente, mas nem sempre, está presente em maior quantidade no compósito. O segundo é conhecido como fase reforçante ou simplesmente reforço, porque melhora ou reforça as propriedades mecânicas da matriz [1,15].

\subsection{2 - Tipos de compósitos}

Conforme MATTHEWS e RAWLINGS [1], os materiais compósitos classificam-se segundo o tipo de matriz; assim, podem ser compósitos de matriz metálica (CMM), de matriz polimérica (CMP) ou ainda de matriz cerâmica (CMC).

As propriedades mecânicas destas três classes de materiais diferem consideravelmente entre si. Segundo as generalizações de MATTHEWS e 
RAWLINGS [1], polímeros têm baixa resistência e baixo módulo de elasticidade, cerâmicas são fortes, duras e frágeis, e metais têm módulo e resistência intermediários e boa ductilidade.

Os compósitos podem ainda ser classificados de acordo com o tipo de reforço utilizado e pela forma como estes reforços estão dispersos na matriz. CLYNE e WITHERS [18] subdividem os reforços utilizados em um compósito em três tipos básicos: monofilamentos, fibras curtas ou whiskers e partículas (figura 2).

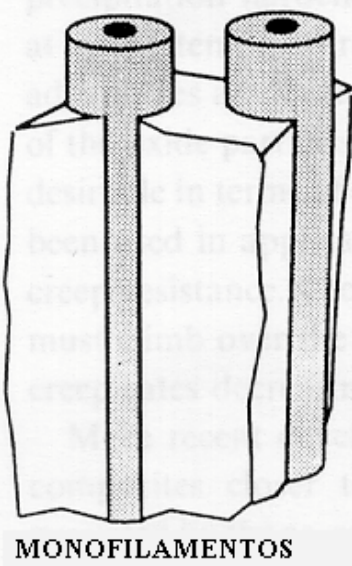

MONOFILAMENTOS

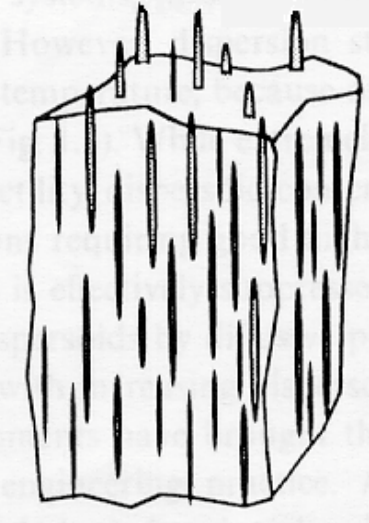

WHISKERS/FIBRAS CURTAS

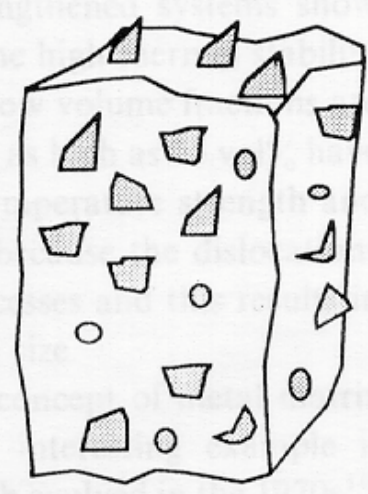

PARTICULADO

Figura 2 - Desenho esquemático de três tipos de CMM, classificados de acordo com o tipo de reforço [18].

Com relação à disposição e orientação destes reforços nos compósitos, MATTHEWS e RAWLINGS [1] classificam de maneira geral, em quatro grupos: particulados randômicos, fibras descontínuas randômicas, fibras descontínuas unidirecionais e fibras contínuas unidirecionais (figura 3).

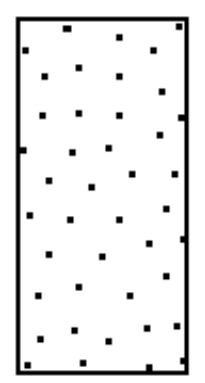

(a)

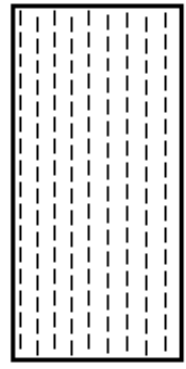

(b)

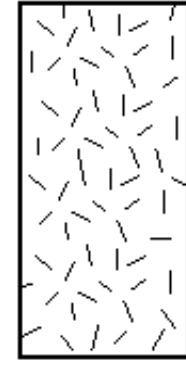

(c)

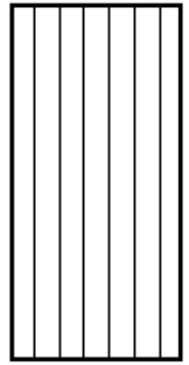

(d)

Figura 3 - Exemplos de materiais compósitos: (a) particulado randômico; (b) fibras descontínuas unidirecionais; (c) fibras descontínuas randômicas; (d) fibras contínuas unidirecionais (adaptação) [1]. 
Os CMM reforçados com partículas possuem propriedades aproximadamente isotrópicas, exceto quando algum processamento secundário (laminação, extrusão. etc.) tende a provocar o alinhamento das mesmas numa direção preferencial [19].

\subsection{3 - Compósitos de matriz metálica (CMM)}

Compósitos de matriz metálica (CMM) geralmente consistem de pelo menos dois componentes: um deles é a matriz metálica (um metal ou uma liga metálica), e o segundo componente é o reforço (em geral um composto intermetálico, um óxido, um carboneto ou um nitreto) [15].

Segundo TAYA et al. [15], MATTHEWS et al. [1], HULL [16] e outros $[19,20,21]$, os compósitos de matriz metálica possuem muitas vantagens sobre os metais monolíticos. Isto inclui alto módulo de elasticidade específico, alta resistência específica, melhores propriedades a elevadas temperaturas, baixo coeficiente de expansão térmica, melhor resistência ao desgaste, boa tenacidade e resistência ao impacto, e, em muitos casos, melhoria das propriedades à fadiga.

Existem muitas combinações possíveis de materiais metálicos e cerâmicos que podem ser utilizados como matriz e reforço, respectivamente, na concepção de um compósito de matriz metálica. Cada uma destas combinações possui propriedades e características próprias, que o tornam interessante para aplicações específicas e especiais.

Segundo SRIVATSAN, SUDARSHAN e LAVERNIA [19], o passo mais importante na seqüência de produção de CMM reforçados descontinuamente, envolve a seleção correta da fase reforçante e da matriz. O critério chave para a seleção da fase reforçante inclui: módulo elástico, resistência à tração, densidade, temperatura de 
fusão, estabilidade térmica, compatibilidade com a matriz, coeficiente de expansão térmica, tamanho, forma e custo.

Quanto à matriz, de maneira geral, parâmetros como densidade, ductilidade, tenacidade, módulo de elasticidade e algumas formas específicas de resistência (torsional e de cisalhamento, por exemplo) $[1,15,21]$, são de fundamental importância.

Os reforços normalmente utilizados em $\mathrm{CMM}$ são o $\mathrm{SiC}, \mathrm{Al}_{2} \mathrm{O}_{3}, \mathrm{TiC}$, $\mathrm{TiB}_{2}$ da categoria dos cerâmicos, ou W, Be, Ta e Mo da classe dos metais. Como matriz, os materiais mais utilizados são as ligas de $\mathrm{Al}$, Ti e $\mathrm{Mg}$; $\mathrm{Cu}$, Fe e $\mathrm{Pb}$ aparecem em aplicações mais esporádicas [1,15].

Para SRIVATSAN, SUDARSHAN e LAVERNIA [19] e outros [22], a resistência de compósitos de matriz metálica reforçados com partículas é governada pelos seguintes parâmetros: tamanho da partícula de reforço, espaçamento interpartículas, forma e fração volumétrica dos reforços particulados e condições da interface matriz/reforço.

\subsection{4 - Métodos de produção de CMM}

Existem vários métodos de obtenção de materiais compósitos de matriz metálica. SRIVATSAN, IBRAHIM, MOHAMED e LAVERNIA [22] dividem em três categorias os processos mais utilizados especificamente para reforços particulados: processos de fase sólida, processos de fase líquida e processos de duas fases (sólido/líquido). 
AMBROZIO FILHO, GOLDENSTEIN, GONÇALVES, ROSSI, SOUZA e YOSHIMURA [23] e HARRIS [4] são mais abrangentes e dividem os processos de fabricação em duas categorias: processos com fase líquida ("compocasting", codeposição por spray e infiltração, entre outros) e processos em estado sólido (metalurgia do pó e ligação por difusão).

MATTHEWS e RAWLINGS [1] classificam os métodos de produção de CMM em quatro grupos: estado sólido, estado líquido, deposição e in situ.

Enfim, cada um dos métodos citados anteriormente diferencia-se dos demais basicamente por dois motivos principais: (1) estado físico da matriz no momento em que é posta em contato com o reforço, (2) rota obedecida até a consolidação efetiva entre as partes.

Para CLYNE e WITHERS [18] todos os processos anteriores são primários e podem ou não exigir processos secundários (extrusão, laminação ou forjamento), que envolvem normalmente transformações termomecânicas.

De todos os processos citados anteriormente, além do processo via metalurgia do pó (adotado no presente trabalho e melhor detalhado no sub-item que se segue), especial atenção pode ser dada ao processo de co-deposição por spray (figura 4), que é uma técnica bastante recente e consiste basicamente na pulverização da matriz fundida, juntamente com o reforço sobre um substrato, de maneira semelhante à atomização. Este processo possibilita obter pré-formados cuja microestrutura da matriz é extremamente fina, reduzindo a possibilidade de reação química extensiva da matriz com o reforço, possibilitando assim alcançar propriedades mecânicas superiores [19, 20]. 


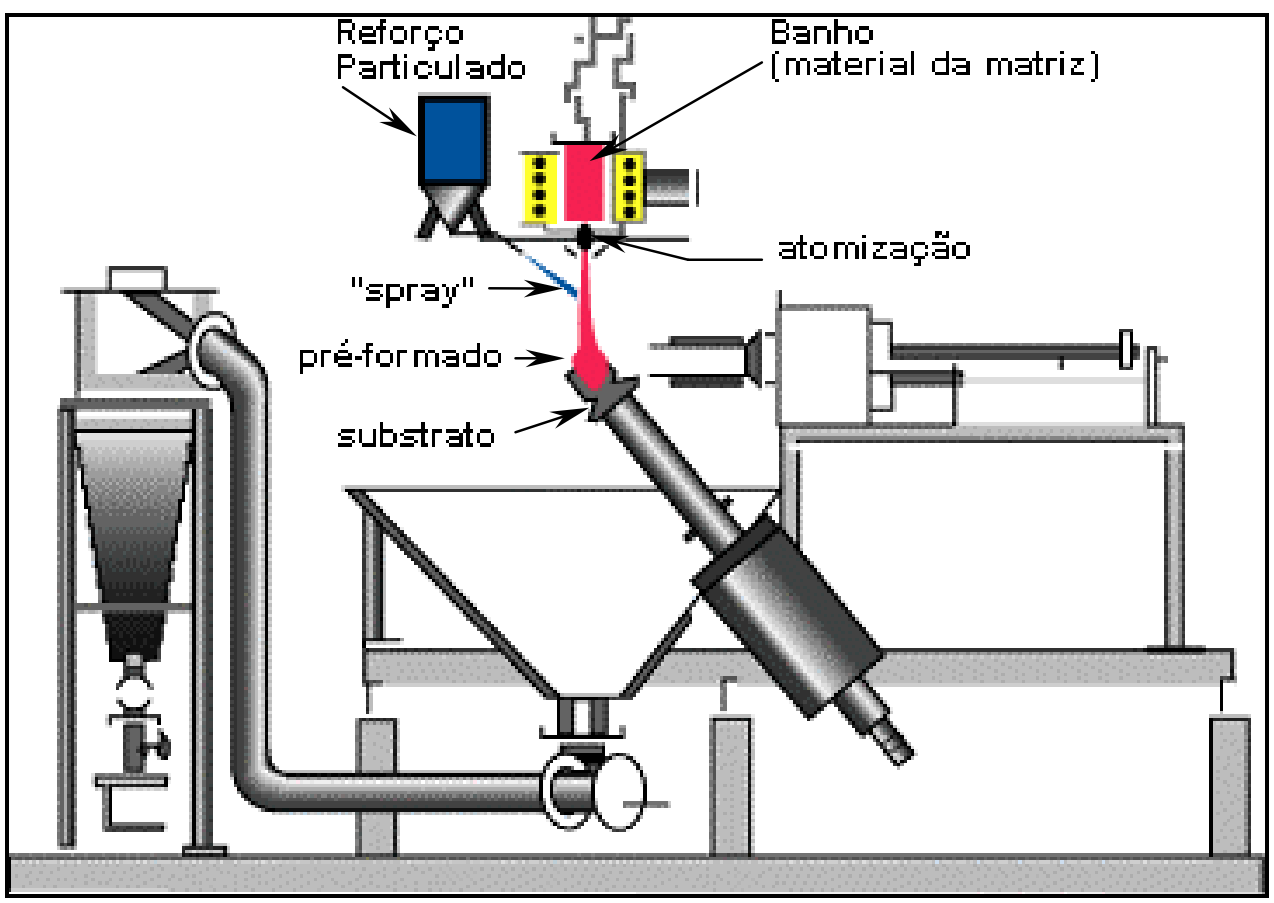

Figura 4 - Desenho esquemático do processo Osprey para fabricação de materiais compósitos por co-deposição de material de matriz e reforço [24].

\subsubsection{1 - Produção de CMM via metalurgia do pó}

A rota de processamento via metalurgia do pó está inserida na categoria dos processos de estado sólido ou fase sólida [1, 19, 22, 23]. Conforme MATTHEWS e RAWLINGS [1], a metalurgia do pó é especialmente indicada para a produção de metais reforçados com fibras descontínuas, whiskers ou partículas.

De maneira geral, os pesquisadores $[15,19,23]$ enumeram as seguintes etapas na execução da técnica de metalurgia do pó (figura 22): mistura das partículas da matriz com o reforço; compactação (uniaxial ou isostática); desgaseificação e, por último, consolidação a alta temperatura (extrusão ou HIP, por exemplo). 
LLOYD [20] relaciona as seguintes vantagens e desvantagens da técnica da metalurgia do pó para a obtenção de CMM:

\section{Vantagens:}

- Pode utilizar qualquer liga como matriz;

- Devido à minimização de reações entre a matriz e o reforço proporcionada por este método, qualquer tipo de reforço pode ser utilizado;

- Ligas rapidamente solidificadas, com composições químicas fora de equilíbrio podem ser utilizadas para a matriz, possibilitando que o compósito seja aplicado sob condições de elevadas temperaturas;

- Altas frações volumétricas de reforço são possíveis, maximizando o módulo e minimizando o coeficiente de expansão térmica do compósito.

\section{Desvantagens:}

- O processo envolve o manuseio de grandes quantidades de pós altamente reativos e potencialmente explosivos.

- A rota de manufatura é relativamente complexa e limitada em forma de produtos que pode produzir, o que torna o processo mais caro com relação a outros métodos convencionais.

Conforme LLOYD [20] e AMBROZIO FILHO et al. [23], uma característica importante no processamento por esta técnica, é a relação entre tamanho da partícula do pó da matriz e do reforço (RTP matriz : reforço). A aglomeração de partículas e presença de porosidades no processo é fortemente dependente desta relação e será ainda maior com o aumento da quantidade de material de reforço presente na matriz. 


\subsection{5 - Aplicações de CMM}

Apesar de estarem passando, ainda, por uma fase de muitos estudos, as evidências até aqui têm mostrado que os CMM têm um futuro promissor.

EDSER [25], em seu artigo, realça que um número significativo de aplicações para CMM deverão ser desenvolvidas ou introduzidas nos carros norte americanos já nas primeiras décadas do novo milênio.

Historicamente, a primeira aplicação comercial para estes materiais na indústria automobilística ocorreu em 1982, quando a Toyota começou a produzir pistões de CMM para seus motores a diesel [26].

Um passo muito importante, sobretudo para os CMM com matriz de alumínio, foi dado em 1997 com a formação de um consórcio, cuja missão é expandir as aplicações comerciais e militares dos alumínios reforçados com partículas, através do desenvolvimento de programas de tecnologia de manufatura, aumento na confiabilidade dos projetos e expansão dos conhecimentos sobre as propriedades e os produtores destes materiais [27].

De maneira geral as aplicações de CMM têm ocorrido, sobretudo, nas indústrias aeroespacial e automobilística, entretanto, também têm sido verificadas em outros segmentos industriais, como é o caso, por exemplo, das indústrias de materiais esportivos.

Um breve resumo de aplicações de CMM e respectivas referências é apresentado na tabela 1, a seguir. 
Tabela 1 - Aplicações de CMM

\begin{tabular}{|l|l|c|}
\hline \multicolumn{1}{|c|}{ Componente } & \multicolumn{1}{|c|}{ Aplicação } & Referência \\
\hline Longarinas, antenas. & aeroespacial & 1 \\
\hline Cabeça de pistão. & automobilística & 1 \\
\hline Supercondutores, contatos, filamentos, eletrodos & elétrica & 1 \\
\hline $\begin{array}{l}\text { Câmara de combustão, nariz, trocadores de calor, } \\
\text { fuselagem, membros estruturais, etc. }\end{array}$ & aeroespacial & 1 \\
\hline Componentes de motor, pistão e biela. & automobilística & 15 \\
\hline Raquete de tênis, taco de golfe. & esportiva & 15 \\
\hline $\begin{array}{l}\text { Pistão de motor à diesel, disco de freio, eixo de } \\
\text { acionamento (cardã). }\end{array}$ & automobilística & 18 \\
\hline Quadro de bicicleta. & esportiva & 18 \\
\hline Componentes para satélites. & aeroespacial & 18 \\
\hline Invólucros para conjuntos microeletrônicos. & microeletrônica & 18 \\
\hline
\end{tabular}

\section{2 - Fadiga}

\subsection{1 - Generalidades}

Antes de introduzir o tema fadiga propriamente dito, é importante dar uma visão geral sobre os modos de falha descritos por COLLINS [29], primeiramente para proporcionar uma melhor compreensão do fenômeno do ponto de vista global, e em seguida dentro do contexto deste trabalho.

COLLINS [29] define "modo de falha" como processos físicos ou processos que ocorrem ou combinam seus efeitos para produzir falha. Foi sugerido (STARKEY apud COLLINS [29], 1993, p. 6) que uma classificação sistemática poderia ser criada para que todos os possíveis modos de falha, pudessem ser previstos. Tal classificação é baseada na definição de três categorias: (1) manifestações de falha, (2) agentes indutores de falha, e (3) localizações de falha. Estas categorias, com algumas subcategorias são melhor detalhadas através das figura 5. Cada modo de falha 
específico é identificado como uma combinação de uma ou mais manifestações de falha, associados com um ou mais agentes indutores e uma localização de falha.

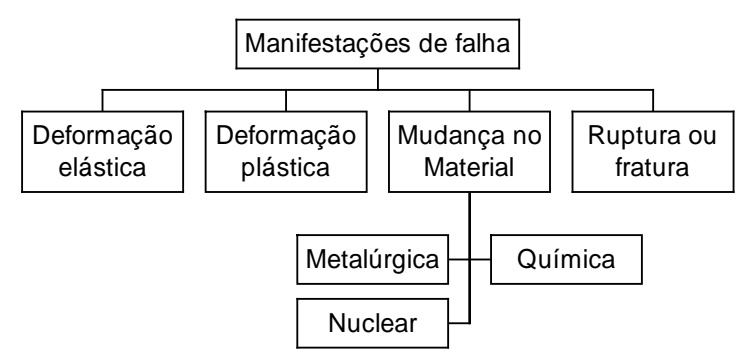

(a)

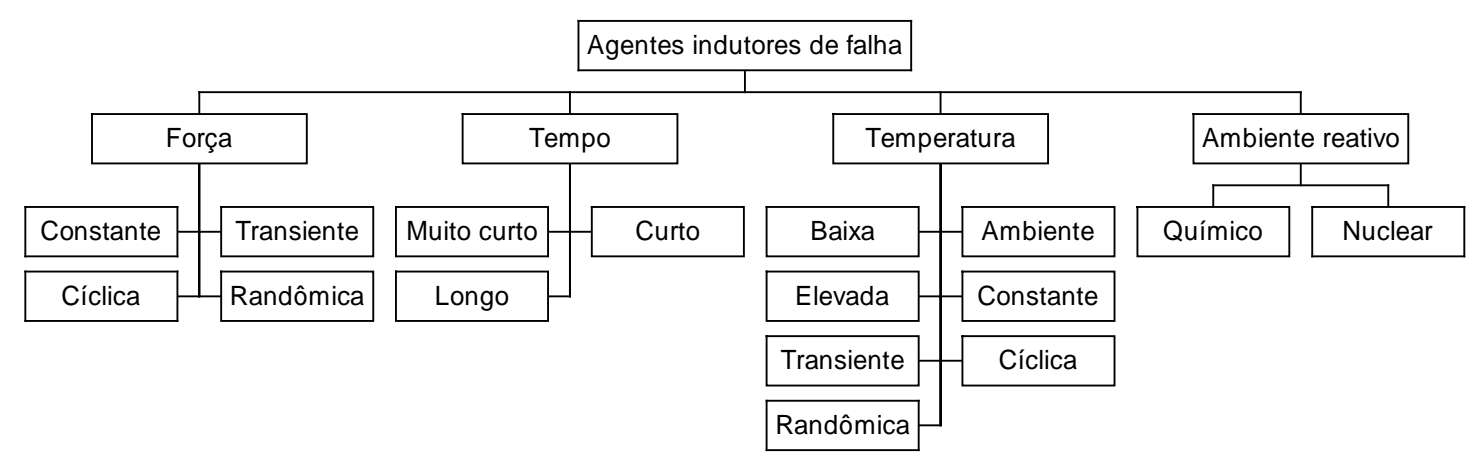

(b)

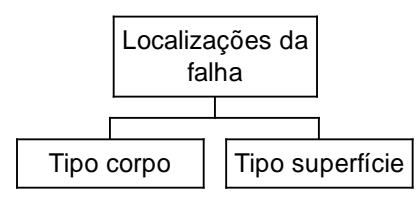

(c)

Figura 5 - Categorias de classificações dos modos de falha [29]. (a) Modos de manifestações de falha; (b) Agentes indutores de falha; (c) Localizações da falha.

A figura 6 mostra os modos de falha mais comumente observados na prática. Através dele é possível notar que certos modos de falha são fenômenos isolados, ao passo que outros são fenômenos combinados. Em destaque na figura $\mathbf{6}$, o modo de falha mecânica (fadiga de alto ciclo) estudado neste trabalho. 


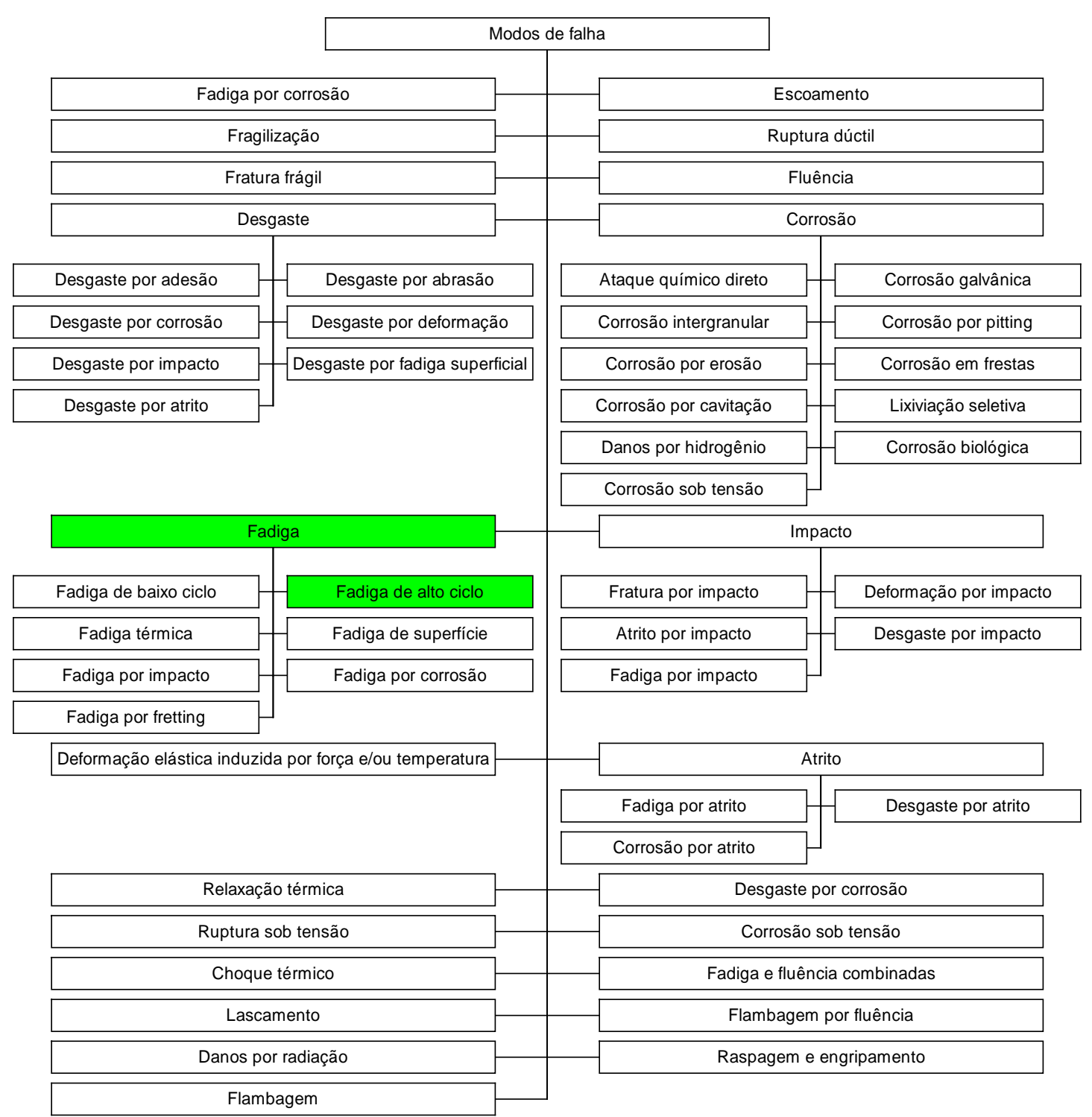

Figura 6 - Modos de falha mecânica mais comuns [29].

\subsection{2 - O fenômeno}

DIETER [17] e CHIAVERINI [30] definem fadiga, basicamente como a tendência que um material apresenta de romper-se sob a aplicação de tensões cíclicas ou alternadas, de grandeza muito inferior ao da sua resistência nominal. SURESH [31] ressalta que, embora a palavra fadiga seja comumente associada com o cansaço físico e mental das pessoas, a mesma tem sido uma terminologia largamente 
aceita no vocabulário de engenharia para caracterizar danos e falhas de materiais decorrentes de carregamentos de natureza cíclica.

SURESH [31] aponta para uma definição descritiva de fadiga que é dada no relatório intitulado "General Principles for Fatigue Testing of Metals" que foi publicado pela ISO em 1964. Nele, fadiga é definida como um termo que se aplica a mudanças nas propriedades que podem ocorrer em um material metálico devido a aplicação repetida de tensões e deformações, embora, usualmente este termo se aplique especialmente para aquelas mudanças que levam a um trincamento ou falha do material. Esta descrição também é geralmente válida para fadiga de materiais não metálicos.

De maneira geral, os diversos autores e pesquisadores do fenômeno são convergentes em admitir que fadiga é basicamente o cansaço de um material sujeito a cargas dinâmicas ou flutuações de tensão de magnitudes muito inferiores ao do seu limite de ruptura ou mesmo de escoamento. Este cansaço provoca mudanças no material e estas mudanças levam o mesmo a falhar após um número de ciclos considerável.

DIETER [17] relaciona três fatores básicos necessários para ocorrer falha por fadiga: (1) uma tensão de tração máxima suficientemente alta; (2) uma flutuação ou variação suficientemente grande da tensão aplicada e; (3) um número suficientemente grande de ciclos da tensão aplicada.

Segundo COLLINS [29], a fadiga pode ser caracterizada como um fenômeno de falha progressiva que consiste na iniciação e propagação de trincas até um tamanho crítico e instável. Sustentado em mudanças estruturais básicas que ocorrem quando um metal é sujeito a tensões cíclicas, PLUMBRIDGE e RYDER (apud DIETER [17],1986, p.394), acharam conveniente dividir o processo de fadiga em quatro estágios: (1) iniciação da trinca; (2) crescimento da trinca em bandas de deslizamento; (3) crescimento da trinca em alta tensão de tração e; (4) fratura final 
estática. BOYER [32] simplifica um pouco e unifica os estágios de crescimento de trinca em um único, o qual denomina de "crescimento cíclico progressivo da trinca".

A fadiga caracteriza-se por apresentar ciclos de tensões variáveis ou flutuantes ao longo do tempo. As funções seno ou cosseno (figura 7) são bastante usuais para representar ciclos de tensões homogêneos, entretanto, os fenômenos de fadiga podem apresentar ciclos de tensões completamente aleatórios, tornando a análise do fenômeno ainda muito mais complexa [17].

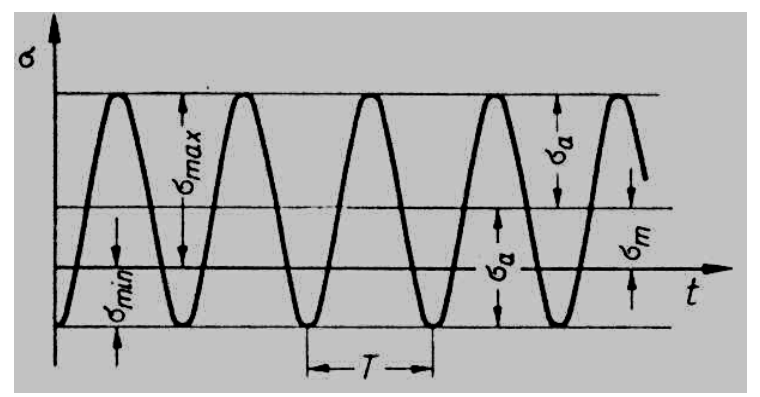

Figura 7 - Exemplo de um espectro de tensões de fadiga do tipo senoidal [33].

Do ciclo de tensões como o ilustrado na figura 7, é possível reconhecer e determinar as componentes de tensão envolvidas. No caso, visualiza-se diretamente a tensão mínima ( $\sigma$ mín), tensão máxima ( $\sigma$ máx) e a tensão alternada ( $\sigma a)$.

Algumas relações [17] são muito importantes principalmente na etapa de apresentação dos resultados de fadiga, entre elas citam-se:

Relação de tensões $(R)$, expressa matematicamente por:

$$
\mathrm{R}=\frac{\sigma \text { mín }}{\sigma \text { máx }}
$$

Tensão média $(\sigma \mathrm{m})$, expressa por:

$$
\sigma \mathrm{m}=\frac{\sigma \mathrm{máx}+\sigma \mathrm{mín}}{2}
$$


De acordo com o METALS HANDBOOK [34], em geral, a fadiga é dependente dos seguintes fatores:

- Tipo de carregamento;

- Forma da curva de carregamento;

- Freqüência do carregamento cíclico;

- Padrão de carregamento (carregamento periódico a amplitude variável ou constante, carregamento programado ou carregamento aleatório);

- Magnitude das tensões;

- Tamanho do componente;

- Método de fabricação e rugosidade superficial;

- Temperatura de operação;

- Atmosfera de operação.

COLLINS [29] enfatiza que uma característica muito importante da fadiga é que seus danos são cumulativos e irreversíveis.

\subsection{3 - Mecanismos de fadiga}

Conforme FUCHS e STEPHENS [35] muitos metais estruturais são policristalinos e assim são constituídos de um grande número de cristais ou grãos orientados individualmente. Cada grão possui propriedades mecânicas, direção de orientação e propriedades direcionais particulares.

O deslizamento ocorre em metais dúcteis dentro de grãos individuais devido à movimentação de discordâncias ao longo de planos cristalográficos e podem ocorrer sob a ação de carregamentos cíclicos e monotônicos. Normalmente, os 
deslizamentos grosseiros (figura 8a) estão associados com carregamentos monotônicos ou cíclicos de alta amplitude de tensão; sob carregamentos cíclicos de baixa amplitude de tensão, deslizamentos finos (figura 8b) são mais freqüentes.

DIETER [17] reforça que uma característica estrutural importante nas deformações por fadiga é a formação de saliências e ranhuras sobre a superfície, denominadas extrusões e intrusões, respectivamente. Estas formações apresentam características e condições favoráveis para o aparecimento e crescimento de trincas de fadiga $[17,35]$.

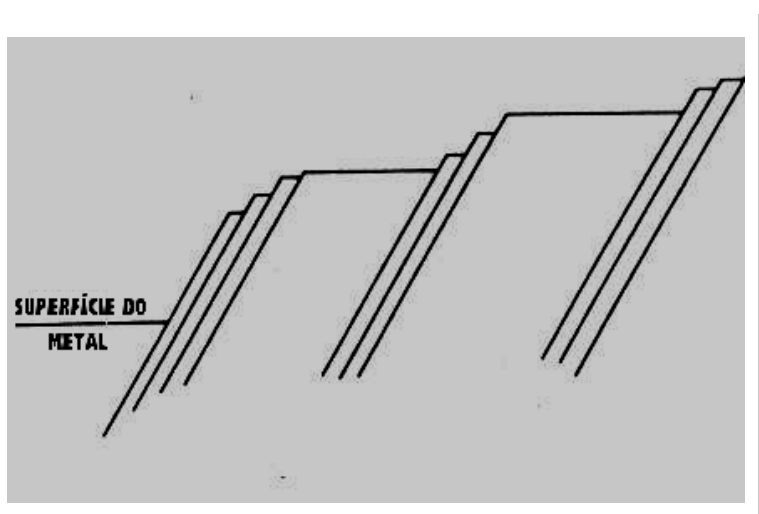

(a)

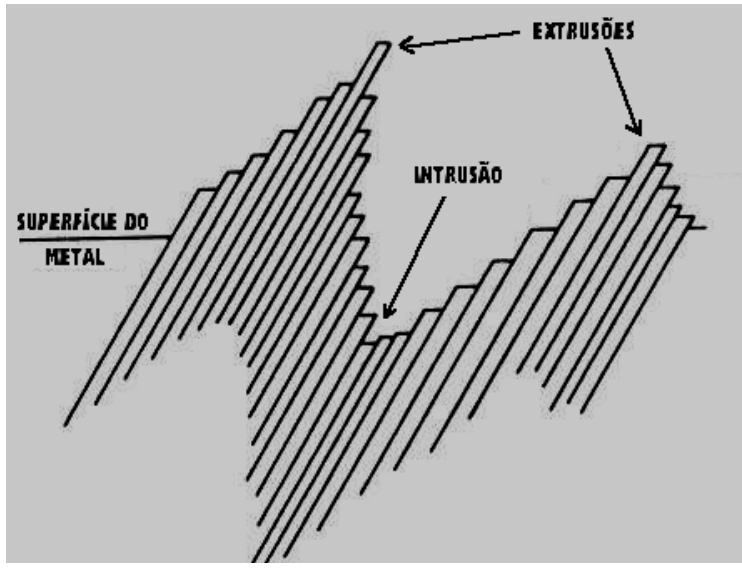

(b)

Figura 8 - (a) Esquema simplificado de deslizamento grosseiro normalmente associado com carregamentos monotônicos ou cíclicos de altas amplitudes de tensão. (b) Esquema simplificado de deslizamentos finos decorrentes normalmente de carregamentos cíclicos de baixas amplitudes de tensão. Nos detalhes estão indicados os mecanismos de intrusão e extrusão [35].

Normalmente, as trincas de fadiga têm origem na superfície e crescem através de alguns grãos controlados primariamente por tensões de cisalhamento, e continuam crescendo em ziguezague, essencialmente de maneira perpendicular e controlada pela máxima tensão de tração. As trincas podem se propagar através dos contornos de grão ou ao longo dos mesmos, ou seja, transcristalinamente ou intercristalinamente respectivamente (figura 9) [35]. 


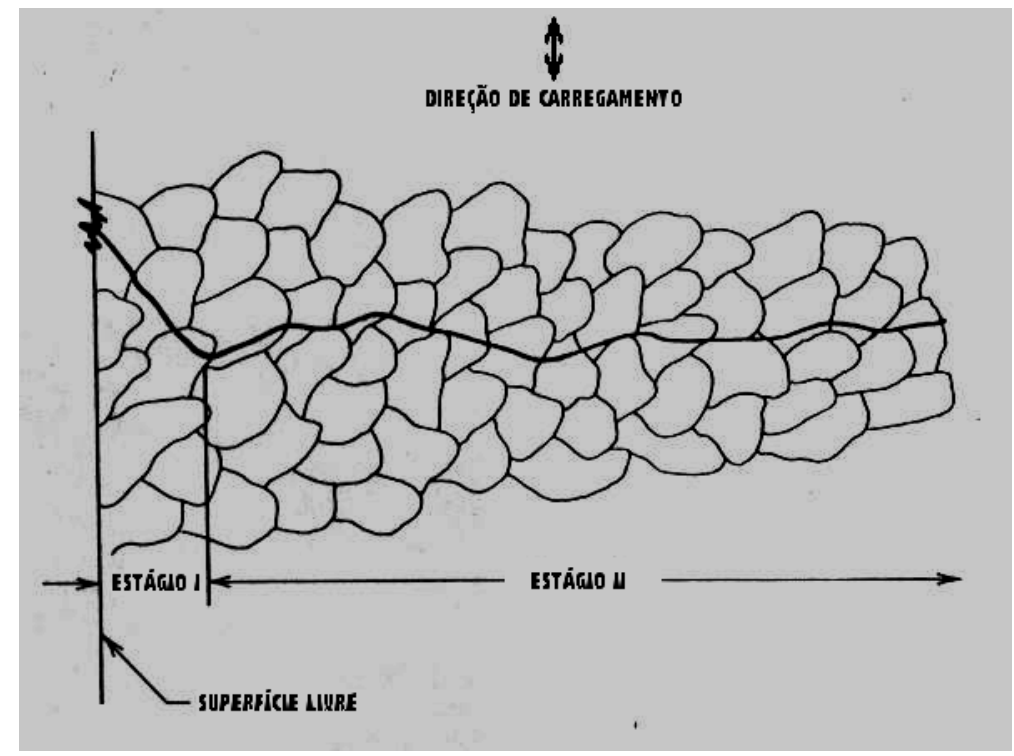

Figura 9 - Desenho esquemático mostrando os estágios I e I/ de crescimento de trinca de fadiga de maneira transcristalina [35].

Em materiais monolíticos, as características mais comuns das superfícies de fratura de componentes sujeitos à fadiga são a formação de estrias, coalescência de microvazios e microclivagem. Estrias e coalescência de microvazios são freqüentes em materiais dúcteis. O crescimento por microclivagem é considerado um processo de menor energia e, portanto, um mecanismo indesejável [35].

O mecanismo de fadiga em metais frágeis pode não apresentar a formação de bandas de deslizamento. Microtrincas são formadas diretamente nas descontinuidades, como inclusões ou vazios, e crescem ao longo dos planos de máxima tensão de tração [35].

\subsection{4 - Métodos de determinação da fadiga}

Existem diversas formas e equipamentos para a determinação da vida à fadiga de materiais e componentes e, para cada condição, tipo de ensaio e equipamento adotado, há uma geometria específica de corpo de prova devidamente normalizada pelas associações internacionais (ISO, ASTM, etc.). 
Conforme FUCHS e STEPHENS [35] existem basicamente dois tipos de equipamentos para ensaio de fadiga: os que trabalham com amplitude de tensão constante e os que trabalham com amplitude de deflexão ou deformação constante. Dentre os diversos tipos de equipamentos existentes, os mais conhecidos são: flexão rotativa (figura 10), flexão rotativa em balanço (figura 11) e servohidráulica de circuito fechado. Os dois primeiros tipos apresentam a desvantagem de trabalharem de forma reversa, isto é, a tensão média $\left(\sigma_{\mathrm{m}}\right)$ é zero e o ciclo de tensões apresenta parcelas iguais de tração e de compressão, o que torna estes equipamentos muito limitados em termos de possibilidades de flexibilização do ciclo de tensões.

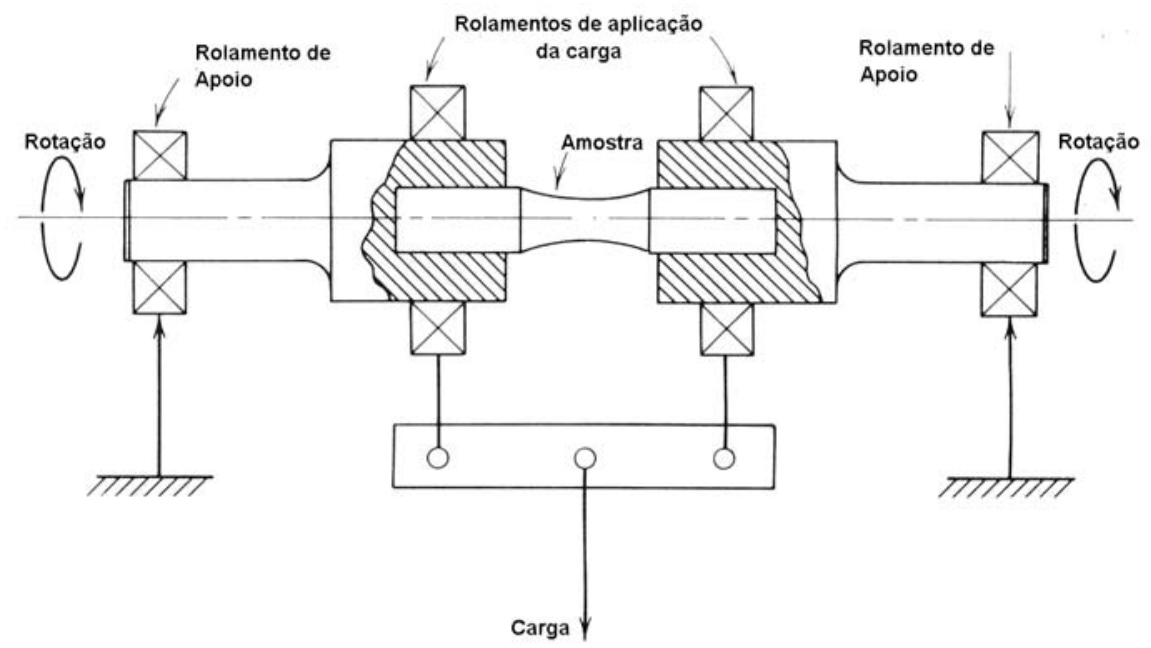

Figura 10 - Esquema simplificado de uma máquina para ensaio de fadiga do tipo flexão-rotativa [29].

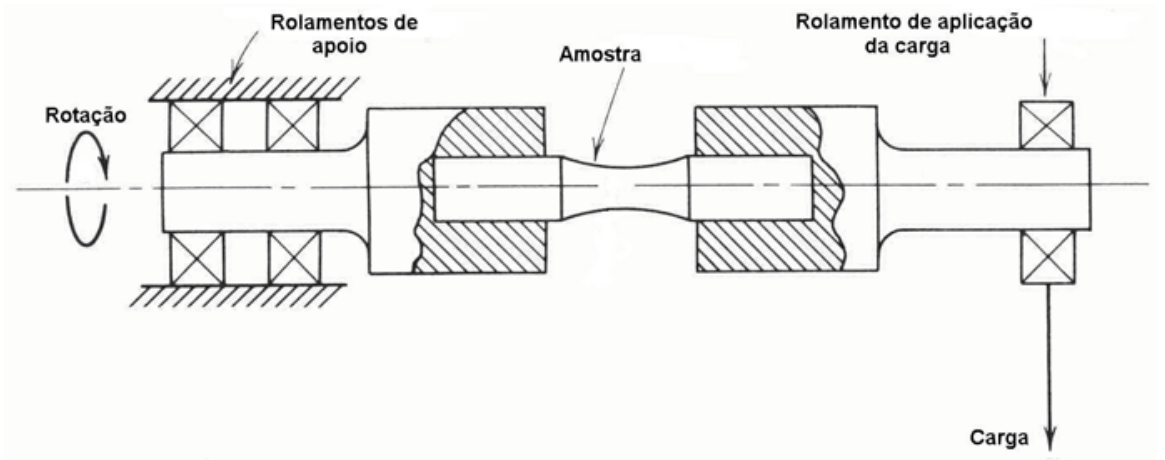

Figura 11- Esquema simplificado de uma máquina para ensaio de fadiga do tipo flexão-rotativa em balanço [29].

Segundo DIETER [17] e COLLINS [29] os dados de fadiga da literatura têm sido, na grande maioria das vezes, determinados para condições de ciclos de 
tensões reversas $\left(\sigma_{m}=0\right)$, entretanto, na prática, encontram-se situações de tensão muitas vezes diferentes desta condição e nestas circunstâncias o equipamento servohidráulico de circuito fechado é mais indicado para os testes de fadiga.

Os equipamentos servohidráulicos de circuito fechado, controlados por computador ou recursos eletrônicos, são atualmente largamente utilizados em todos os modernos laboratórios de testes de fadiga, salienta COLLINS [29]. Nestes equipamentos é possível executar testes de fadiga de flexão e axial, bem como determinar a tenacidade à fratura, entre outros ensaios. Sua versatilidade permite entre outras coisas, trabalhar com tensões médias diferentes de zero e executar ensaios com controle de carga, deslocamento ou deformação.

\subsection{5 - Fadiga de baixo e de alto ciclo}

Conforme COLLINS [29] o processo de fadiga abrange dois domínios de tensionamento cíclico que são significativamente diferentes em caráter, e cada uma das falhas é provavelmente produzida por diferentes mecanismos físicos. Um domínio, é aquele para o qual significativas deformações plásticas ocorrem durante cada ciclo. Este domínio está associado com altas cargas e baixas vidas, ou baixo número de ciclos para produzir falha por fadiga e é comumente conhecida como "fadiga de baixo ciclo". O outro domínio de carregamento cíclico ocorre quando os ciclos de tensão estão largamente confinados no regime elástico. Este domínio está associado com baixas cargas e longas vidas, ou alto número de ciclos para produzir falha por fadiga e é comumente conhecida como "fadiga de alto ciclo".

De maneira geral, os pesquisadores [17,29,32,35], têm associado "fadiga de baixo ciclo", com vidas abaixo de valores da ordem de $10^{4}$ ou $10^{5}$ ciclos, e "fadiga de alto ciclo" a vidas superiores a estes valores. 


\subsection{6 - Curvas de fadiga}

Conforme DIETER [17], as maneiras usuais de se apresentar os resultados de um ensaio de fadiga são através de gráficos do tipo S-N (também conhecido como curvas de Wölher) ou do tipo E-N.

Os gráficos S-N são utilizados para exprimir os resultados de fadiga de alto ciclo. Neles, a tensão aplicada é representada no eixo das ordenadas e o número de ciclos até a ruptura (vida), no eixo das abscissas [17].

Para os ensaios de baixo ciclo, representa-se os valores de deformação no eixo das ordenadas e a respectiva vida no eixo das abscissas, em gráficos denominados E-N [17].

Conforme DIETER [17], COLLINS [29] e FUCHS et al. [35], os gráficos S-N podem ser plotados com escalas di-logarítmicas ou semi-logarítmicas. Utilizandose a segunda opção, a escala logarítmica deve, preferencialmente, ser atribuída ao eixo das abscissas.

\subsection{7 - Análise estatística da fadiga}

COLLINS [29], DIETER [17], FUCHS et al. [35] e HWANG e HAN [36] alertam para a necessidade de utilização de técnicas estatísticas adequadas para a avaliação dos resultados de fadiga devido a grande dispersão de dados que este tipo de ensaio apresenta.

A forma mais comumente utilizada para exprimir a probabilidade de falha de um material sujeito a fadiga é através dos limites de confiabilidade. Conforme COLLINS [29], a confiabilidade (C) é expressa matematicamente por $\mathbf{1}-\mathbf{P}$, onde P é a probabilidade de falha. Assim, uma curva com $5 \%$ de probabilidade de falha pode, alternativamente, ser designada como curva de confiabilidade de $95 \%(C=0,95)$. 
De maneira geral, para fins de engenharia, a função de distribuição estatística que representa a distribuição da vida em fadiga é considerada como sendo normal ou gaussiana $[17,29,35,37]$, para probabilidades de falha no intervalo de 10 a $90 \%$. Para probabilidades de falha muito pequenas a distribuição de Weibull é a mais indicada $[17,36]$.

\subsection{8 - Planejamento de ensaio}

O planejamento de ensaio é um item importante quando há a necessidade de se fazer um estudo da vida à fadiga de um material ou componente. A escolha do procedimento de ensaio depende basicamente do objetivo que se deseja atingir com o ensaio.

Existem diversos procedimentos de testes de fadiga [29], dentre os quais, citam-se:

- método padrão,

- teste a nível de tensão constante,

- método da sobrevivência,

- método do valor extremo, entre outros.

Conforme as colocações de COLLINS [29], o método padrão é aplicável quando existem poucos corpos de prova para teste e uma estimativa da curva S-N se faz necessária.

O manual ASTM-STP 588, através da norma ASTM-E739 [37], adota critérios para definir o número mínimo de corpos de prova com base no tipo de programa de teste adotado. Os testes destinados a "pesquisas exploratórias e testes de desenvolvimento" mencionados na norma, podem ser comparados ao método 
padrão descrito por COLLINS [29], na medida em que também requerem um número reduzido de corpos de prova.

Esta norma também se refere ao índice de repetição (equação 3), que serve como indicativo para avaliar a qualidade do programa de teste adotado. Quanto maior o índice de repetição, melhor é o programa adotado.

$$
\% \quad \text { repetição }=100 \cdot\left[1-\left(\frac{N}{n}\right)\right]
$$

onde: $\mathrm{N}=$ Número total de diferentes tensões ou deformações utilizadas nos ensaios e, $\mathrm{n}=$ Número total de corpos de prova ensaiados.

Conforme a norma, programas de testes que envolvem $50 \%$ de repetição são considerados aceitáveis para muitas aplicações de pesquisa e desenvolvimento.

\subsection{9 - Fadiga em CMM}

Devido a natureza particular dos CMM, espera-se que os mecanismos de propagação de trincas nos mesmos, sejam diferentes ou até mesmo uma combinação daqueles encontrados em materiais monolíticos. Os trabalhos sobre mecanismos e características de propagação de trincas em materiais compósitos parecem ainda muito particulares e dirigidos para uma combinação específica, de forma que uma extensão e generalização dos resultados pode ser muito arriscada, devendo ser cuidadosamente avaliada. 
KUMAI, HU, HIGO e NUNOMURA [38] representaram esquematicamente as características de propagação de trincas como função do tipo de processamento utilizado para produção do material (figura 12); entretanto, sabe-se que na prática muitos outros fatores e variáveis podem influenciar este comportamento, como por exemplo, a forma e o tamanho das partículas de reforço.

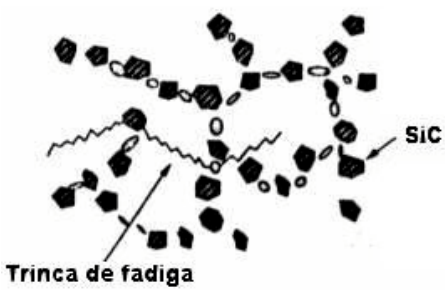

(a)

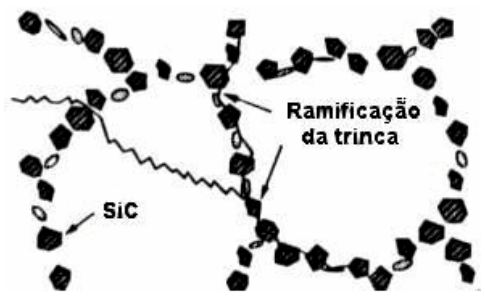

(b)

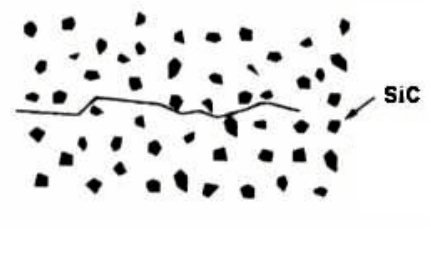

(c)

Figura 12 - Representação esquemática das características da trajetória de crescimento de trincas de fadiga [38]. (a) compósito obtido por fundição sob pressão, (b) compósito obtido por fundição em areia, (c) compósito obtido por metalurgia do pó.

LIU e BATHIAS [39] são mais cuidadosos em suas observações, relatando que a iniciação de trincas em CMM apresentam muitas possibilidades, entre elas:

- a trinca pode ter início numa grande inclusão,

- $\quad$ perto de porosidades,

- em interfaces orientadas de maneira perpendicular à direção de carregamento.

CLYNE e WITHERS [18] acrescentam:

- a trinca pode iniciar numa partícula de reforço grande,

- em matrizes com tensão de escoamento elevada,

- em locais sujeitos a grandes deformações plásticas,

- em reforços localizados em contornos de grão,

- em locais com aglomeração de partículas, etc. 
Para os casos particulares estudados por MASUDA e TANAKA [40], os mecanismos foram avaliados principalmente em função do tipo de reforço utilizado e do nível de carregamento imposto aos CMM. A figura 13 apresenta modelos de propagação de trincas de fadiga para compósitos reforçados com partículas de SiC sujeitos a baixos níveis de tensão (figura 13a) e a altos níveis de tensão (figura 13b). No primeiro caso, a trinca propaga-se preferencialmente através da matriz, enquanto que no segundo caso elas tendem a se orientar na direção das partículas de reforço, culminando inclusive, com a ruptura das mesmas em alguns casos.

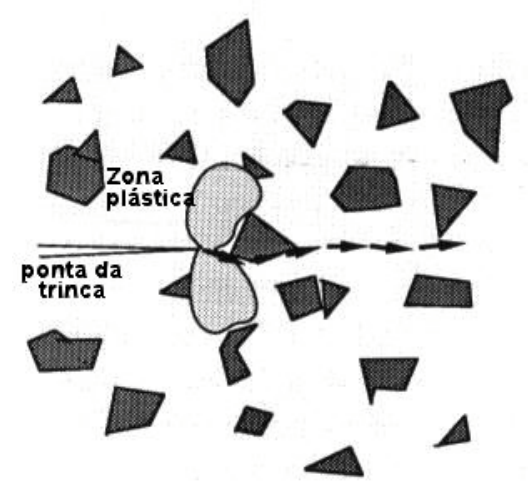

(a)

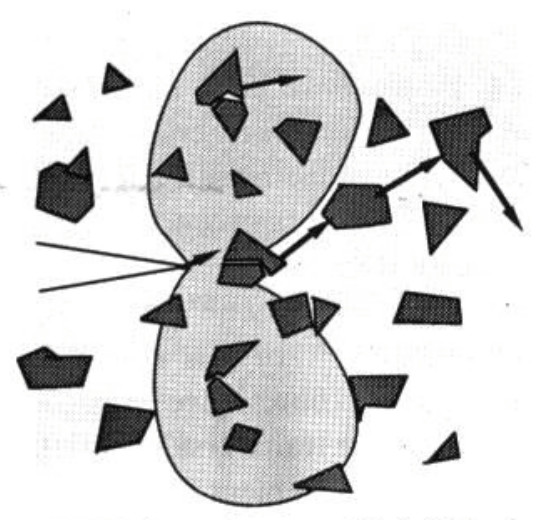

(b)

Figura 13 - Modelos de propagação de trincas como função do nível de tensão e tamanho da zona plástica na ponta da trinca [18]. (a) para baixos níveis de tensão e pequena zona plástica na ponta da trinca, (b) para altos níveis de tensão e grandes zonas plásticas na ponta da trinca.

Além dos mecanismos que influenciam no crescimento e propagação de trincas de fadiga, existem também os que contribuem para o seu fechamento e conseqüentemente retardamento do processo de propagação. SHANG, YU e RITCHIE [41] citam dois deles: fechamento de trincas via asperezas em cunha ("asperity wedging"), figura 14a e bloqueio da trinca via ligamentos não rompidos, figura 14b; entretanto, enfatizam que estes mecanismos são resultado de interações das partículas de SiC com o processo de fratura por fadiga. Estas interações, por sua vez são dependentes mecanicamente do nível de tensão aplicada e microestruturalmente do tamanho e distribuição das partículas, isto para uma fração volumétrica constante 
de SiC. SURESH [31] também enumera uma série destes mecanismos, dentre eles dois destacam-se porque as partículas reforçantes do compósito agem diretamente como agentes retardadores do processo de crescimento da trinca. São eles: mecanismo de desvio da trinca (figura 14c) e bloqueio da trinca por partículas (figura 14d).

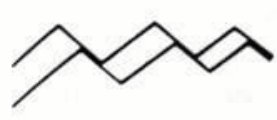

(a)

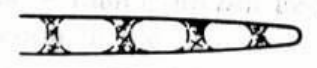

(b)

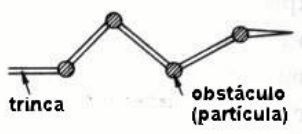

(c)

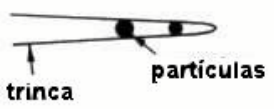

(d)

Figura 14 - Ilustração esquemática de mecanismos que promovem o retardamento do crescimento de trincas de fadiga [31,41]. (a) asperezas em cunha, (b) ligamentos não rompidos, (c) desvio da trinca e (d) bloqueio da trinca por partículas.

Segundo CLYNE e WITHERS [18] as trincas podem se propagar por uma variedade de micro-mecanismos, dependendo de fatores como resistência da interface matriz/reforço, encruamento da matriz e integridade do reforço.

MATTHEWS e RAWLINGS [1] relatam que em fadiga de CMM, os pontos de iniciação de trincas encontram-se freqüentemente, em defeitos internos como partículas cerâmicas grandes, presença de aglomerações ("clusters") e compostos intermetálicos frágeis; diferentemente do que ocorre em materiais monolíticos, que segundo DIETER [17], CHIAVERINI [30] e HERTZBERG [42] na maioria dos casos, surgem numa superfície livre, preferencialmente em pontos de concentração de tensões.

Apesar de em alguns casos, as falhas por fadiga em compósitos estarem associadas com defeitos e alterações advindas da introdução da fase reforçante, os reforços de um compósito, freqüentemente, levam a uma significativa melhoria da resistência à fadiga do material. Entretanto, também há exemplos onde a resistência à fadiga foi degradada ou não apresentou melhorias significativas com a introdução de reforços [1] (figura 15). 


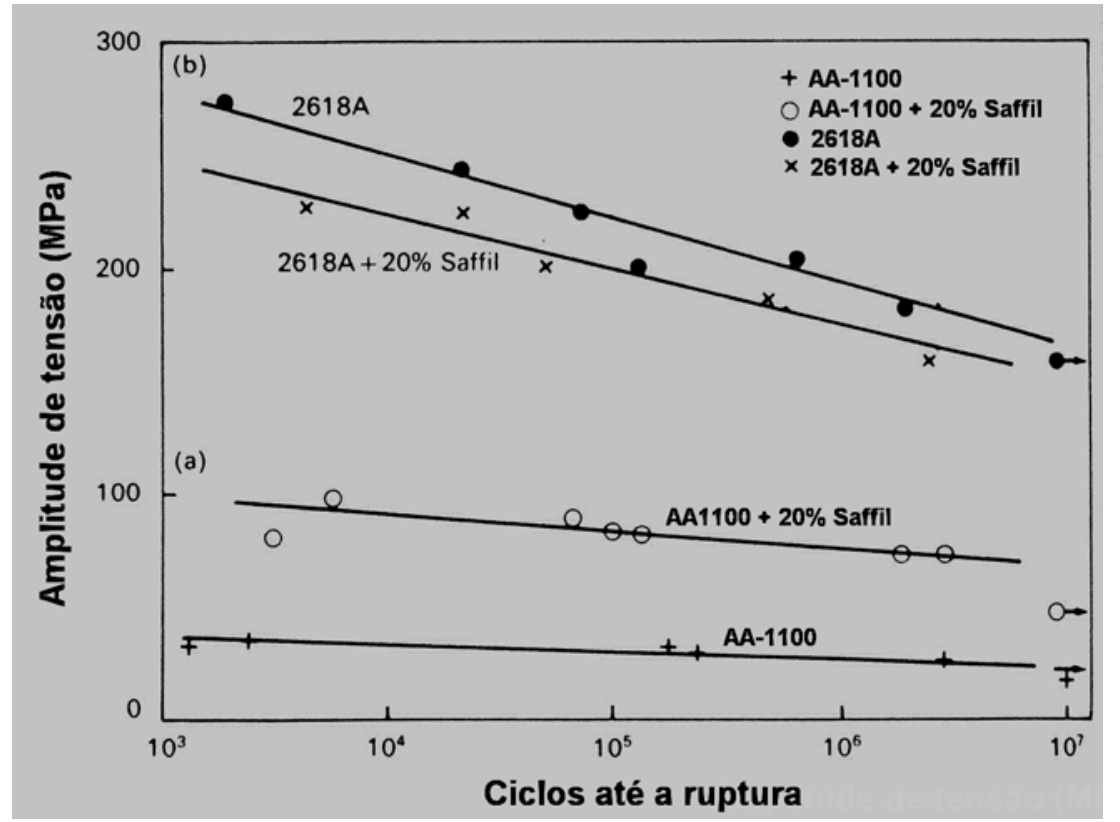

Figura 15 - Curvas de fadiga (S-N) de ligas de alumínio não reforçadas e compósitos com $20 \%$ de fibras de alumina (Saffil) [1]

\section{3 - Tratamentos superficiais}

\subsection{1 - Generalidades}

Conforme HERTZBERG [42] e FORREST [43], existem diferentes maneiras de se tratar a superfície dos metais. Os tratamentos de superfície estão divididos em três grandes grupos: tratamentos mecânicos, tratamentos térmicos e revestimentos superficiais.

Os tratamentos mecânicos incluem processos normais de usinagem, retífica e polimento e também, tratamentos especiais como jateamento e laminação a frio, que são utilizados principalmente por seus efeitos benéficos sobre a resistência à fadiga. Os tratamentos térmicos incluem endurecimento por chama e por indução e os revestimentos incluem cementação, nitretação e galvanização, entre outros.

Os tratamentos mecânicos podem aparecer como operações finais no 
processamento de um componente, entretanto, os tratamentos térmicos e revestimentos, normalmente, requerem tratamentos mecânicos anteriores ou mesmo posteriores, para preparação de superfície ou mesmo correção de distorções deixadas principalmente pelos tratamentos térmicos.

\subsection{2 - Usinagem e jateamento}

Usinagem é uma operação ou tratamento superficial mecânico que promove a conformação de um material por meio de máquina operatriz. Utiliza-se a ação cisalhante de uma ferramenta cortante que aplica uma força concentrada sobre uma pequena área deste material, afim de conferir forma, dimensão e acabamento planejados a uma peça $[44,45]$ (figura 16).

A parcela de material removida por esta operação normalmente é denominada apara ou cavaco. O acabamento superficial produzido por ela depende dos parâmetros de corte adotados e da geometria da ferramenta. Devido à ação cisalhante da ferramenta nas operações de usinagem denominadas de torneamento cilíndrico externo, sabe-se que tensões residuais superficiais de tração são inseridas na superfície do material.

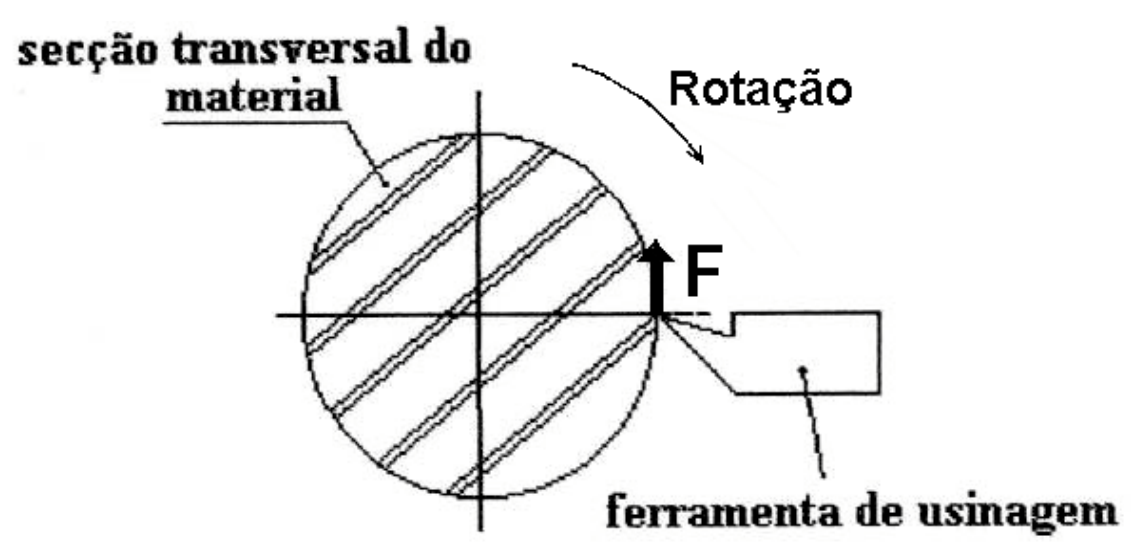

Figura 16 - Desenho esquemático de uma ferramenta de usinagem em posição de trabalho numa operação de usinagem denominada torneamento cilíndrico externo. 
Jateamento é um processo de tratamento superficial mecânico que consiste em arremessar pequenas partículas duras contra a superfície do material a ser tratado. As partículas duras (microesferas de vidro, esferas de aço, etc) possuem tamanhos que variam de 0,08 a 0,8mm de diâmetro e são aceleradas normalmente por pressão obtida através de sistema de ar comprimido [42] (figura 17). Esta operação normalmente insere tensões residuais compressivas sobre a superfície do material tratado, e é dependente dos seguintes fatores: tamanho das partículas, velocidade das partículas, tempo de exposição, distância entre o bocal e a superfície tratada e ângulo de impacto[13].

Embora não tenha sido utilizado no presente trabalho por não se dispor do equipamento necessário, existe um método que possibilita quantificar a intensidade de jateamento através da medida da deformação que o jato de partículas produz em uma chapa padrão pelo efeito da energia cinética. Este método é conhecido como "ALMEN" [46].

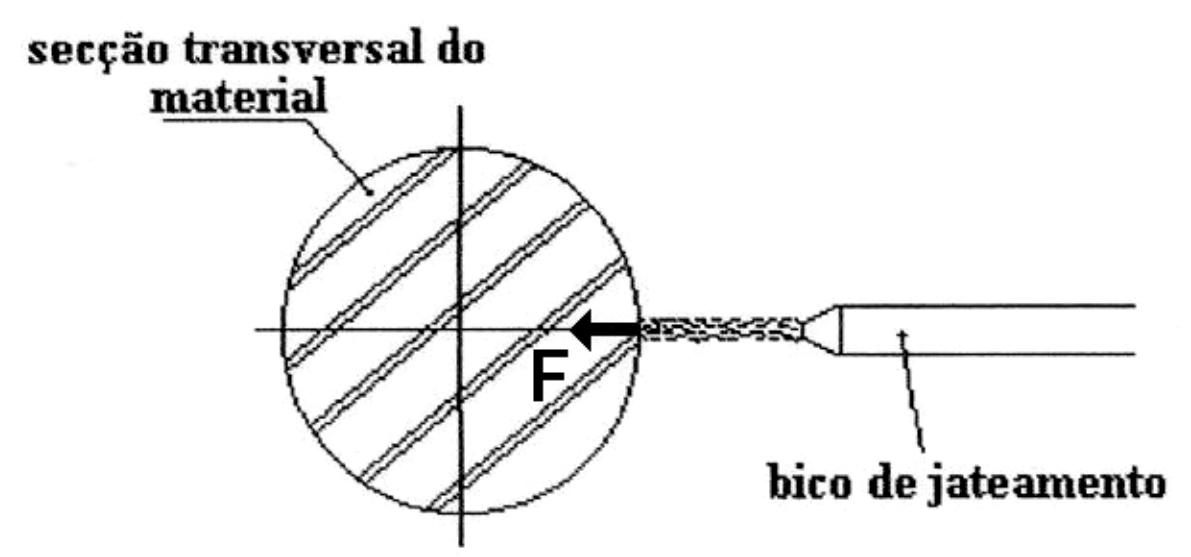

Figura 17 - Desenho esquemático de uma operação de jateamento sobre a superfície de um material de secção transversal cilíndrica.

\subsubsection{1 - Usinagem de CMM}

Dada a natureza particular dos materiais compósitos com relação aos materiais convencionais, é natural se esperar que a conformação destes materiais por meio da usinagem também apresente certas particularidades. 
JESUS [28], em seu trabalho sobre usinabilidade de compósitos, estudou os mesmos materiais utilizados aqui e concluiu que estes apresentam propriedades e características que agem no sentido de reduzir drasticamente a vida da ferramenta de usinagem. Os índices de usinabilidade para os materiais reforçados com 10 e $15 \%$ de SiC, foram $48 \%$ e $29 \%$, respectivamente, tomando como referência o material reforçado com 5 \% (usinabilidade $100 \%$ ). Segundo ele, estes são valores muito baixos e, indicam a extrema dificuldade de usinagem destes materiais quando comparado com a usinagem de materiais convencionais.

\section{4- Tensões residuais}

\subsection{1 - Generalidades}

DEGARMO, BLACK e KOHSER [13], expõem que os diversos processos envolvidos na manufatura tendem a provocar mudanças nas propriedades metalúrgicas, mecânicas e físicas, sobre ou próximo às superfícies geradas nos produtos manufaturados. Estes efeitos podem ser benéficos ou detrimentais dependendo do processo, material e aplicação do produto [13].

As regiões superficiais ou subsuperficiais dos materiais são alteradas devido principalmente a deformações plásticas, altas temperaturas, diferenças de expansão ou contração devidas a mudanças ou variações de temperatura e reações químicas [13].

As tensões residuais superficiais são os principais efeitos decorrentes destas mudanças. Elas podem ser de tração ou de compressão. 


\subsection{2 - Tensão residual compressiva e de tração}

Tensões residuais de tração são normalmente indesejáveis porque tendem a se concentrar em detalhes ou defeitos na superfície do produto contribuindo para o surgimento e crescimento de trincas. As tensões de caráter compressivo, entretanto, tendem a superar e neutralizar as cargas aplicadas que favorecem o aparecimento de trincas; portanto, a presença destas tensões em componentes mecânicos é uma condição altamente favorável.

As tensões residuais podem surgir nos materiais em quase todas as etapas de processamento, como quando um material é sujeito a tratamento térmico (figura 18), soldagem ou usinagem [47].

\section{Curvas de resfriamento}

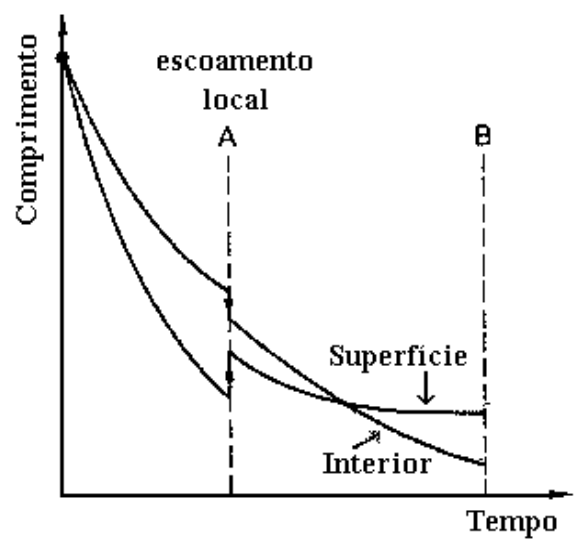

(a)

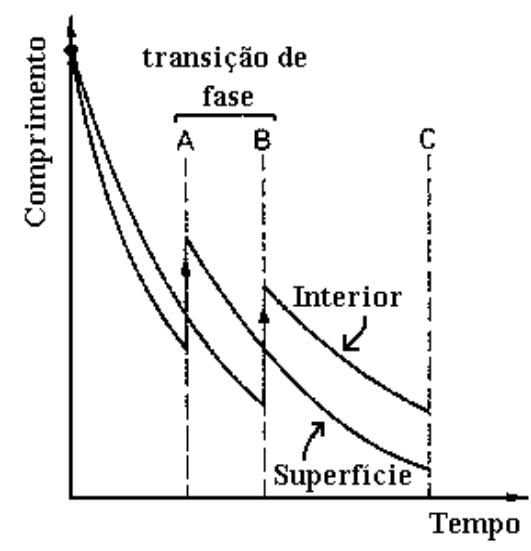

(b)

Figura 18 - Curvas que mostram as tensões residuais que podem surgir durante o resfriamento executado após tratamento térmico. (a) Curva de resfriamento do alumínio e (b) Curva de resfriamento do aço [47].

$\mathrm{Na}$ figura 18a o ponto $\mathrm{B}$ representa temperatura ambiente. A esta temperatura é possível notar que a deformação residual na superfície é maior do que no interior, caracterizando assim a existência de tensões residuais compressivas na superfície deste material. Já na figura 18b ocorreu o inverso à temperatura ambiente (ponto C), caracterizando assim a presença de tensões residuais de tração [47]. 
As operações de usinagem denominadas torneamento cilíndrico externo, produzem deformação plástica e as superfícies cortadas ou usinadas resultam geralmente em tensões residuais de tração [13].

O processo de jateamento, ao contrário, introduz tensões residuais compressivas na superfície da peça, que podem ser benéficas em muitos aspectos, sobretudo para a melhoria da vida à fadiga [42,43] (figura 19).

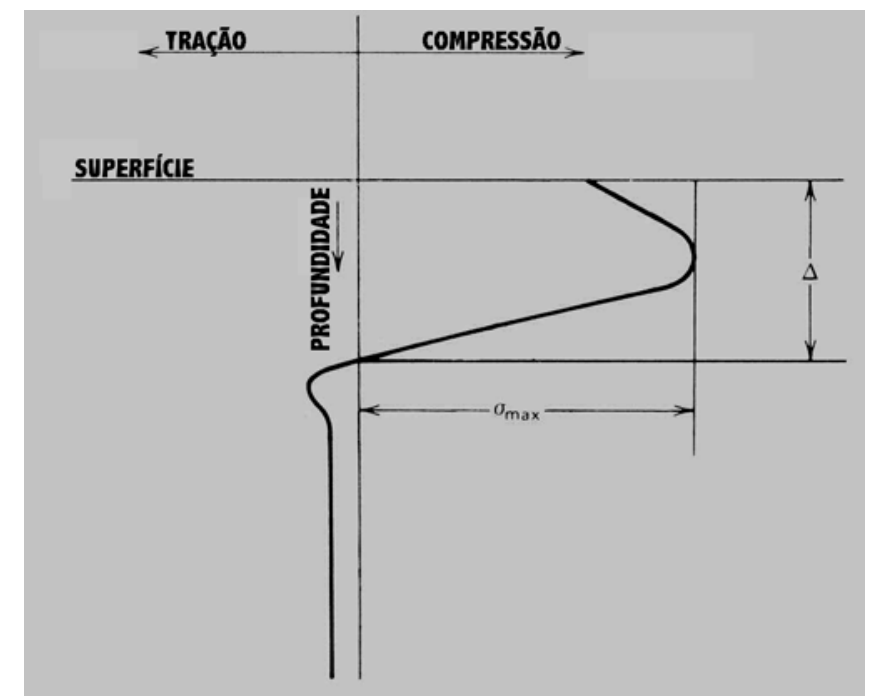

Figura 19 - Diagrama mostrando a distribuição de tensão residual após o jateamento. A tensão residual compressiva se estende da superfície até a profundidade $\Delta$ [42].

\section{5 - Rugosidade}

\subsection{1 - Generalidades}

Conforme AGOSTINHO, RODRIGUES E LIRANI [48], rugosidade superficial é definida como a soma das diferenças de forma de terceira a quinta ordens, que resultam da ação inerente ao tipo de acabamento ou tratamento superficial imposto a um material ou componente durante seu processamento ou manufatura. 
Diferença de forma é definida como a totalidade de todas as diferenças da superfície real com relação à superfície ideal geométrica. Para fins de classificação mais exata, as diferenças de forma foram divididas em seis ordens, que vão desde distorções macrogeométricas bastante perceptíveis, até microgeométricas que estão relacionadas com a estrutura reticular do material [48].

A rugosidade superficial está relacionada com a textura produzida sobre a superfície de um material. Ela também possui uma relação bem estreita com os tipos e graus de tensão residual inseridos no material. Assim, há de se esperar que a resposta de materiais submetidos a diferentes tipos de tratamentos superficiais, também tenham diferentes respostas às solicitações que Ihe são impostas (figura 20).

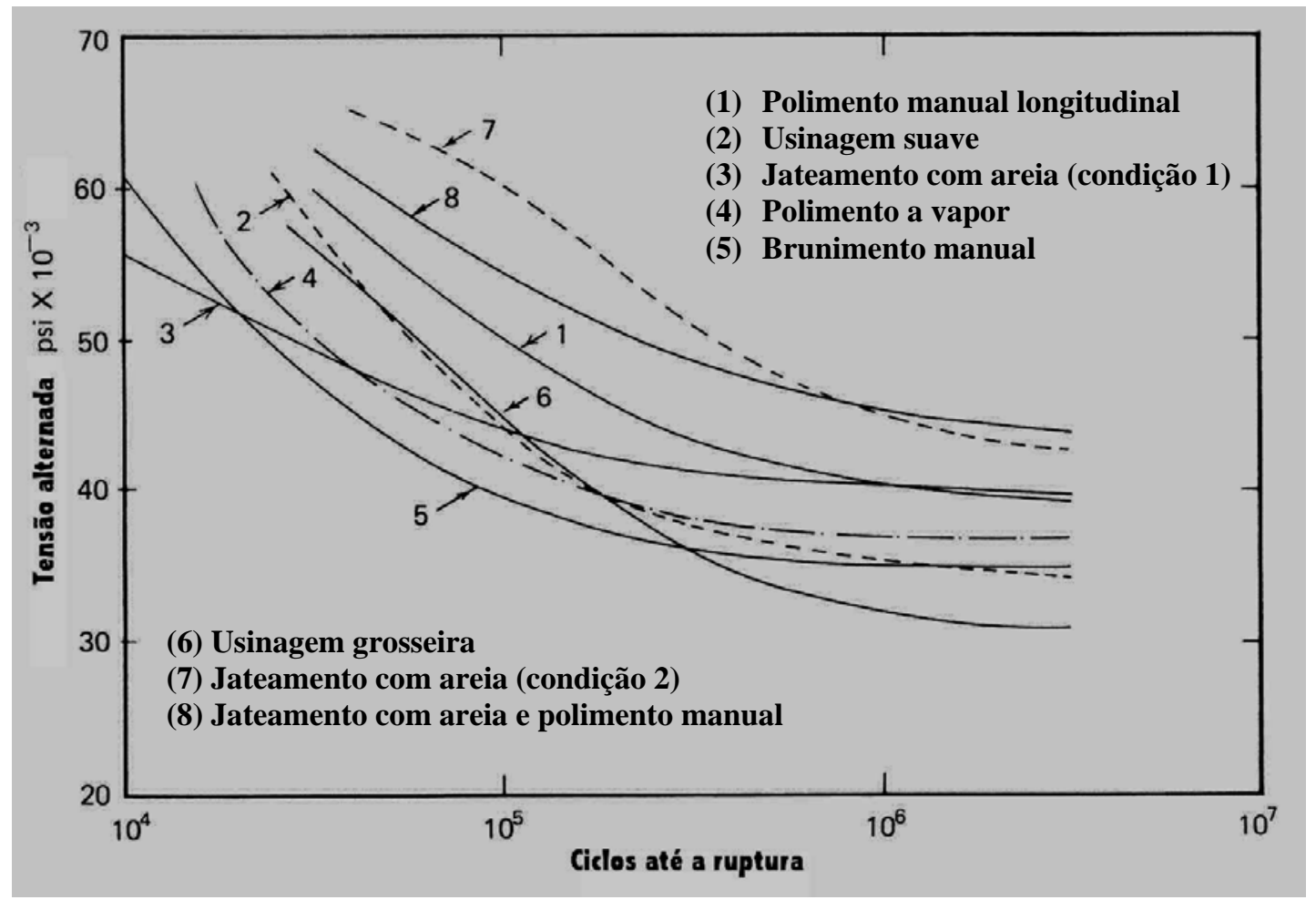

Figura 20 - Efeito do acabamento superficial sobre a curva $S-N$ de uma liga de alumínio 7075-T6 extrudada (HOOKER apud COLLINS [29],1993, p. 210). 
Existem várias formas de se avaliar a rugosidade superficial de um material. Dois sistemas básicos são utilizados em diversos países: o sistema da linha média (M) e o da envolvente (E). O primeiro, como o próprio nome sugere, é baseado numa linha média imaginária paralela ao perfil efetivo das irregularidades; o segundo baseia-se em linhas envoltórias descritas pelos centros de dois círculos $\mathrm{R}$ e $\mathrm{r}$, respectivamente, que rolam sobre o perfil efetivo.

Os sistemas baseados na linha média podem ainda ser classificados em três classes:

- Os que se baseiam na medida da profundidade da rugosidade,

- Os que se baseiam em medidas horizontais e,

- Os que se baseiam em medidas proporcionais.

Os que se baseiam na medida da profundidade da rugosidade são os mais largamente utilizados. Neste grupo encontram-se os seguintes parâmetros para medição da rugosidade superficial: desvio médio aritmético $(\mathrm{Ra})$, desvio médio quadrático $(\mathrm{Rq})$, altura das irregularidades dos 10 pontos $(\mathrm{Rz})$, altura máxima das irregularidades (Rmáx) e profundidade média (Rp). Cada um destes parâmetros possui uma maneira particular de determinação do perfil efetivo, onde o comprimento de amostragem é uma variável importante em todos os casos $[48,49]$. A mesma observação vale para as demais classes mencionadas anteriormente.

O presente trabalho utilizou-se do parâmetro Ra para a determinação de rugosidades, primeiro por motivos de praticidade (equipamentos simples são suficientes para a determinação da rugosidade) e, segundo, porque está entre os que a norma brasileira NBR 6405 [49] recomenda. 


\subsection{2 - Desvio médio aritmético $(\mathrm{Ra})$}

A quantificação da rugosidade através do parâmetro desvio médio aritmético ou rugosidade média $(\mathrm{Ra})$, consiste numa média aritmética dos valores absolutos das ordenadas de afastamento $\left(\mathrm{y}_{\mathrm{i}}\right)$ dos pontos de perfil de rugosidade e a linha média, tendo por comprimento o percurso de medição (Im), (figura 21).

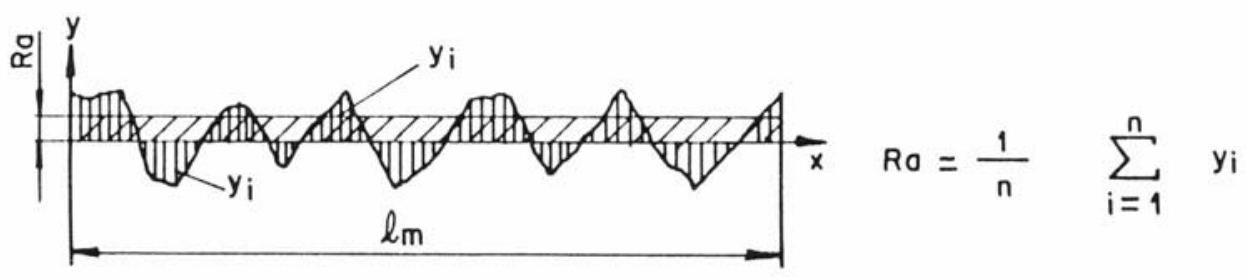

Figura 21 - Desenho esquemático mostrando o perfil de uma superfície genérica e as variáveis que permitem determinar a rugosidade média (Ra) [49]. 


\section{MATERIAIS E MÉTODOS}

\section{1 - Obtenção dos materiais}

\subsection{1 - Materiais obtidos}

A obtenção do material objeto deste estudo, foi feita pela rota da metalurgia do pó. As diretrizes, bem como os parâmetros e metodologias utilizadas foram extraídas do trabalho de MOURISCO [50].

Foram obtidos materiais compósitos com matriz de alumínio reforçados com 5, 10 e $15 \%$ em volume de partículas de carboneto de silício (SiC). Um quarto e último material foi produzido nas mesmas condições dos anteriores apenas com o material da matriz para ser utilizado como material de controle.

Com relação às dimensões finais do material obtido, utilizou-se uma taxa de redução de 16:1 na extrusão, o que possibilitou a obtenção de barras com $31,75 \mathrm{~mm}$ de diâmetro e aproximadamente $2,5 \mathrm{~m}$ de comprimento.

\subsubsection{1 - Matriz e reforço}

O material utilizado como matriz para a produção dos compósitos foi o alumínio puro comercial (AA1100) fornecido pela ALCOA (MG). Foi obtido por atomização a ar sob atmosfera de gás inerte e apresentou tamanho mediano de partículas igual a $22 \mu \mathrm{m}$.

O material de reforço utilizado foi o carboneto de silício (SiC) do tipo preto produzido pela EMAS/CARBORUNDUM (SP), denominado industrialmente como grão 800, tendo partículas com tamanho mediano igual a $6 \mu \mathrm{m}$. 
A composição química dos materiais utilizados (matriz e reforço) está relacionada na Tabela 2.

Tabela 2 - Composição química em peso da matriz e reforço (fonte: fornecedores)

\begin{tabular}{|c|c|c|c|}
\hline Designação & Material & Elemento & $\%$ em peso \\
\hline \multirow{3}{*}{ Matriz } & \multirow{3}{*}{ Pó de alumínio } & $\mathrm{Al}$ & $99,7-99,8$ \\
\cline { 3 - 4 } & & $\mathrm{Si}$ & $0,04-0,12$ \\
\cline { 3 - 4 } & & $\mathrm{Fe}$ & $0,09-0,18$ \\
\cline { 3 - 4 } & & $\mathrm{Ou}$ & $0,001-0,07$ \\
\hline \multirow{3}{*}{ Reforço } & \multirow{3}{*}{ Pó de SiC } & $\mathrm{SiC}$ & 98,87 \\
\cline { 3 - 4 } & \multirow{3}{*}{} & $\mathrm{Si}+\mathrm{SiO}_{2}$ & 0,6 \\
\cline { 3 - 4 } & & $\mathrm{Fe}$ & 0,18 \\
\cline { 3 - 4 } & & $\mathrm{Al}$ & 0,15 \\
\cline { 3 - 4 } & & $\mathrm{Cu}$ & 0,20 \\
\hline
\end{tabular}

\subsection{2 - Procedimentos}

A obtenção do material compósito pela rota da metalurgia do pó, obedeceu as etapas ilustradas na figura 22:
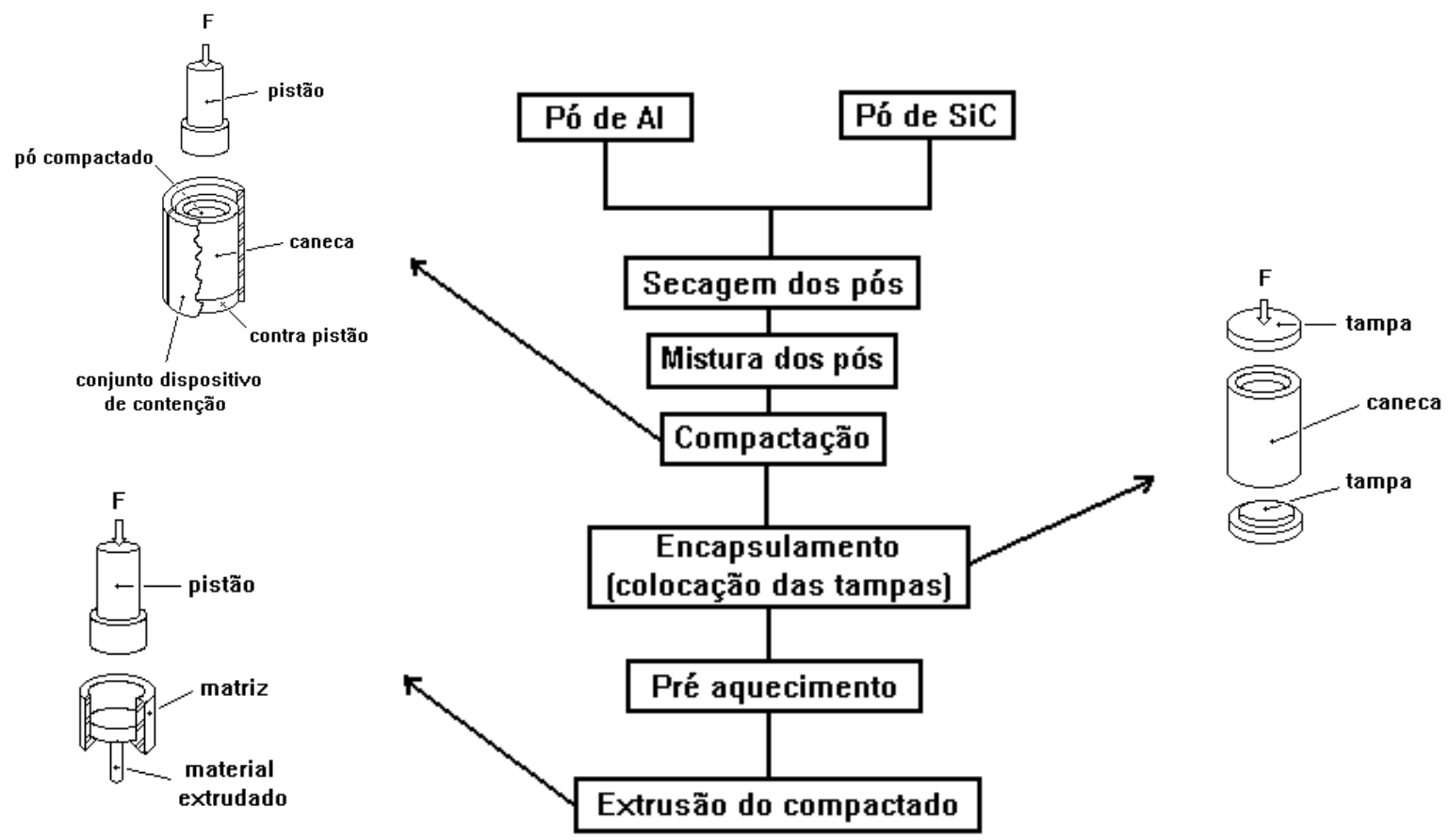

Figura 22 - Fluxograma da sequência de obtenção do material compósito Al/SiC utilizado neste trabalho [28]. 


\subsubsection{1 - Detalhamento das etapas de obtenção dos materiais}

1- A secagem dos pós de alumínio e de SiC foi feita em estufa por 4 horas a $100^{\circ} \mathrm{C}$.

2- Os pós foram misturados em um misturador tipo "V" por 4 horas a 40 RPM.

3- A compactação dos pós dentro das canecas foi feita numa máquina de ensaio mecânico com capacidade máxima de 200 toneladas. A carga aplicada para alcançar uma densidade de $80 \%$ dos compactados foi 100 toneladas (aproximadamente $8 \mathrm{Kg} / \mathrm{mm}^{2}$ ). Nesta fase foi utilizado um dispositivo de contenção (figura 23), especialmente projetado e construído para esta operação.

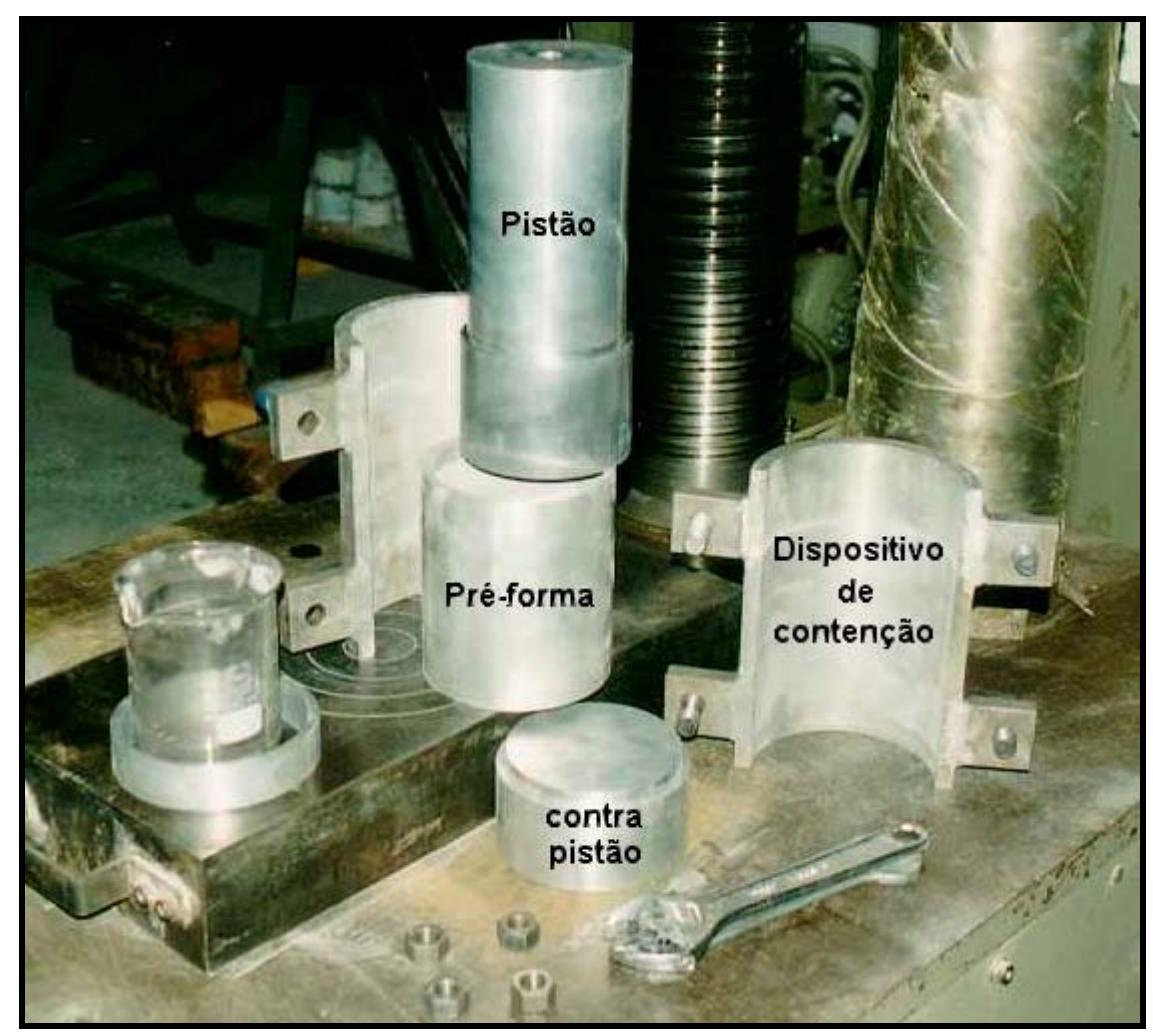

Figura 23 - A figura mostra a pré-forma compactada e os dispositivos utilizados na operação, todos apoiados sobre a base do equipamento de ensaio utilizado.

4- A colocação das tampas (encapsulamento) nas extremidades dos compactados foi feita numa prensa manual hidráulica, aplicando-se uma carga de aproximadamente 1,5 tonelada. 
5- O pré aquecimento das canecas foi feito em forno por 4 horas a $450^{\circ} \mathrm{C}$ para eliminação de gases e facilitar a escoabilidade durante a etapa de extrusão.

6- A extrusão foi feita numa extrusora vertical (figura 24) com a ferramenta a uma temperatura de $220{ }^{\circ} \mathrm{C}$. A velocidade de extrusão foi de aproximadamente $50 \mathrm{~mm} / \mathrm{s}$ e a força máxima aplicada de 450 toneladas. Foi utilizada graxa Molikote como lubrificante.

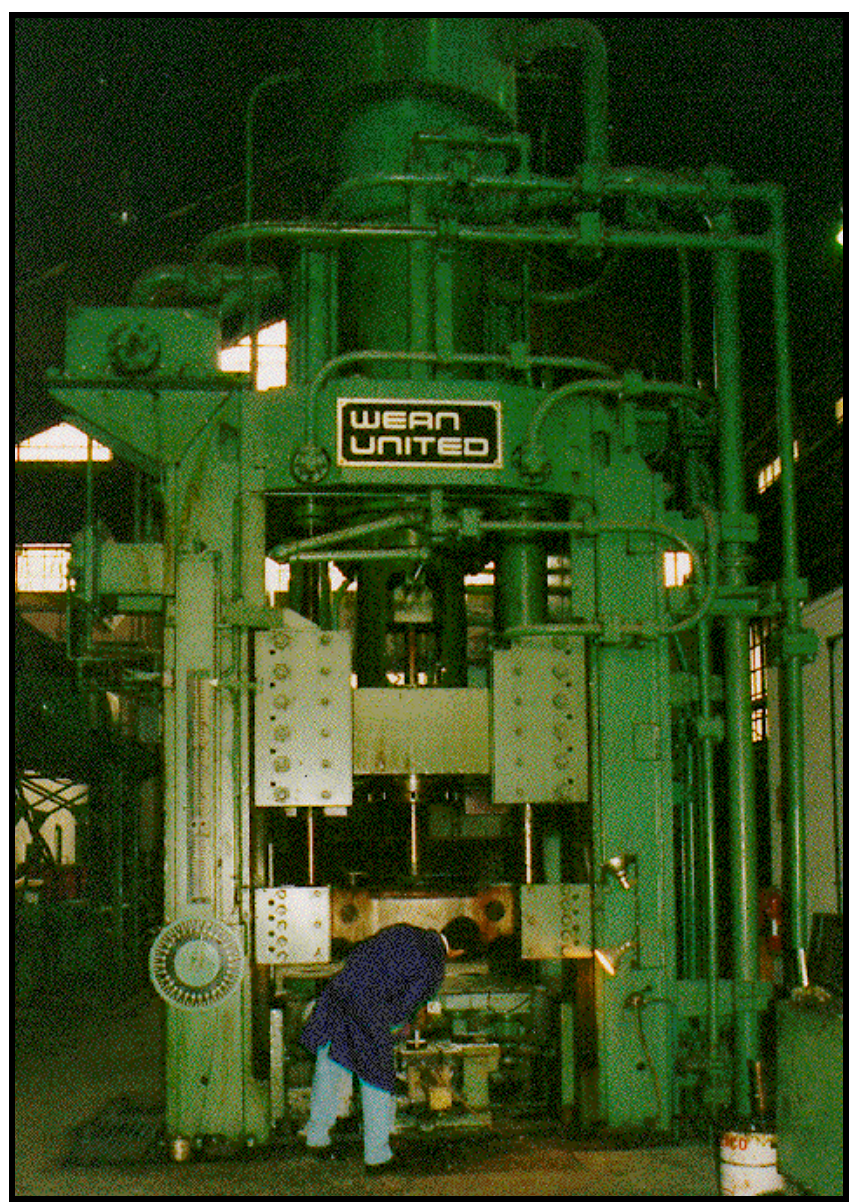

Figura 24 - Extrusora vertical utilizada na obtenção dos materiais.

7- Os materiais foram obtidos com 31,75 mm de diâmetro e aproximadamente 2,5 m de comprimento (figura 25). 


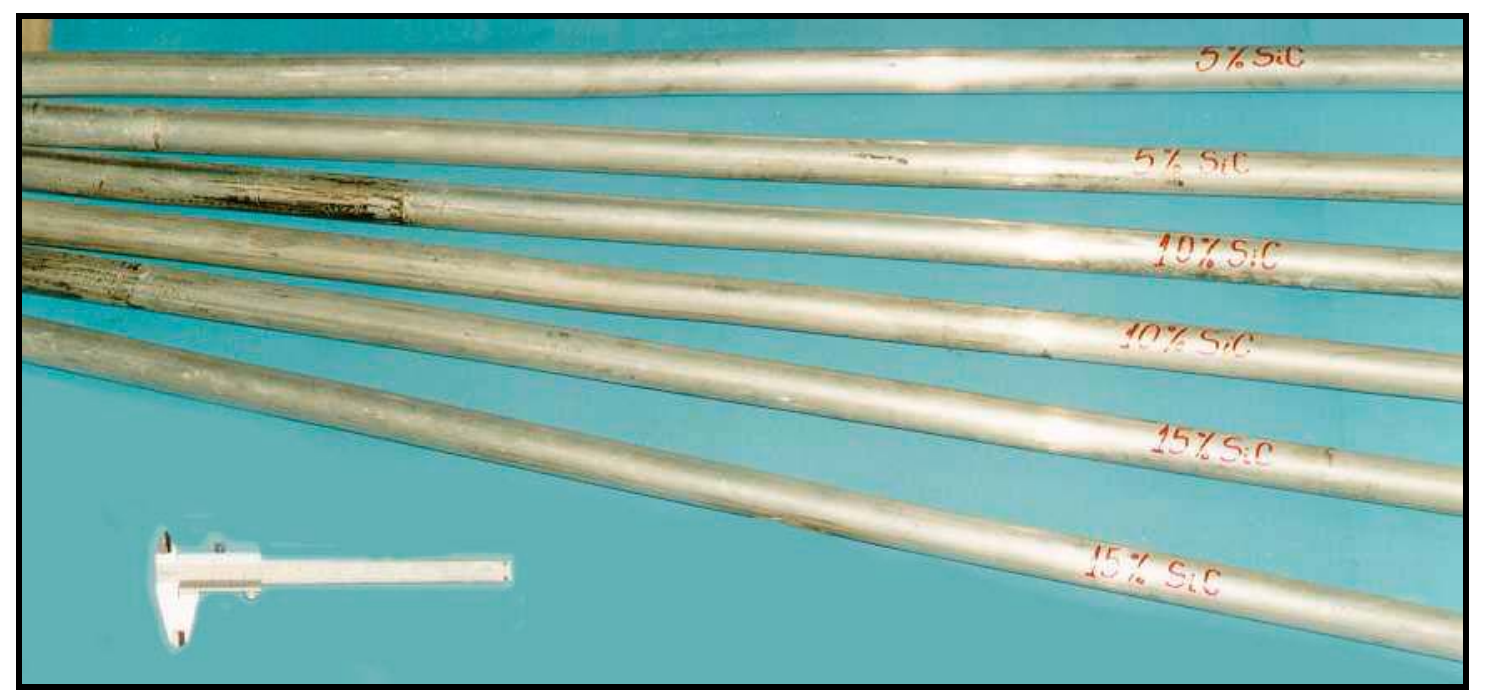

Figura 25 - Aspecto geral dos materiais obtidos

\subsection{3 - Caracterização física, mecânica e microestrutural dos materiais} obtidos

\subsubsection{1 - Dureza e resistência mecânica}

Para a caracterização mecânica dos materiais obtidos foram utilizados ensaios de dureza e de resistência mecânica. Os ensaios de dureza foram executados em amostras (uma amostra para cada material obtido) com diâmetro de $26 \mathrm{~mm}$ e altura de $8 \mathrm{~mm}$. Tomou-se cuidados no sentido de deixar perfeitamente paralelas entre si, as faces das amostras para evitar influência nos resultados. Uma delas, a face de impressão, foi devidamente polida para facilitar a visualização das impressões. Foram feitas cerca de seis impressões em cada amostra.

A dureza medida foi do tipo Brinell (HB) e os parâmetros utilizados foram: carga aplicada de $62,5 \mathrm{~kg}$ e diâmetro do penetrador esférico igual a 2,5 mm. As calotas esféricas impressas nas amostras foram medidas em um projetor óptico de perfil, cujos valores, uma vez aplicados na equação clássica [17], possibilitaram determinar a dureza Brinell dos materiais. 
A determinação da resistência mecânica foi feita numa máquina universal de ensaios mecânicos, através de ensaio de tração. Doze corpos de prova foram confeccionados conforme a norma DIN 50125 [51], sendo três amostras para cada material (figura 26). Foram traçadas as curvas de tensão/deformação para cada corpo de prova e então determinados os valores de limite de escoamento (LE), limite de resistência $(L R)$, taxa de alongamento total $(\varepsilon C P)$ e taxa de redução de área da secção transversal $(\psi)$. Além disso, foram feitas fractografias das superfícies fraturadas em microscópio eletrônico de varredura (MEV) para uma análise mais detalhada.

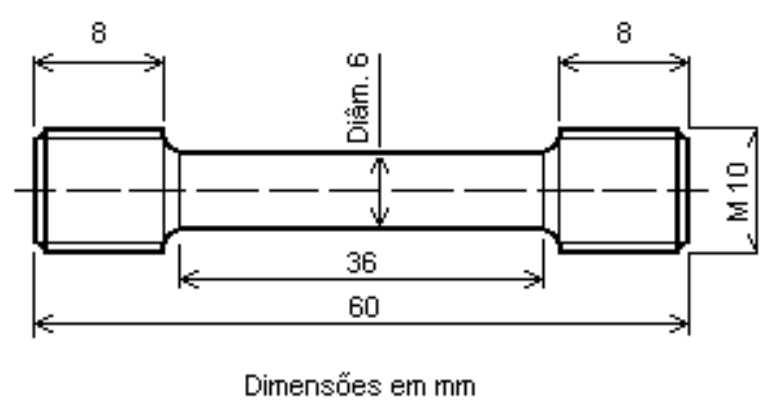

Figura 26 - Desenho esquemático dos corpos de prova utilizados para os ensaios de tração.

\subsubsection{2 - Microestrutura}

Duas amostras de cada material foram retiradas aleatoriamente e preparadas para a caracterização microestrutural por microscopia óptica, sendo uma no sentido transversal e a outra no longitudinal com relação à direção de extrusão. As amostras do sentido transversal não necessitaram ser embutidas para polimento. As do sentido longitudinal foram embutidas em baquelite.

As amostras passaram por uma etapa inicial de lixamento seguida por polimento com pastas de diamante e finalmente sílica coloidal, conforme a tabela 3 a seguir. 
Tabela 3 -Sequência utilizada na preparação das amostras para metalografia

\begin{tabular}{|c|c|c|c|}
\hline $\begin{array}{l}\text { Sequência } \\
\text { preparação }\end{array}$ & $\begin{array}{c}\text { Tipo de } \\
\text { processamento }\end{array}$ & Material & Granulometria \\
\hline \multirow{4}{*}{$\mid$} & \multirow{4}{*}{ Lixamento } & Lixa & 280 mesh \\
\hline & & Lixa & 320 mesh \\
\hline & & Lixa & 400 mesh \\
\hline & & Lixa & 600 mesh \\
\hline $\mid$ & \multirow{4}{*}{ Polimento } & Diamante & $15 \mu \mathrm{m}$ \\
\hline $\mid$ & & Diamante & $6 \mu \mathrm{m}$ \\
\hline $\mid$ & & Diamante & $3 \mu \mathrm{m}$ \\
\hline$\downarrow$ & & Sílica coloidal & $0,25 \mu \mathrm{m}$ \\
\hline
\end{tabular}

$\mathrm{Na}$ sequência de preparação metalográfica das amostras, o polimento com pasta de diamante de $15 \mu \mathrm{m}$ foi muito importante para a eliminação das partículas abrasivas deixadas na superfície das mesmas durante as etapas de lixamento.

\subsubsection{3 - Densidade}

A característica física avaliada nos materiais obtidos foi a densidade hidrostática. Foram utilizadas amostras (uma para cada material obtido) com $26 \mathrm{~mm}$ de diâmetro por $8 \mathrm{~mm}$ de altura. A determinação da densidade foi feita utilizando uma balança com precisão de 0,001 g e água deionizada para imersão das amostras.

A densidade teórica dos materias também foi calculada para fins de comparação. A equação 4, obtida pelo princípio da regra das misturas [17], foi utilizada para a determinação da densidade teórica.

$$
\mathrm{dt}=\mathrm{dm} \times \frac{\% \mathrm{~m}}{100}+\mathrm{dr} \times\left(1-\frac{\% \mathrm{~m}}{100}\right)
$$




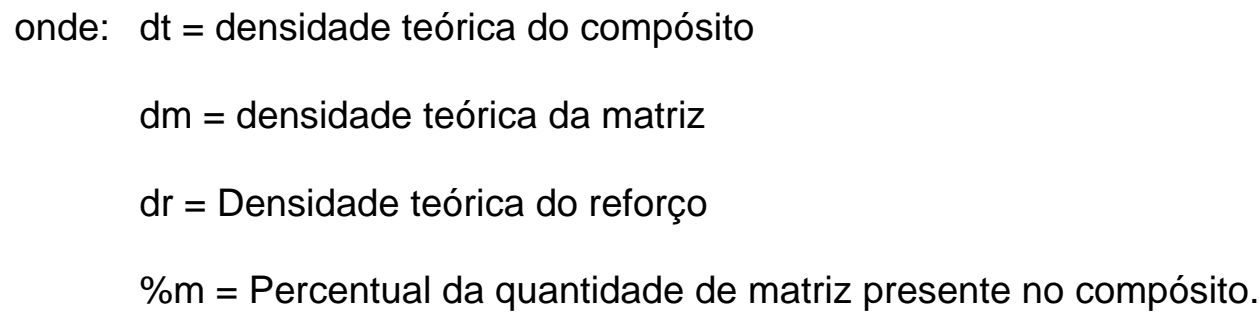

\section{2 - Confecção dos corpos de prova para os ensaios de fadiga}

\subsection{1 - Definição das condições de preparação}

Com base em informações de tamanho de amostragem e repetição contidas na norma ASTM E739 [37] (capítulo 2, item 2.2.8), e uma vez definido o tipo de teste que se pretendia fazer com os materiais em estudo (preliminares e exploratórios - pesquisa exploratória e testes de desenvolvimento), optou-se por confeccionar basicamente 3 grupos de 15 corpos de prova de cada material $(5,10$ e $15 \%)$, um grupo de 15 corpos de prova reforçados com $15 \%$ de SiC e usinados com metal duro (MD) e um grupo de 15 corpos de prova constituído unicamente pelo material da matriz, totalizando 165 corpos de prova.

Os detalhes que diferem um grupo do outro, podem ser visualizados na Tabela 4, a seguir. 
Tabela 4 - Corpos de prova e respectivas condições de preparação.

\begin{tabular}{|c|c|c|c|c|}
\hline GRUPOS & LOTE & MATERIAL & $\begin{array}{c}\text { CONDIÇÃO DE USINAGEM E } \\
\text { JATEAMENTO }\end{array}$ & $\begin{array}{l}\text { QUANTIDADE } \\
\text { DE CPS }\end{array}$ \\
\hline \multirow{3}{*}{1} & 1 & $\mathrm{Al} / \mathrm{SiC} 5 \%$ & \multirow{3}{*}{ PCD f: $0,06 \mathrm{~mm} / \mathrm{rot}$} & 15 \\
\hline & 2 & $\mathrm{Al} / \mathrm{SiC} 10 \%$ & & 15 \\
\hline & 3 & $\mathrm{Al} / \mathrm{SiC} 15 \%$ & & 15 \\
\hline \multirow{3}{*}{2} & 4 & $\mathrm{Al} / \mathrm{SiC} 5 \%$ & \multirow{3}{*}{ PCD f: $0,24 \mathrm{~mm} / \mathrm{rot}$} & 15 \\
\hline & 5 & $\mathrm{Al} / \mathrm{SiC} 10 \%$ & & 15 \\
\hline & 6 & Al/SiC $15 \%$ & & 15 \\
\hline 3 & 7 & $\mathrm{Al} / \mathrm{SiC} 15 \%$ & MD f: $0,06 \mathrm{~mm} / \mathrm{rot}$ & 15 \\
\hline \multirow{3}{*}{4} & 8 & $\mathrm{Al} / \mathrm{SiC} 5 \%$ & \multirow{3}{*}{ PCD f: $0,06 \mathrm{~mm} / \mathrm{rot}+$ jateamento } & 15 \\
\hline & 9 & Al/SiC $10 \%$ & & 15 \\
\hline & 10 & Al/SiC $15 \%$ & & 15 \\
\hline 5 & 11 & $\mathrm{Al} / \mathrm{SiC} 0 \%$ & PCD f: $0,06 \mathrm{~mm} / \mathrm{rot}$ & 15 \\
\hline
\end{tabular}

$(P C D=$ Ferramenta de diamante policristalino; $M D=$ Ferramenta de metal duro classificação ISO TCGX 16 T3 04-AL; $f$ = Taxa de avanço adotada durante a usinagem).

\subsection{2 - Usinagem dos corpos de prova}

\subsubsection{1 - Geometria}

A geometria dos corpos de prova foi definida de acordo com as recomendações da norma ASTM E466 [52] para corpos de prova com raios de tangência entre a seção de teste e as extremidades do mesmo (figura 27).

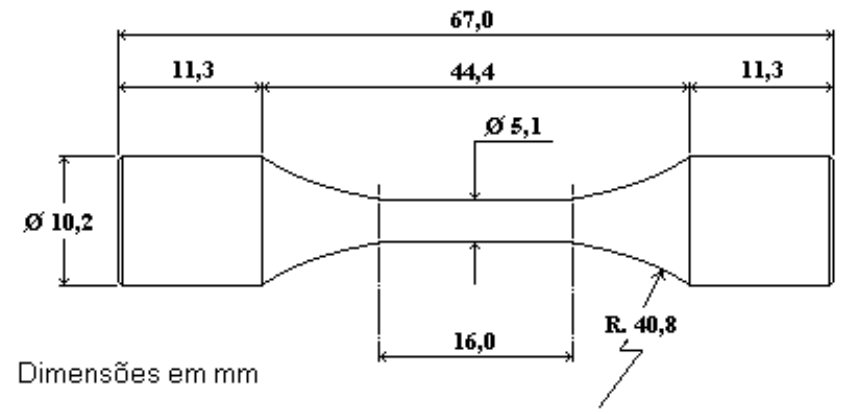

Figura 27 - Desenho esquemático dos corpos de prova de fadiga. 


\subsubsection{2 - Preparação e pré usinagem}

Devido à pequena quantidade disponível de material para a realização do trabalho, um estudo criterioso foi feito para possibilitar um melhor aproveitamento do mesmo. Como o material de partida possuía um diâmetro de $31,75 \mathrm{~mm}$ e o maior diâmetro existente na geometria escolhida do corpo de prova era de 10,2 mm, decidiuse fracionar a secção transversal do material de partida em quatro quartos (figura 28), sendo cada quarto correspondente a um blank de corpo de prova. (OBS: blank = material de partida).

Inicialmente as barras produzidas foram cortadas e faceadas com um comprimento de $67 \mathrm{~mm}$ para posterior marcação e fracionamento.

Para facilitar o processo de fracionamento e obtenção dos blanks, produziu-se um dispositivo tipo máscara, que serviu como gabarito para o transporte e execução dos furos de centro para definir a posição geométrica de cada corpo de prova no material de partida.

Para fracionar os materiais, utilizou-se o equipamento ISOMET 2000 que possibilitou obter cortes com espessuras bem reduzidas (da ordem de 0,8 mm), eliminando assim a possibilidade do corte atingir a superfície útil dos futuros corpos de prova. Um pequeno dispositivo (figura 28) foi utilizado para fixar as peças a serem cortadas no equipamento de corte. 


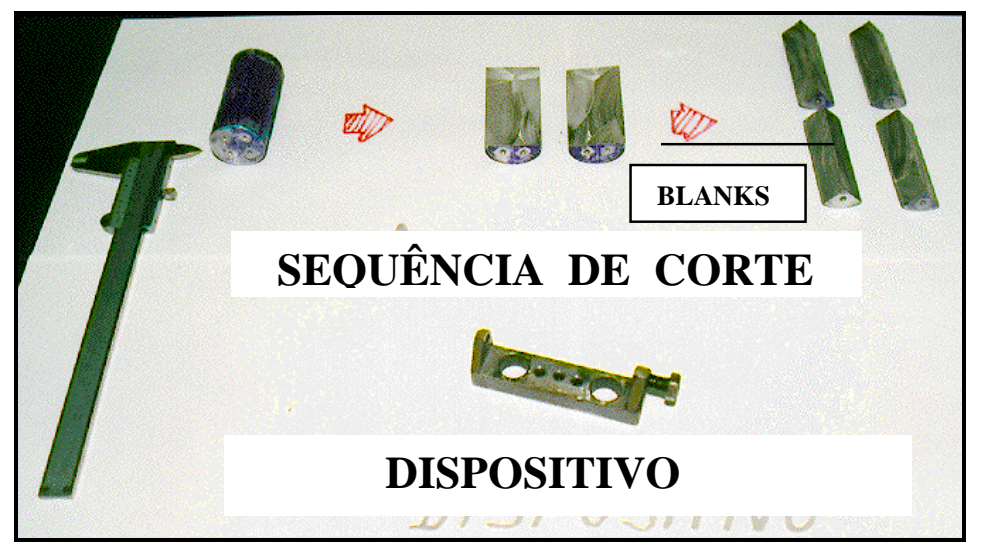

Figura 28 - Seqüência de preparação dos corpos de prova de fadiga, mostrando o fracionamento do material de partida; primeiro em duas partes e depois em quatro. É mostrado também o dispositivo utilizado para fixar o material no equipamento de corte.

Após fracionados, os blanks apresentaram um perfil similar ao de um setor circular com ângulo de 90 graus.

Esta geometria é indesejável na usinagem, pois gera uma condição de corte interrompido, que é prejudicial para a ferramenta de usinagem na medida em que provoca um desgaste mais acelerado da mesma podendo até culminar com a sua ruptura durante o processo. Como o objetivo foi obter condições de acabamento superficial final bem definidas nos corpos de prova, a integridade física da ferramenta foi, então, fator importantíssimo. Assim sendo, optou-se por fazer uma pré-usinagem de todos os corpos de prova, deixando-os com diâmetro de $11 \mathrm{~mm}$. Nesta condição, a maioria dos corpos de prova já apresentaram uma superfície totalmente cilíndrica e muito mais adequada para ser submetida à usinagem final.

\subsubsection{3 - Usinagem final dos corpos de prova}

A usinagem dos corpos de prova foi feita em um torno CNC (figura 29) por uma série de motivos, dentre eles, a grande precisão e reprodutibilidade dimensional alcançadas, variação infinita de velocidades e avanços de corte, boa rigidez e estabilidade do equipamento. 
Os programas CNC foram feitos observando-se os cuidados apontados no apêndice da norma ASTM E466 [52], que visam principalmente evitar a introdução de tensões residuais no material devida a profundidades de corte excessivas na finalização da usinagem. Refrigeração abundante também foi utilizada durante a execução da usinagem dos corpos de prova, para evitar mudanças microestruturais na região de usinagem, devido a altas temperaturas localizadas.

Com o propósito de melhorar o aproveitamento das ferramentas disponíveis, foram elaborados dois programas CNC (Apêndice 1). Um deles usina o perfil da direita para a esquerda e o outro faz o inverso. Com o segundo programa (esquerda para a direita) foi possível utilizar o flanco direito das ferramentas que, praticamente, não foi afetado quando se usinava da direita para a esquerda.

Para usinar os diferentes grupos de corpos de prova propostos na Tabela 4, apenas o tipo de ferramenta e/ou avanço foram alterados conforme o caso.

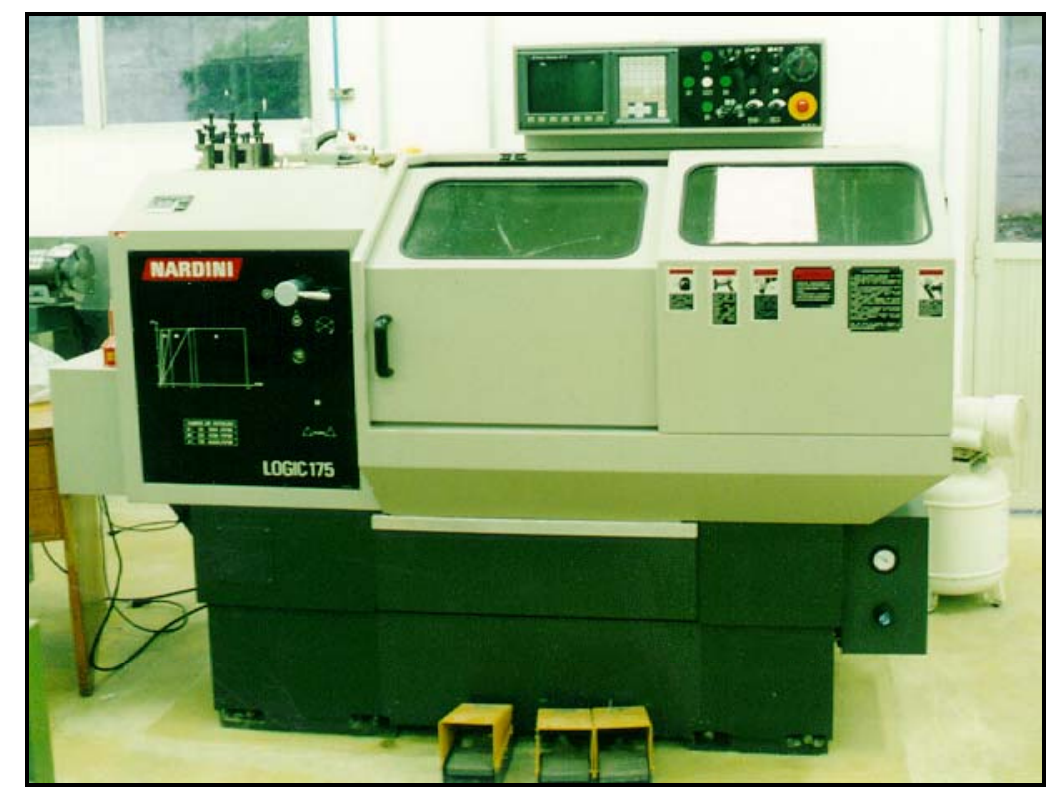

Figura 29 - Equipamento utilizado para usinar os corpos de prova de fadiga e de tração. 


\subsubsection{4 - Jateamento}

A operação de jateamento foi executada em todos os corpos de prova do grupo 4 (vide tabela 4), utilizando-se microesferas de vidro com tamanho mediano de $360 \mu \mathrm{m}$. O jateamento foi feito em um equipamento específico à pressão de 4 $\mathrm{Kg} / \mathrm{cm}^{2}$.

A taxa de cobertura do jateamento foi de $300 \%$ e o ângulo de impacto $90^{\circ}$. A determinação da intensidade do jateamento pelo método ALMEN [46] não foi possível por não dispor-se do equipamento necessário.

Para promover um jateamento uniforme sobre toda a superfície do corpo de prova, foi utilizado um dispositivo adaptado conforme ilustrado na figura $\mathbf{3 0 .}$ Neste dispositivo, o corpo de prova a ser jateado é fixado entre pontas na região central do mesmo e é girado manualmente através de manivela, enquanto o jato de microesferas de vidro é lançado sobre a superfície do corpo de prova.

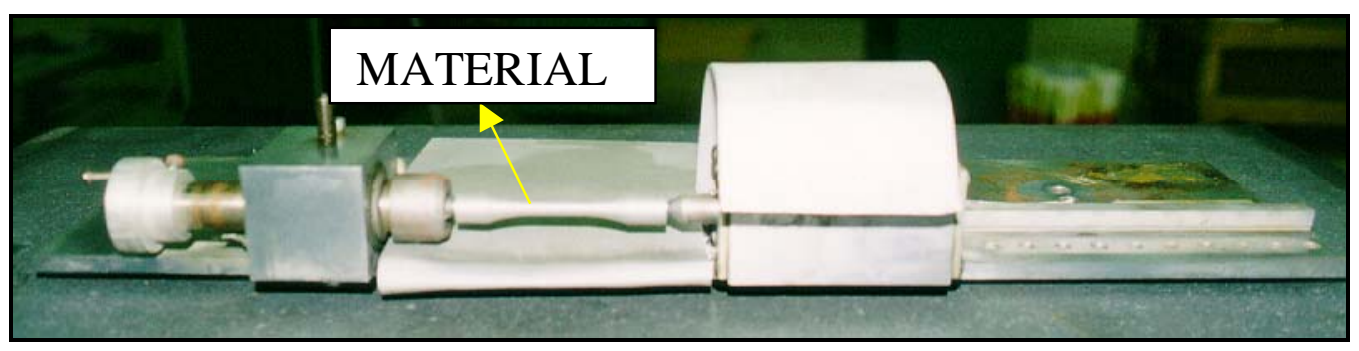

Figura 30 - Dispositivo utilizado para a execução da operação de jateamento.

O jateamento foi executado em superfícies previamente usinadas com ferramenta de diamante (PCD) e taxa de avanço de 0,06 mm/rot.

\subsubsection{5 - Dimensão e rugosidade dos corpos de prova}

Após a usinagem efetuou-se a medição da rugosidade superficial de todos os corpos de prova utilizando-se um rugosímetro analógico marca Mitutoyo, modelo Surftest III. Para as peças com acabamento mais grosseiro o fundo de escala 
utilizado foi de $10 \mu \mathrm{m}$ e para acabamentos mais finos $3 \mu \mathrm{m}$. O curso de medição (cutoff) foi de $6 \mathrm{~mm}$.

A rugosidade teórica também foi calculada para fins de comparação, utilizando-se a equação 5 que normalmente é aplicada para materiais convencionais, mas que tem sido utilizada por alguns pesquisadores [7] para materiais compósitos.

$$
\mathrm{Ra}=\frac{32,1 \times \mathrm{f}^{2}}{\mathrm{r}}[\mu \mathrm{m}]
$$

onde: $\mathrm{Ra}=$ Rugosidade média aritmética

$\mathrm{f}=$ Avanço de corte em $\mathrm{mm} / \mathrm{rot}$

$r=$ raio da ponta da ferramenta em $\mathrm{mm}$

JESUS FILHO e ROSSI [11], em seus experimentos colocam em dúvida a validade desta equação para materiais compósitos. Segundo eles, a equação deve levar em consideração o tamanho das partículas de reforço e a fração volumétrica do compósito, que são variáveis importantes nestes casos.

O levantamento dimensional se restringiu à secção principal de ensaio (diâmetro de 5,1 mm - figura 27) e foi feito em todos os corpos de prova utilizando-se um micrômetro externo de capacidade 0-25 mm com precisão de 0,001 mm.

\section{3 - Ensaios de fadiga}

\subsection{1 - Definição dos parâmetros de ensaio}

$\mathrm{Na}$ tentativa de definir parâmetros adequados para a execução dos ensaios de fadiga, principalmente do ponto de vista prático, foram usinados dois corpos de prova de cada tipo de material para a execução de testes preliminares. 
Foi definido que os ensaios de fadiga seriam executados no campo de tração-tração, devido principalmente à forma pela qual os corpos de prova seriam fixados no equipamento (sistema de garras).

Os primeiros testes mostraram que a vida à fadiga dos corpos de prova sob tensões abaixo do limite de escoamento foi extremamente longa (da ordem de $5 \times 10^{6}$ ciclos). Diante do elevado número de corpos de prova para ensaiar (165), decidiu-se trabalhar com níveis de tensões máximas igual ou ligeiramente superiores ao limite de escoamento de cada tipo de material.

Foram fixados, a princípio, cinco níveis de tensões para os ensaios, onde as cargas máximas aplicadas correspondiam a 100, 105, 110, 115 e $120 \%$ do limite de escoamento de cada tipo de material.

Mesmo assim, para as cargas máximas correspondentes a $100 \%$ do limite de escoamento dos materiais, a vida à fadiga ultrapassou $2 \times 10^{6}$ ciclos, que foi o valor máximo fixado para os ensaios. Assim, apenas alguns corpos de prova foram ensaiados com tensão máxima correspondente a $100 \%$ do limite de escoamento. Este patamar de tensão foi então abandonado, dando lugar ao nível de tensão correspondente a $125 \%$.

Os cinco níveis de tensão máxima utilizados para a maioria dos corpos de prova foram 105, 110, 115, 120 e $125 \%$ do limite de escoamento de cada material. OMAM et al. [3] também utilizaram critério semelhante para definir os níveis de tensão utilizados em seus experimentos.

A freqüência de trabalho também foi definida nestes testes preliminares em $15 \mathrm{~Hz}$ e a razão de tensões adotada foi $\mathrm{R}=0,1$. Os ensaios foram executados em condições ambientais normais. 


\subsection{2 - Equipamento utilizado}

Foram utilizados três equipamentos durante a execução dos ensaios de fadiga deste trabalho; $80 \%$ dos corpos de prova foram ensaiados em uma máquina servohidráulica Instron 1334 de 50 toneladas de capacidade (figuras 31a-b) utilizando-se célula de carga de $500 \mathrm{Kg}$, e fundo de escala $100 \%$. Os $20 \%$ restantes foram distribuídos entre uma Instron e uma MTS, ambas de 10 toneladas de capacidade, células de carga de $500 \mathrm{Kg}$ e $100 \%$ de fundo de escala.

Todas as máquinas encontravam-se perfeitamente calibradas. Isto foi confirmado com rápida verificação através de pesos com massas conhecidas.

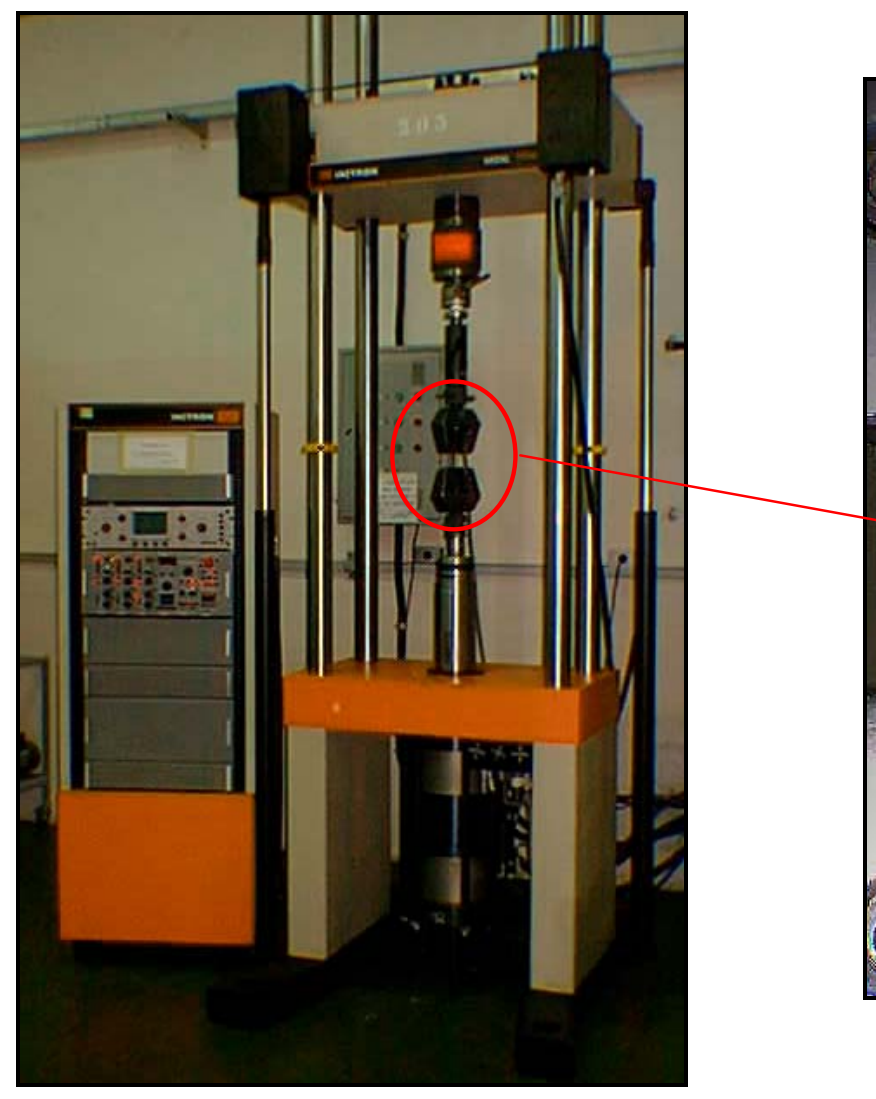

(a)

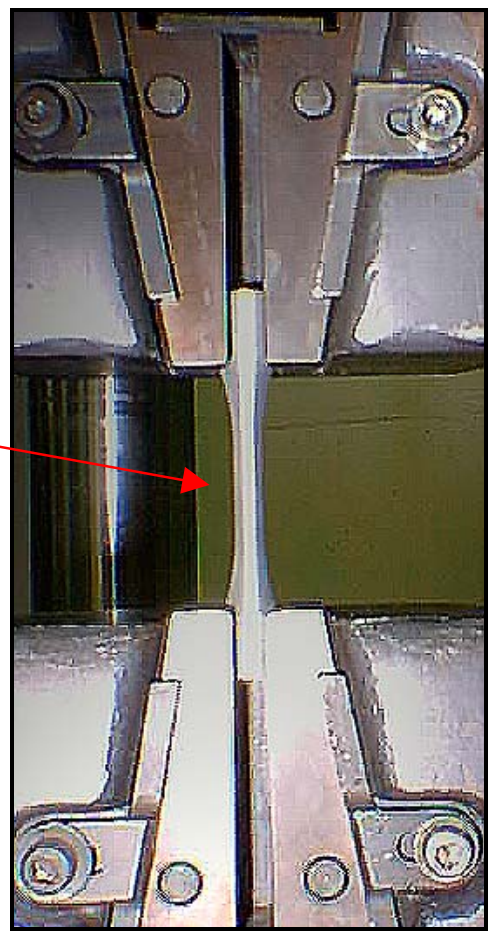

(b)

Figura 31 - (a)Equipamento servohidráulico de 50 toneladas de capacidade utilizado nos ensaios de fadiga; (b) Detalhe de um corpo de prova preso no equipamento. 
Também foram feitas fractografias do aspecto transversal dos corpos de prova fraturados por fadiga, utilizando-se um microscópio óptico Olympus BX60M com câmera digital Polaroid modelo DMC1 acoplada, e das superfícies de fratura por MEV. 


\section{RESULTADOS E DISCUSSÃO}

\section{1 - Caracterização mecânica, física e microestrutural}

Neste capítulo serão apresentados todos os resultados obtidos neste trabalho, tanto aqueles relacionados com a obtenção dos materiais quanto os referentes aos ensaios de fadiga realizados. Os resultados serão discutidos e correlacionados com os de outros pesquisadores, sempre que possível.

\subsection{1 - Caracterização mecânica}

Os ensaios utilizados para a caracterização mecânica dos materiais obtidos foram dureza e resistência mecânica. Na tabela 5 estão relacionados os valores médios das propriedades mecânicas avaliadas com os respectivos desvios. A figura 32 ajuda a visualizar melhor o comportamento das propriedades mecânicas dos materiais com a variação da fração volumétrica de reforços.

Tabela 5 - Resultados dos ensaios de dureza e resistência mecânica dos materiais obtidos.

\begin{tabular}{|c|c|c|c|c|c|}
\hline Material & dureza (HB) & LE (MPa) & LR (MPa) & $\varepsilon$ CP (\%) & $\psi(\%)$ \\
\hline Al/SiC 0 \% & $32,2 \pm 0,8$ & $88 \pm 1$ & $121 \pm 1$ & $32 \pm 2$ & $64 \pm 4$ \\
\hline Al/SiC 5\% & $38,9 \pm 0,6$ & $84 \pm 3$ & $128 \pm 2$ & $26 \pm 2$ & $47 \pm 5$ \\
\hline Al/SiC 10 \% & $44,4 \pm 0,7$ & $93 \pm 4$ & $135 \pm 2$ & $22 \pm 3$ & $32 \pm 5$ \\
\hline Al/SiC 15 \% & $49,2 \pm 0,8$ & $94 \pm 3$ & $138 \pm 4$ & $15 \pm 2$ & $20 \pm 4$ \\
\hline
\end{tabular}

$\mathrm{HB}=$ Dureza Brinell; LE = Limite de escoamento (0,2\%); LR = Limite de resistência; $\varepsilon$ $\mathrm{CP}=$ Deformação total do corpo de prova; $\psi$ = Redução de área. 


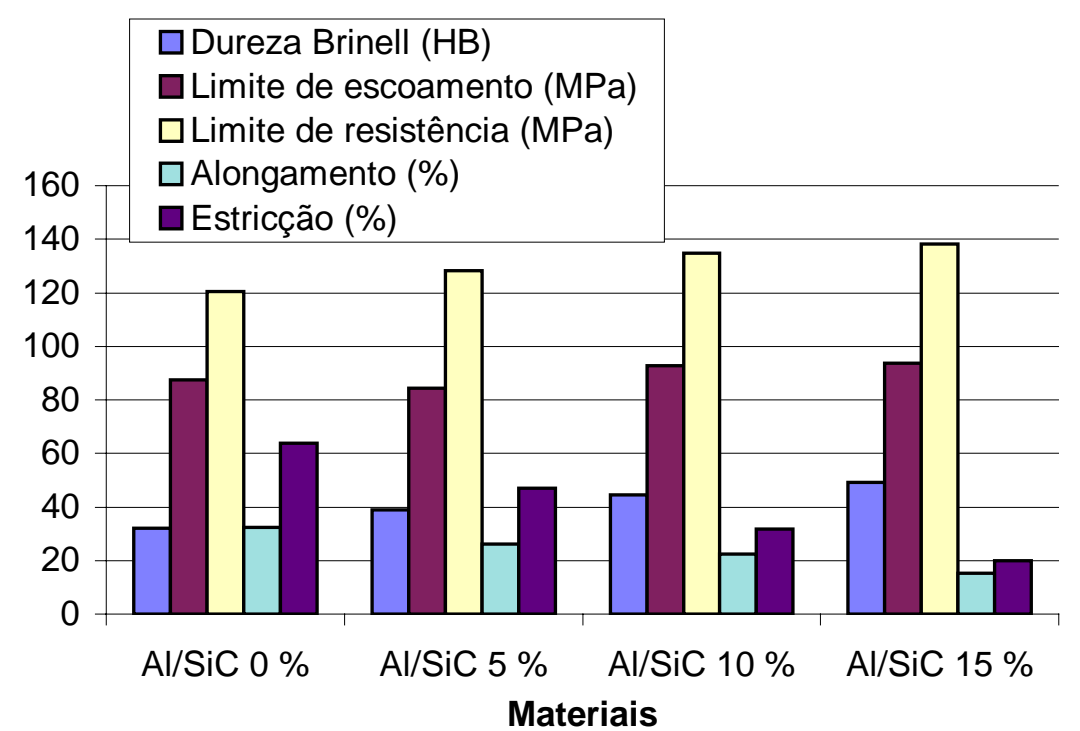

Figura 32 - Propriedades mecânicas dos materiais obtidos.

Através da figura 32, é possível verificar o aumento da dureza na medida em que a fração volumétrica de reforços aumenta. Esse comportamento é esperado, já que neste caso as partículas de reforço isoladamente têm dureza muito mais elevada que o material da matriz. Ainda é possível notar que o acréscimo nos valores de dureza tende a uma queda na taxa de crescimento com o aumento da quantidade de reforços.

Nota-se ainda que o limite de resistência aumenta na medida em que aumenta a quantidade de reforços, entretanto a taxa de crescimento vai gradativamente diminuindo. Esta tendência indica que a adição de partículas de reforço deixa de ser interessante a partir de certo ponto se o objetivo principal for a melhoria do limite de resistência mecânica do material. O aumento no valor de resistência com o aumento da quantidade de reforços, pode ser explicado pelo aumento no número de barreiras para movimentação de discordâncias.

O limite de escoamento dos materiais reforçados com $5 \%$ de $\mathrm{SiC}$ apresentaram valor inferior ao do material não reforçado. Isto pode ser devido à menor fração volumétrica de reforços presentes nestes materiais, que pode ter funcionado como defeitos localizados na matriz, levando esta componente da resistência 
mecânica (limite de escoamento) a apresentar menor valor, uma vez que o limite de resistência já apresentou alguma melhoria com relação ao material não reforçado.

\subsubsection{1 - Fractografias - ensaios de tração}

As figuras 33 a $\mathbf{3 6}$ referem-se a fractografias das regiões fraturadas dos materiais obtidos, após a execução dos ensaios de tração.
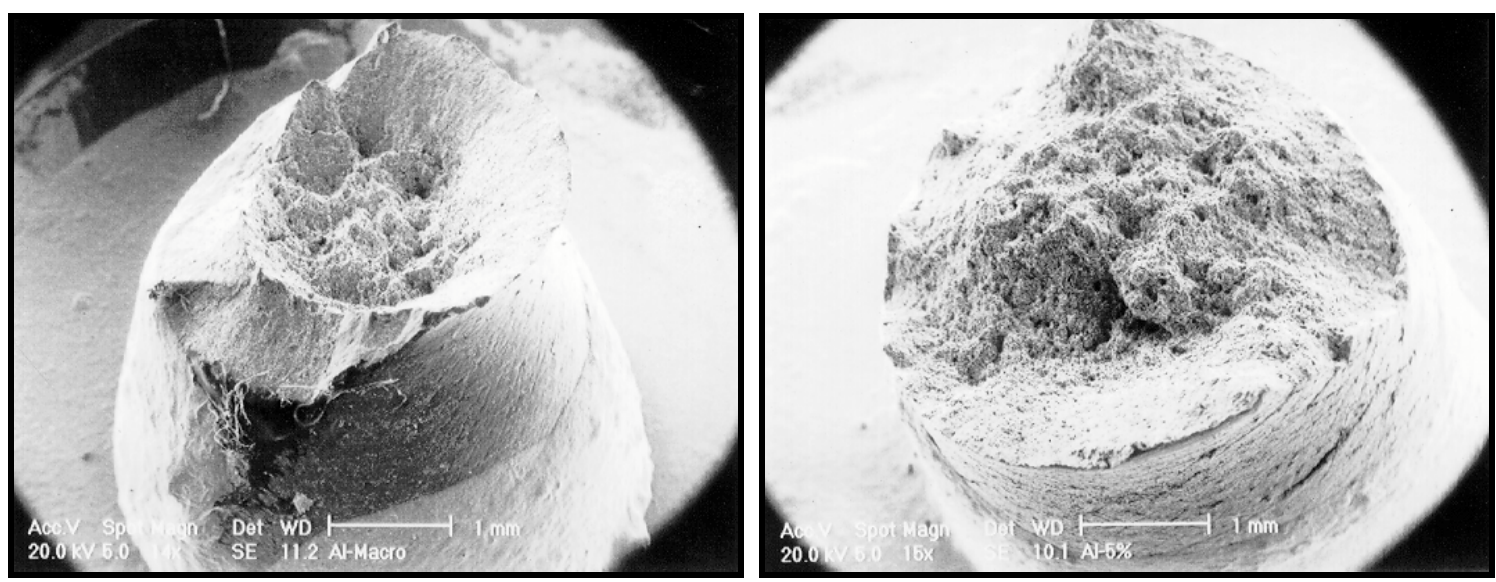

Figura 33 - Micrografia eletrônica de Figura 34 - Micrografia eletrônica de varredura mostrando o aspecto geral da varredura mostrando o aspecto geral da superfície de fratura obtida no ensaio de superfície de fratura obtida no ensaio de tração do Al/SiC $0 \%$. tração do Al/SiC $5 \%$.
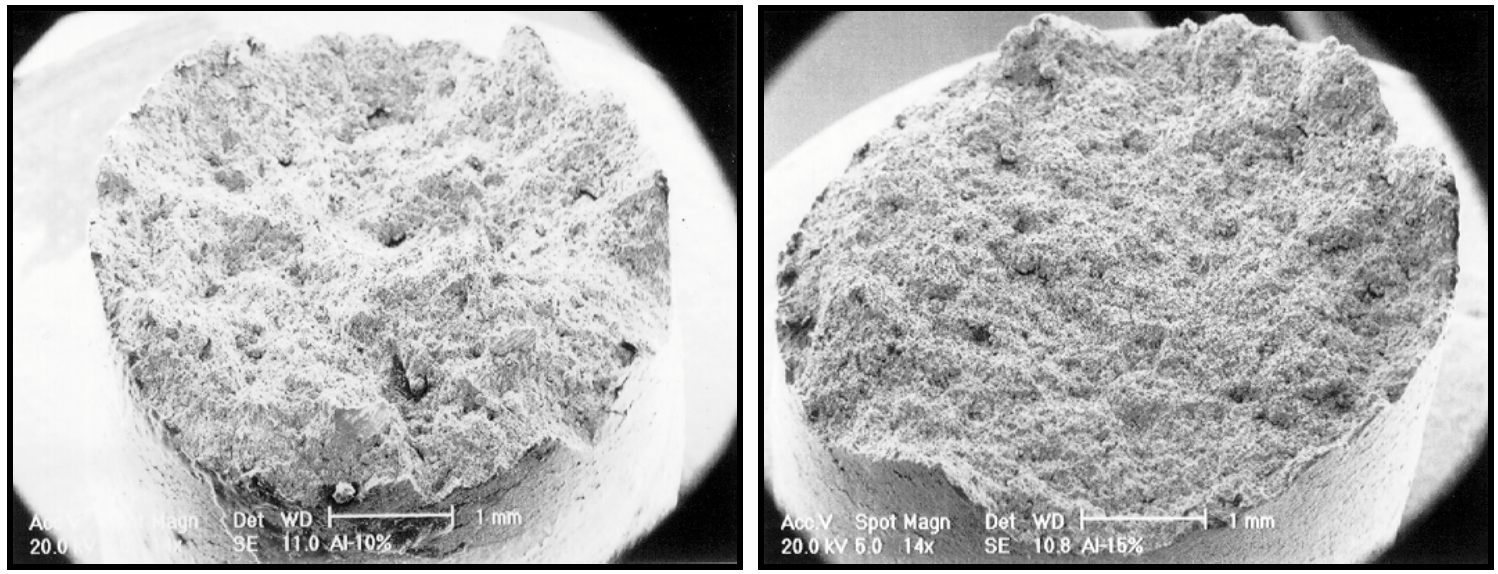

Figura 35 - Micrografia eletrônica de Figura 36 - Micrografia eletrônica de varredura mostrando o aspecto geral da var superfície de fratura obtida no ensaio de sup tração do Al/SiC $10 \%$. varredura mostrando o aspecto geral da superfície de fratura obtida no ensaio de tração do Al/SiC $15 \%$. 
As fractografias dos ensaios de tração mostraram nítida transição dúctilfrágil no aspecto das superfícies de fratura, começando com uma aparência dúctil (alumínio sem reforço, figura 33, onde se vê claramente, a forma de uma "taça" na região de fratura, que é uma característica dos materiais dúcteis) e continuam fragilizando gradativamente na medida em que é adicionada mais fase reforçante (Figuras 34 a 36). O material com a maior quantidade de reforço (Figura 36) apresentou uma superfície de fratura bem plana, característica de material mais frágil.

\subsection{2 - Caracterização física}

A propriedade física avaliada nos materiais obtidos foi a densidade. Os resultados obtidos, bem como a comparação com os valores teóricos calculados, são mostrados na tabela 6 e ilustrados na figura 37.

Tabela 6 - Valores das densidades teórica e hidrostática dos materiais obtidos e a relação densidade hidrostática/densidade teórica (Dh/Dt).

\begin{tabular}{|c|c|c|c|}
\hline Material & $\begin{array}{c}\text { Densidade hidrostática - } \\
\mathrm{Dh}\left(\mathrm{g} / \mathrm{cm}^{3}\right)\end{array}$ & $\begin{array}{c}\text { Densidade } \\
\text { teórica - Dt }\left(\mathrm{g} / \mathrm{cm}^{3}\right)\end{array}$ & $\begin{array}{c}\text { Dh/Dt } \\
(\%)\end{array}$ \\
\hline Al/SiC 0 \% & $2,687 \pm 0,004$ & 2,7020 & 99,44 \\
\hline Al/SiC 5 \% & $2,713 \pm 0,002$ & 2,7277 & 99,46 \\
\hline Al/SiC 10\% & $2,718 \pm 0,001$ & 2,7535 & 98,71 \\
\hline Al/SiC 15\% & $2,729 \pm 0,001$ & 2,7793 & 98,19 \\
\hline
\end{tabular}




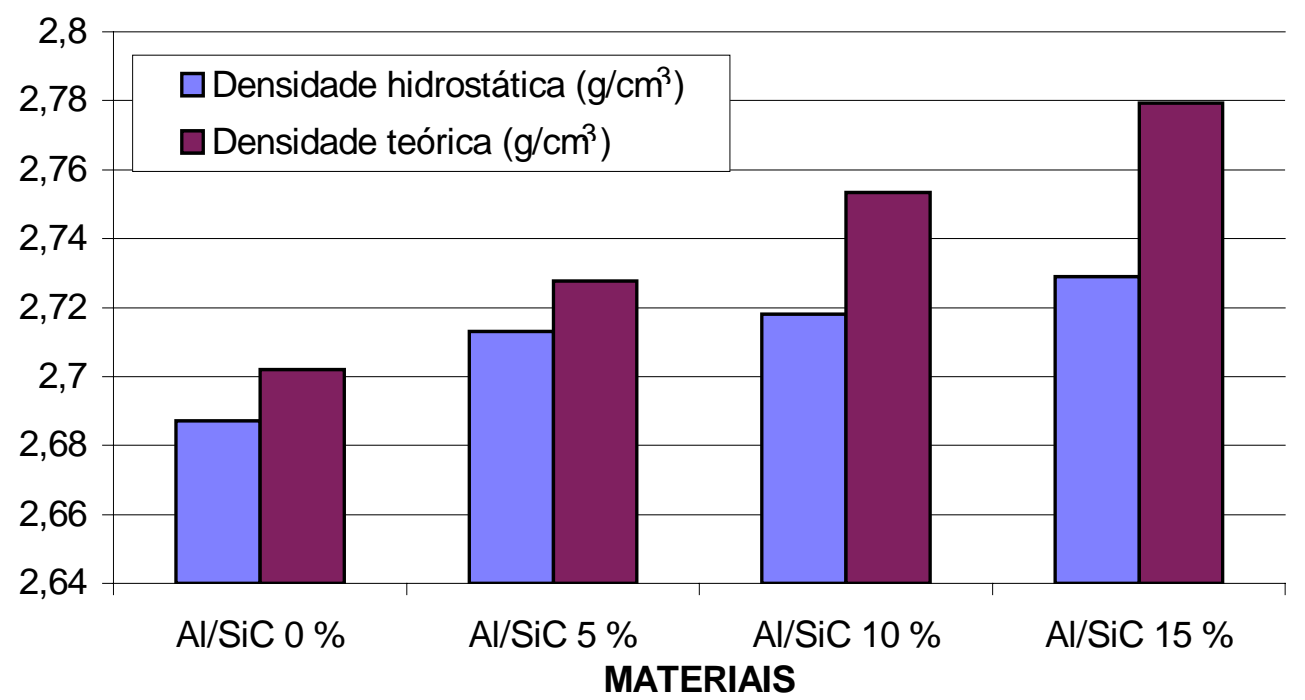

Figura 37 - Densidades hidrostática e teórica dos materiais produzidos (compósitos com 5,10 e $15 \%$ vol. de reforço)

As densidades finais dos materiais produzidos ficaram abaixo dos respectivos valores de densidade teórica (figura 37). Estes resultados já eram esperados, pois, dada a natureza do processo, vazios microscópicos e porosidades no interior do material são inevitáveis.

Nota-se ainda que, com o aumento da fração volumétrica de reforços, a relação dh/dt (tabela 6) diminui. Isto se deve ao fato de que com o aumento da fração volumétrica de reforços, aumenta a tendência de ocorrerem aglomerações de partículas, contribuindo assim para a formação de vazios e porosidades no material e a conseqüente redução da densidade.

A figura 37 ajuda a visualizar melhor que com o aumento da fração volumétrica de reforços, a diferença entre a densidade hidrostática e a densidade teórica $(\mathrm{dh} / \mathrm{dt})$ aumenta cada vez mais. 


\subsection{3 - Microestruturas}

As figuras 38 a 45, obtidas em microscópio óptico, mostram as microestruturas dos diversos materiais obtidos em duas direções principais: longitudinal e transversal com relação à direção de extrusão. As microestruturas foram visualizadas sem a necessidade de ataque químico anterior.

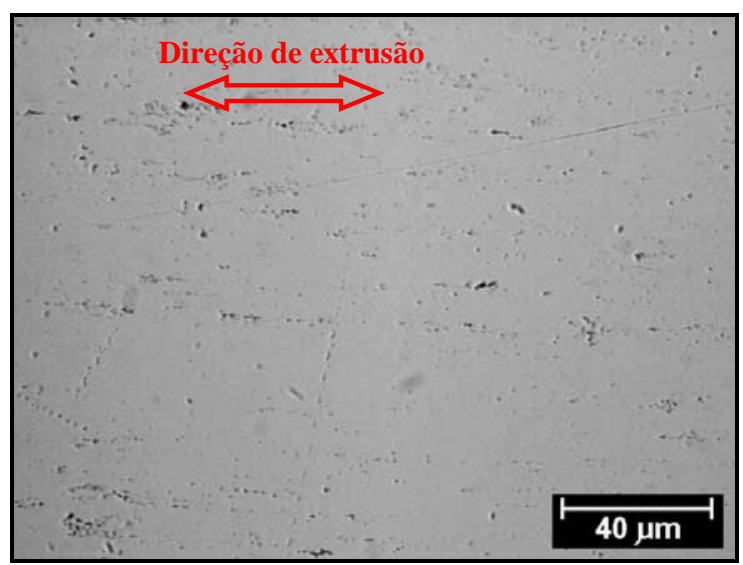

Figura 38 - Micrografia óptica mostrando o aspecto da secção longitudinal do Al/SiC $0 \%$.

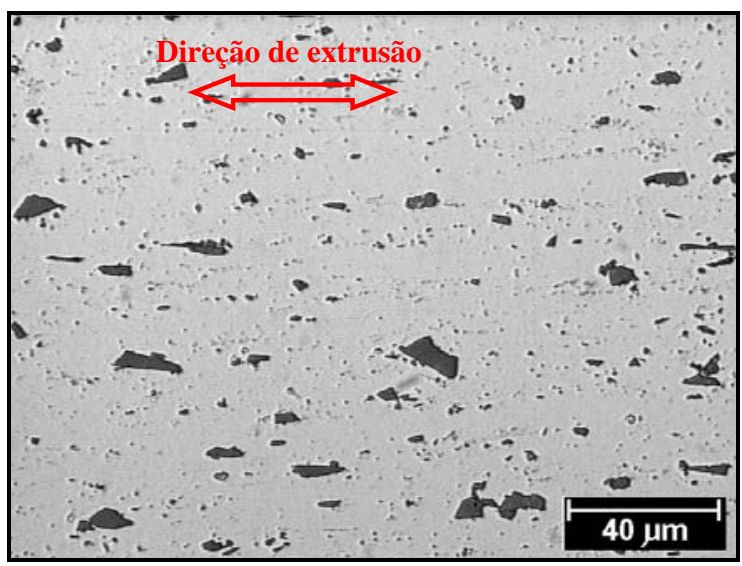

Figura 40 - Micrografia óptica mostrando Figura 41 - Micrografia óptica mostrando o aspecto da secção longitudinal do Al/SiC $5 \%$.
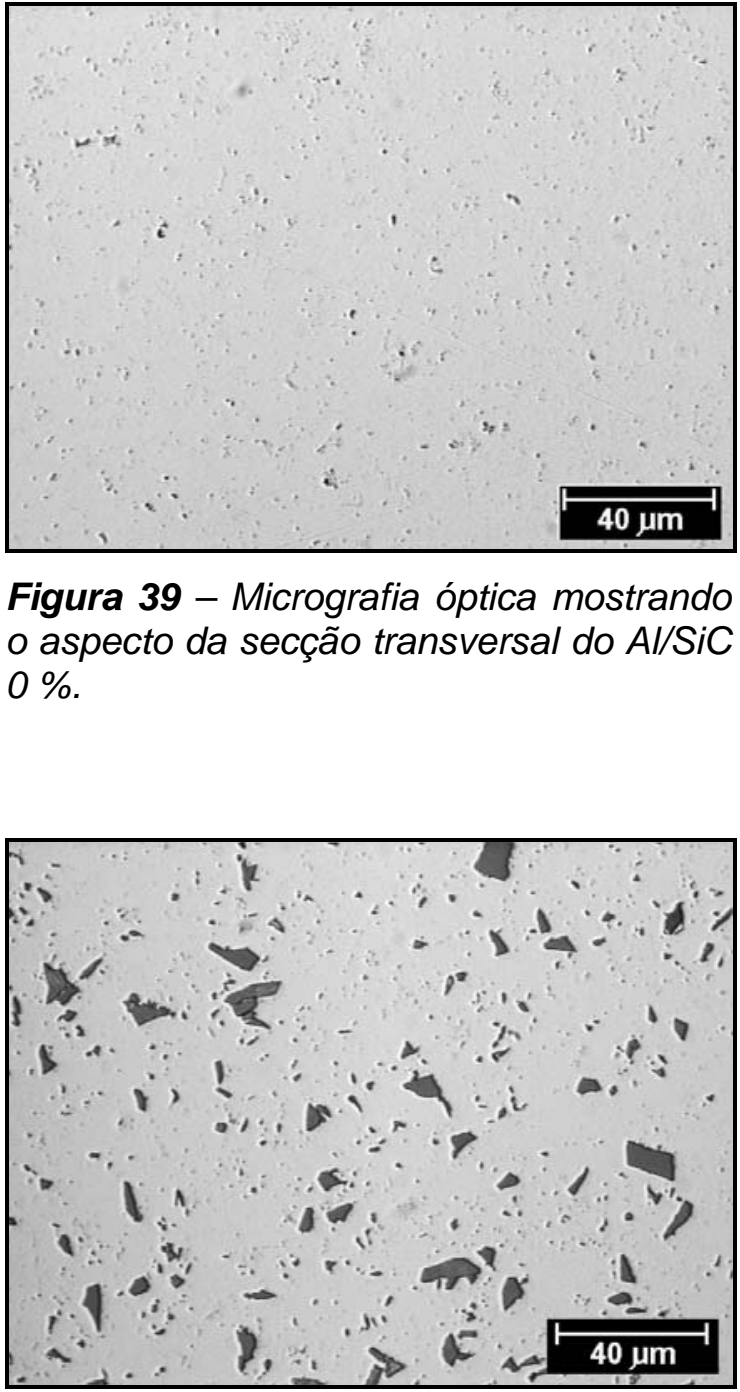

Figura 39 - Micrografia óptica mostrando o aspecto da secção transversal do Al/SiC $0 \%$.

o aspecto da secção transversal do Al/SiC $5 \%$. 

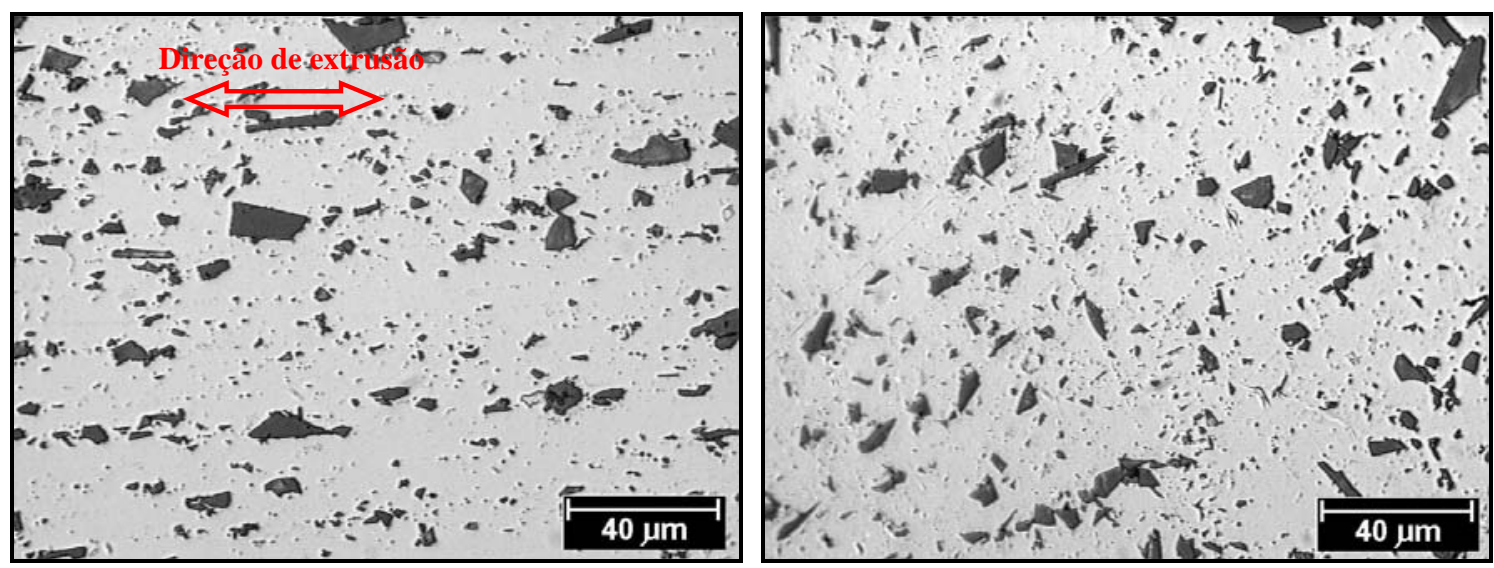

Figura 42 - Micrografia óptica mostrando o aspecto da secção longitudinal do Al/SiC $10 \%$.

Figura 43 - Micrografia óptica mostrando o aspecto da secção transversal do Al/SiC $10 \%$.
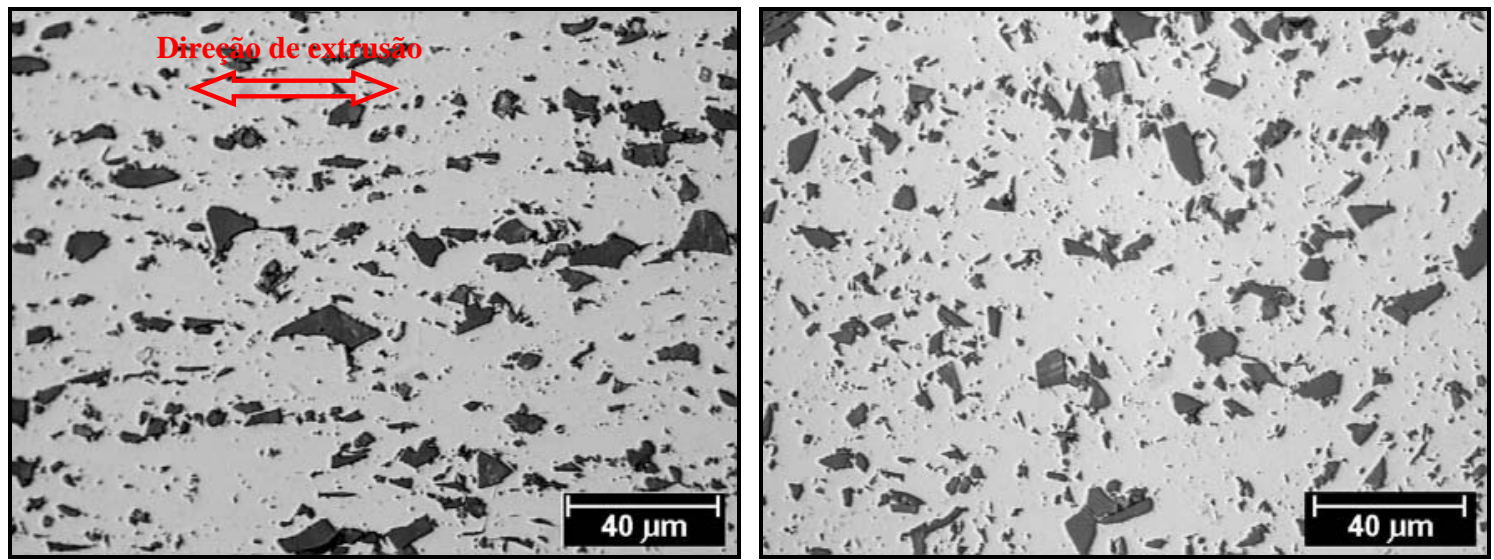

Figura 44 - Micrografia óptica mostrando o aspecto da secção longitudinal do Al/SiC $15 \%$.

Figura 45 - Micrografia óptica mostrando o aspecto da secção transversal do Al/SiC $15 \%$.

De uma maneira geral, as micrografias dos materiais obtidos mostraram estruturas bem definidas e uma homogeneidade na distribuição das partículas de reforço. As frações volumétricas dos materiais obtidos foram confirmadas pelo método de extração de reforços [28] cujos valores exatos encontrados foram: 5,05 \%, 9,91 \% e 14,77 \% para os valores nominais esperados de $5 \%, 10 \%$ e $15 \%$ respectivamente.

É possível notar o alinhamento das partículas de reforço (figuras 40, 42 e 44) e das inclusões e vazios (figura 38) na direção de extrusão.

Apesar dos materiais terem apresentado, de maneira geral, boa distribuição das partículas e estruturas bem definidas sem a existência de defeitos 
significativos, foram encontrados alguns defeitos como porosidades e ausência de fases reforçantes (veios de alumínio puro), como os ilustrados nas figuras 46 a $\mathbf{5 1}$. A incidência de veios de alumínio puro foi maior do que de porosidades, exceto para o $\mathrm{Al} / \mathrm{SiC} 15 \%$.

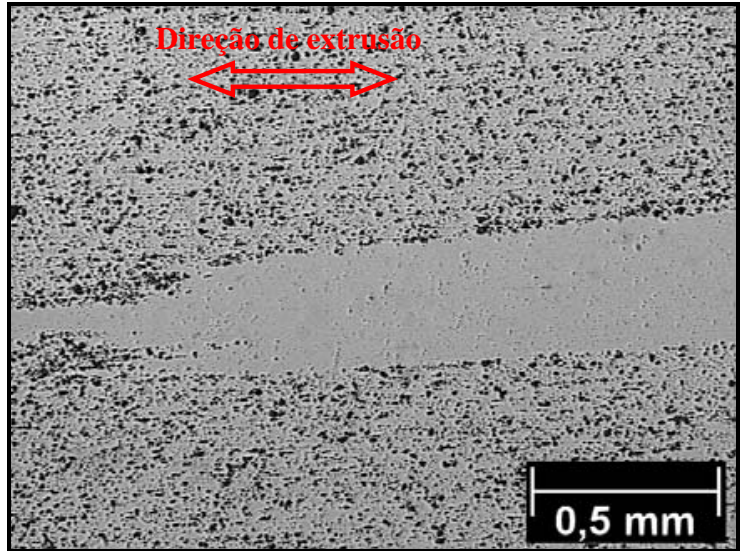

Figura 46 - Aspecto longitudinal do Al/SiC $5 \%$, mostrando um veio de Al puro alinhado na direção de extrusão

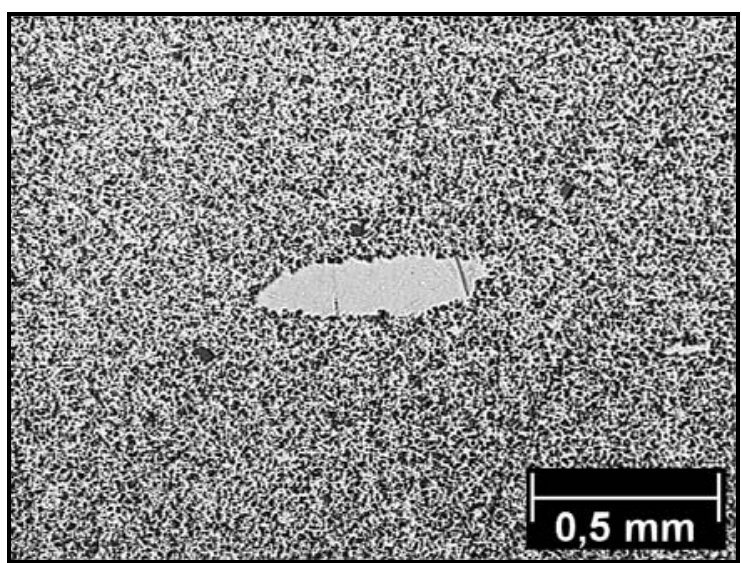

Figura 48 - Aspecto transversal do Al/SiC Figura 49 - Aspecto longitudinal do Al/SiC $10 \%$, onde é possível ver a secção transversal de um veio de Al puro.

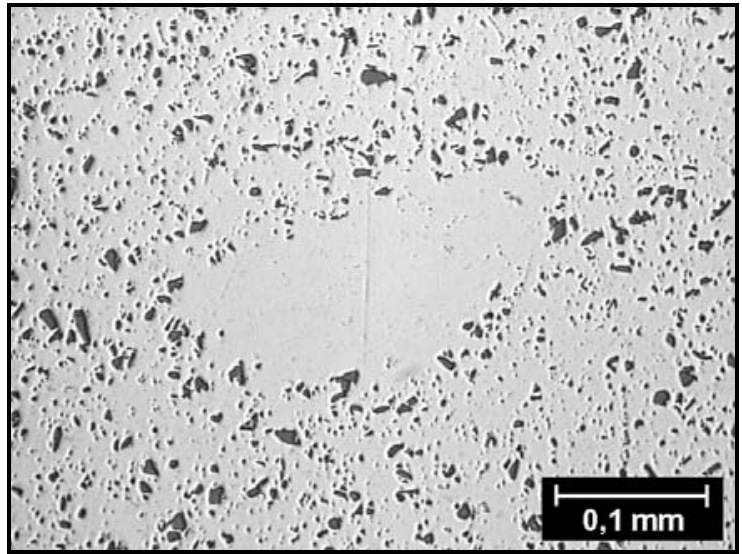

Figura 47 - Aspecto transversal do Al/SiC $5 \%$, onde é possível ver a secção transversal de um veio de Al puro.

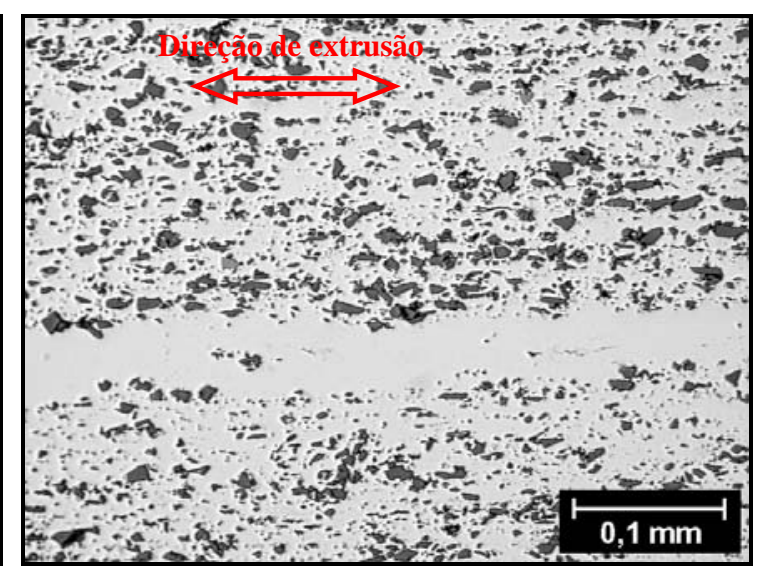

$15 \%$, mostrando um veio de Al puro alinhado na direção de extrusão. 


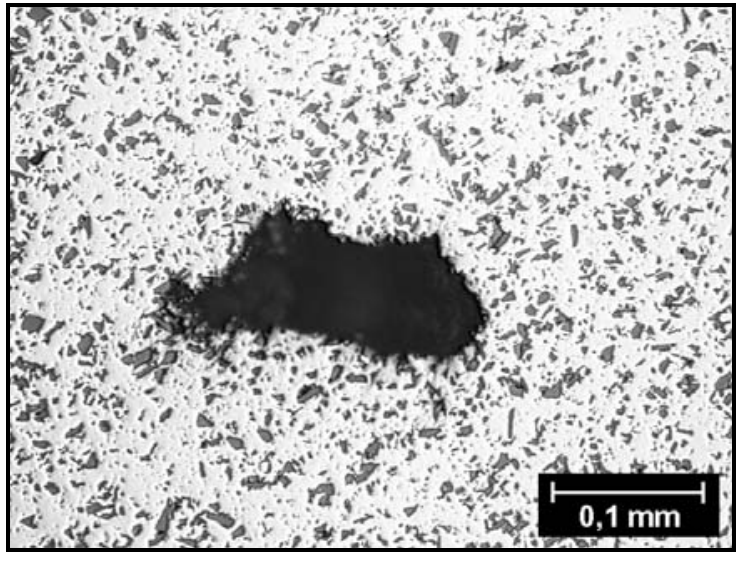

Figura 50 - Aspecto transversal do Al/SiC $15 \%$, onde é possível visualizar um poro.

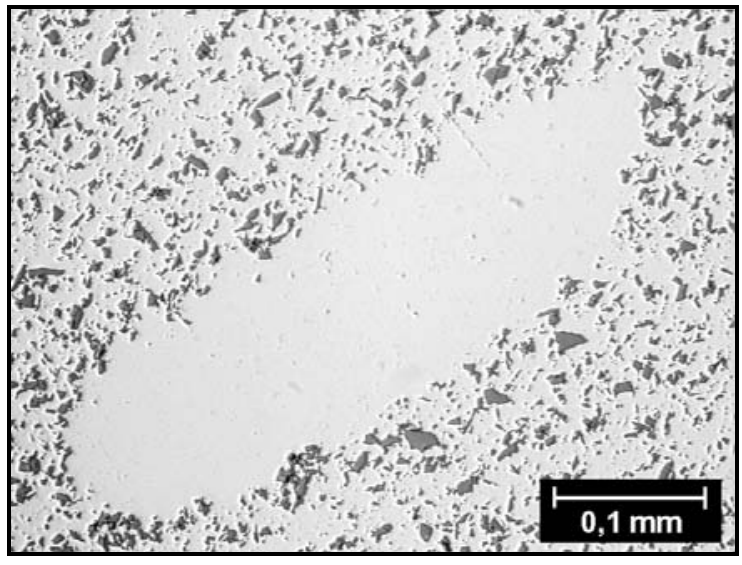

Figura 51 - Aspecto transversal do Al/SiC $15 \%$, onde é possível ver a secção transversal de um veio de Al puro.

AMBROZIO FILHO et al. [23] alertam para a importância da relação tamanho de partículas (RTP) da matriz e do reforço. Quanto maior a RTP, maior a aglomeração de partículas reforçantes e conseqüentemente, a heterogeneidade da microestrutura. A relação tamanho de partículas (RTP) dos materiais estudados neste trabalho é relativamente alta $(\mathrm{RTP}=22 \mu \mathrm{m} / 6 \mu \mathrm{m}=3,7)$, portanto, era grande a possibilidade de aglomeração de partículas de reforço durante o processamento.

Os veios de alumínio puro encontrados podem estar associados com alguma umidade residual dos pós na etapa de secagem dos mesmos. Isto mostra que o processo deve então ser revisado e melhorado neste aspecto.

Com relação às porosidades (figura 50), elas foram mais freqüentes nos materiais reforçados com $15 \%$ de SiC. Esta observação concorda com o fato da densidade diminuir com o aumento da fração volumétrica discutida no sub-item 4.1.2 e com as colocações de AMBROZIO FILHO et al. [23] de que o aumento da porosidade do extrudado é verificado sistematicamente com o aumento da fração volumétrica de reforço. 


\subsection{4 - Rugosidade e dimensões dos corpos de prova usinados}

Os resultados do levantamento da rugosidade dos corpos de prova são apresentados na figura $\mathbf{5 2 .}$

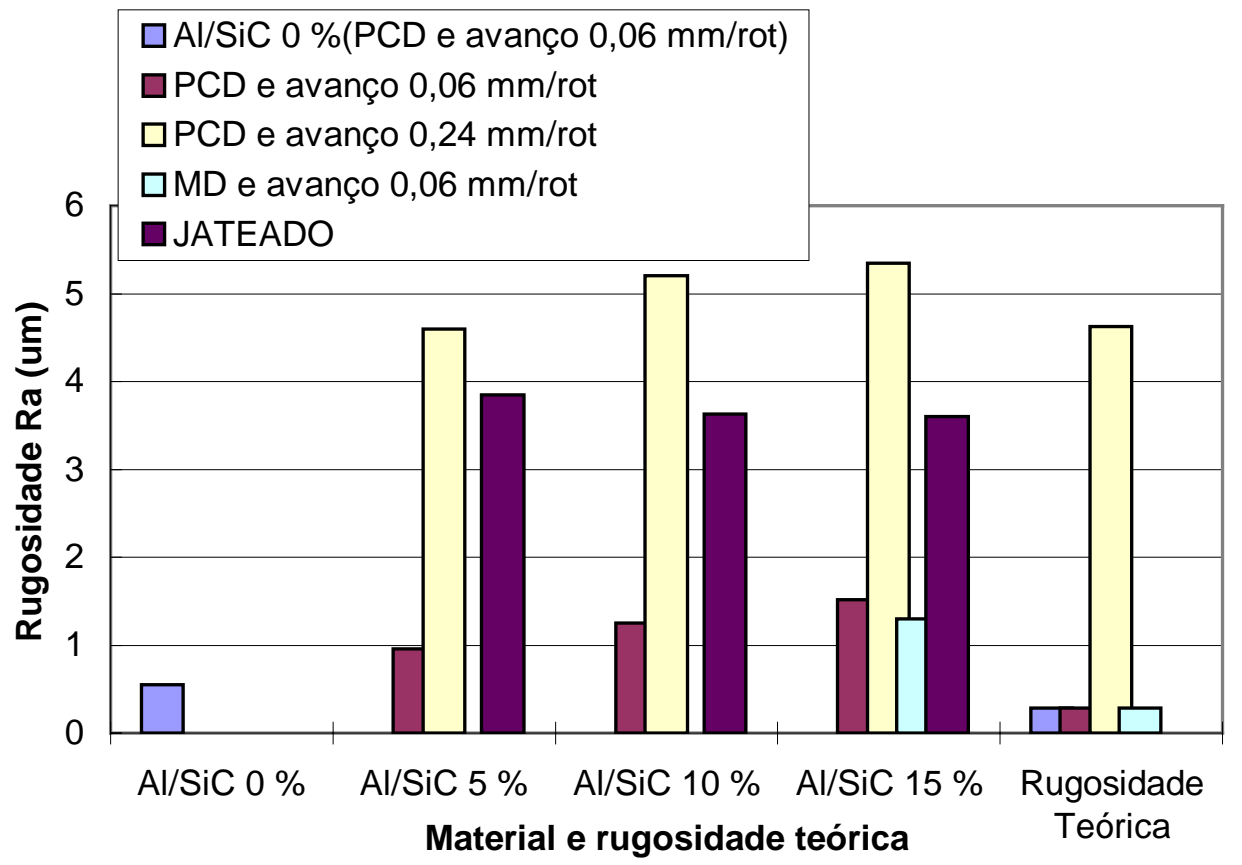

Figura 52 - Gráfico comparativo da rugosidade média (medida e teórica) dos corpos de prova (Obs: (1) não existe valor de rugosidade teórica para os materiais jateados, pois, a equação não se aplica para este processo; (2) $M D=$ Metal Duro e $P C D=$ Diamante Policristalino).

O acabamento superficial das superfícies usinadas em todos os casos piorou com o aumento da fração volumétrica de reforço, enquanto que para os materiais jateados ocorreu o inverso (figura 52).

No caso das superfícies usinadas, este comportamento é influenciado pela natureza do processo que impõe forças tangenciais e puntuais na superfície do material (figura 16), fazendo com que as partículas de reforço mais superficiais sejam arrancadas e, mesmo, arrastadas sobre a superfície do material [11]. Estes danos tornam-se maiores à medida em que aumenta a quantidade de reforço presente nos 
materiais. BARAGETTI e GUAGLIANO [53] também observaram danos semelhantes em seus trabalhos.

A matriz, por sua vez mais dúctil, tende a apresentar um melhor acabamento porque é mais facilmente cisalhada; entretanto, o acabamento é prejudicado quando as partículas de reforço são arrancadas e arrastadas sobre ela. Esta tendência também aumenta com o aumento da fração volumétrica de reforço do material.

No jateamento, as forças atuantes sobre a superfície do material agem no sentido radial, e sempre perpendiculares a um plano tangente ao ponto de ação do jato (figura 17), quando o ângulo de impacto for de $90^{\circ}$. Neste caso, não há tendência ao arrancamento das partículas de reforço da superfície do material, uma vez que a ação do jato tende a empurrá-las para o interior do mesmo. Esta condição pode favorecer a obtenção de um melhor acabamento superficial porque sem 0 arrancamento das partículas de reforço, a superfície tende a ficar livre de vazios ou "buracos". Entretanto, o grau do acabamento superficial obtido no jateamento é fortemente dependente de fatores como tamanho, tipo e forma das partículas utilizadas no processo conforme os relatos e/ou experimentos de OMAM et al. [3], BARAGETTI et al. [53], CHERNENKOFF, MOCARSKI e YEAGER [54], COUTURIER, LIEURADE, FLAVENOT e LU [55] e LU, MIEGE, FLAVENOT e THERY [56]. Provavelmente, estes fatores, sobretudo o tamanho das partículas, foram os responsáveis pelos graus de acabamento obtidos no jateamento, que alcançaram níveis comparáveis aos dos materiais usinados grosseiramente (figura 52).

O material da matriz, por ser mais dúctil, é muito mais agredido pelo processo de jateamento. Assim, como os materiais com menor fração volumétrica de reforço apresentam maior superfície dominada pela matriz o acabamento superficial tendeu a ser pior, quando comparado com materiais de frações volumétricas superiores. 
Embora RASUL e MEGUID [58] não tenham trabalhado com materiais compósitos em seus experimentos, a usinagem de seus corpos de prova de aço 817M40 usando taxas de avanço de 0,28 e 0,04 mm/rot, que são praticamente iguais às utilizadas neste trabalho $(0,24$ e $0,06 \mathrm{~mm} / \mathrm{rot})$, produziu superfícies com rugosidades semelhantes e da mesma ordem de grandeza das obtidas aqui, ou seja, $5,7 \mu \mathrm{m}$ para um avanço de $0,28 \mathrm{~mm} /$ rot e $1,2 \mu \mathrm{m}$ para $0,04 \mathrm{~mm} /$ rot. Esta é uma observação curiosa porque normalmente materiais monolíticos usinados nas mesmas condições e com os mesmos parâmetros e recursos utilizados para usinar um compósito, tendem a apresentar acabamento superficial bem melhor. Um exemplo disto está na própria figura 52 representado pelo Al/SiC $0 \%$ (material de controle).

As figuras 53 a 60 mostram o aspecto geral do perfil e da superfície dos materiais reforçados com $5 \%$ de SiC e do Al/SiC $0 \%$, submetidos a tratamentos superficiais mecânicos diferentes.
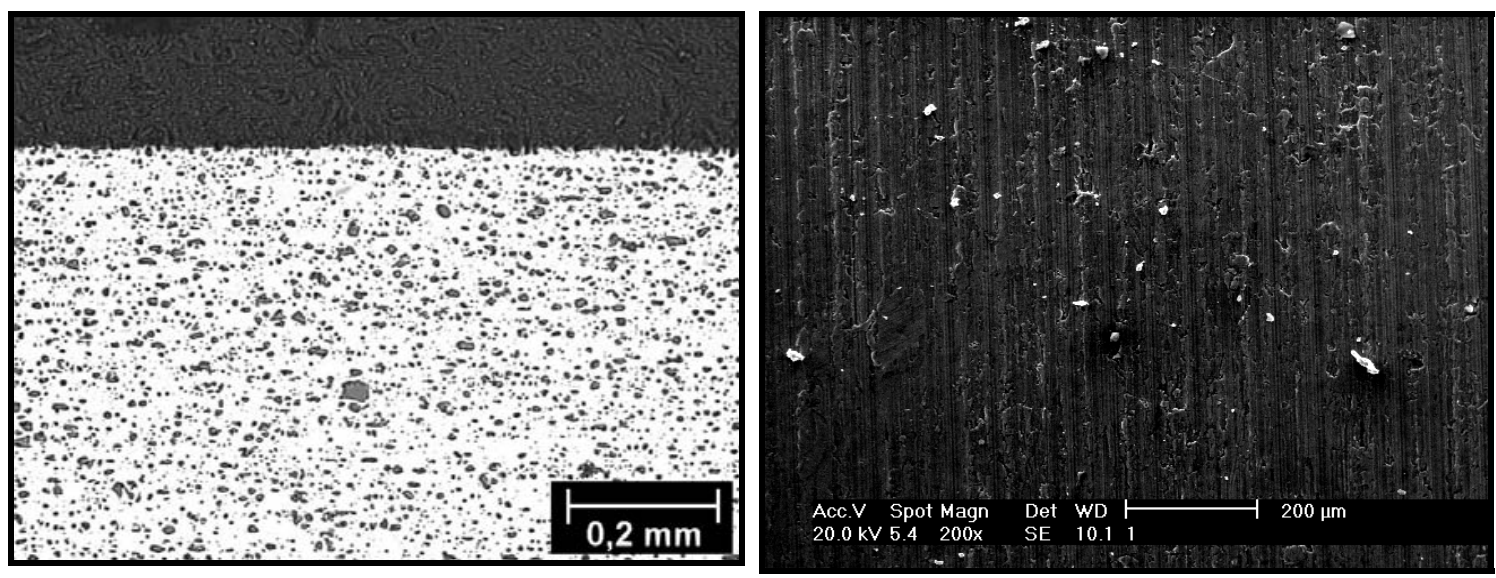

Figura 53 - Micrografia óptica do perfil do Figura 54 - Micrografia eletrônica de Al-SiC $5 \%$ usinado com diamante e varredura mostrando o aspecto geral da avanço de $0,06 \mathrm{~mm} / \mathrm{rot}$. superfície do Al-SiC $5 \%$ usinado com diamante e avanço de $0,06 \mathrm{~mm} / \mathrm{rot}$. 

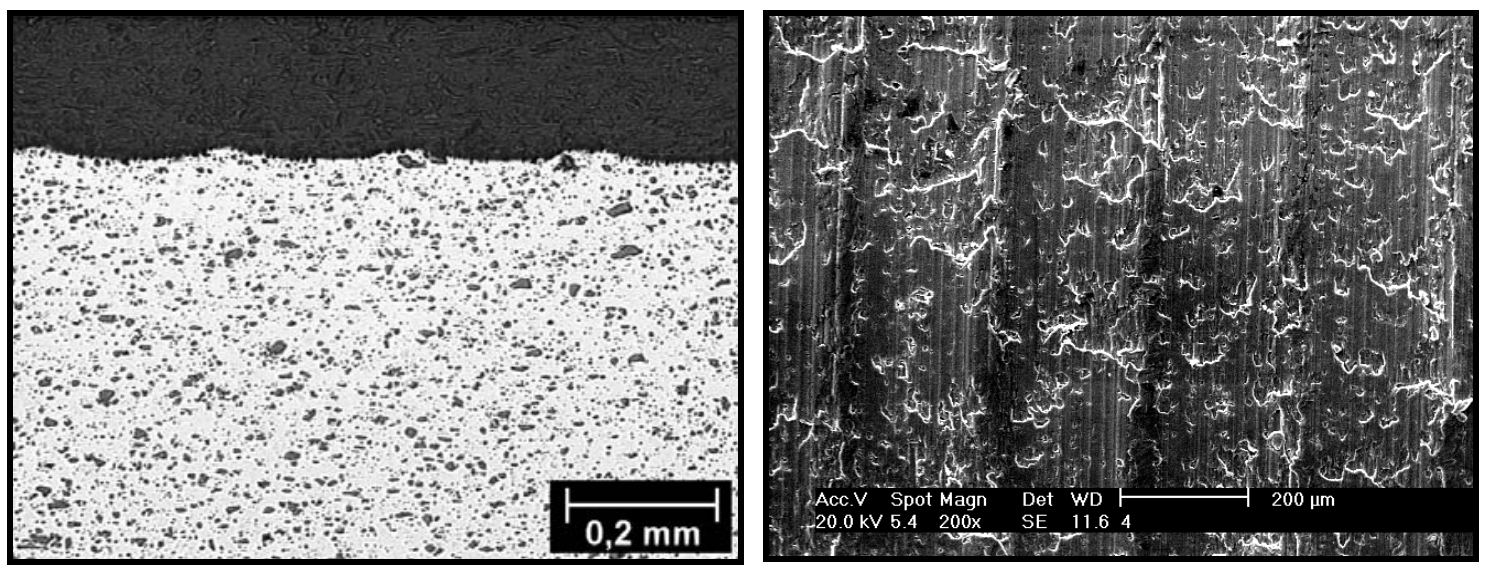

Figura 55 - Micrografia óptica do perfil do Figura 56 - Micrografia eletrônica de Al-SiC $5 \%$ usinado com diamante e var avanço de $0,24 \mathrm{~mm} / \mathrm{rot}$.

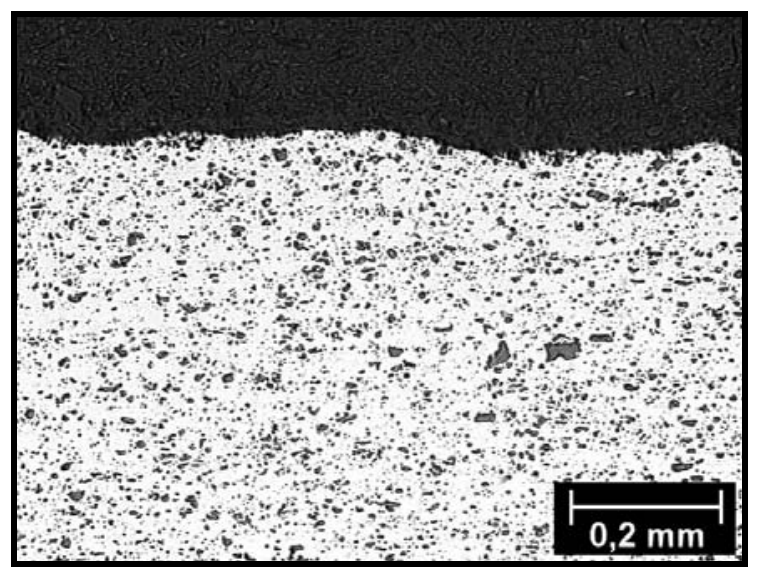
varredura mostrando o aspecto geral da superfície do Al-SiC $5 \%$ usinado com diamante e avanço de $0,24 \mathrm{~mm} / \mathrm{rot}$.

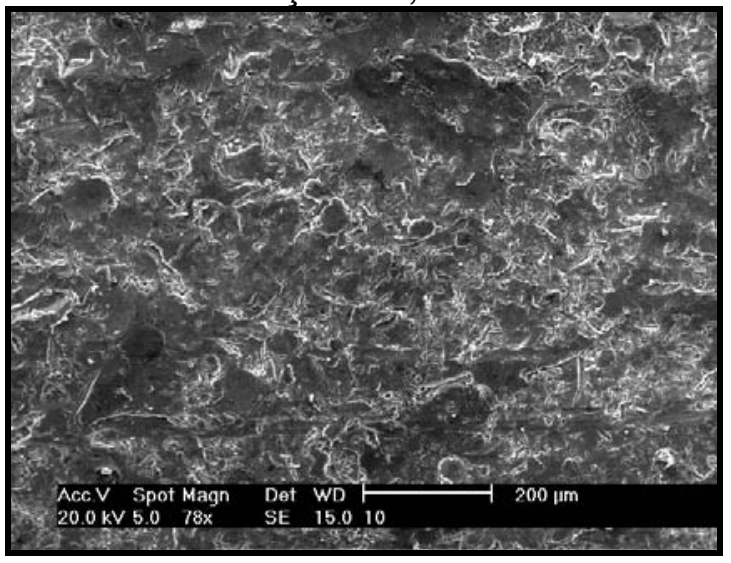

Figura 57 - Micrografia óptica do perfil do Figura 58 - Micrografia eletrônica de Al-SiC $5 \%$ JATEADO, mostrando uma varredura do aspecto geral da superfície superfície rebatida pelo efeito da ação do Al-SiC $5 \%$ JATEADO, mostrando uma compressiva do processo utilizado.

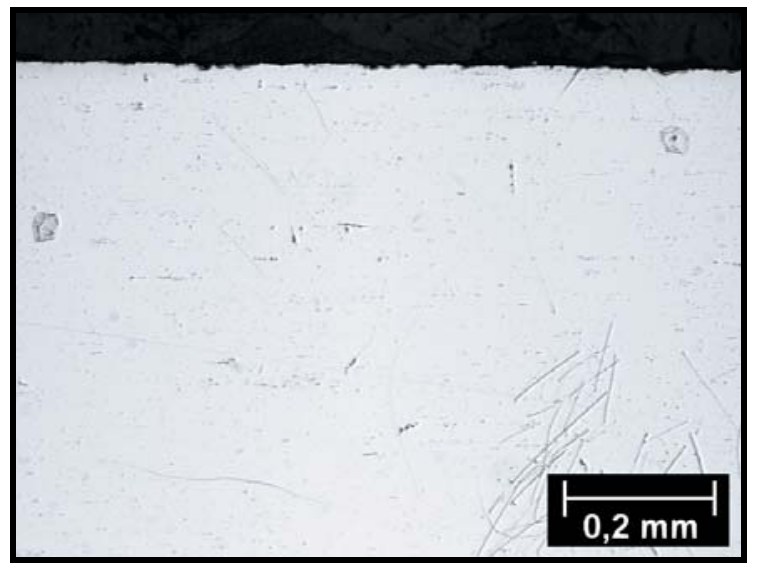
superfície rebatida pelo efeito da ação compressiva do processo utilizado.

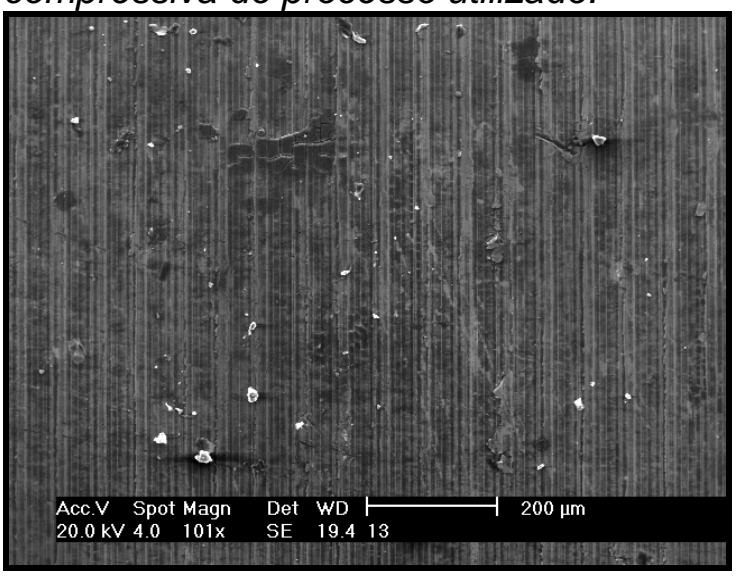

Figura 59 - Micrografia óptica do perfil do Figura 60 - Micrografia eletrônica de Al-SiC $0 \%$ usinado com diamante e avanço de $0,06 \mathrm{~mm} / \mathrm{rot}$.

varredura mostrando o aspecto geral da superfície do Al-SiC $0 \%$ usinado com diamante e avanço de $0,06 \mathrm{~mm} / \mathrm{rot}$. 
Nas figuras 53 e 59, é possível notar uma superfície bem uniforme deixada pela ferramenta de usinagem. Na figura 55, a superfície também é uniforme, entretanto é bastante visível o caminho percorrido pela ferramenta de usinagem. No jateamento (figura 57), embora seja difícil a visualização em razão das partículas utilizadas no processo serem maiores frente à magnitude da ampliação da figura, deve haver também uma certa uniformidade da superfície, visto que o ataque da superfície pelas partículas é feita de maneira aleatória, o que, portanto, causa uma distribuição homogênea das irregularidades sobre a superfície.

O aspecto geral da superfície jateada (figura 58) se mostra bastante rugosa, mas com uma distribuição homogênea de defeitos. LU et al. [56] também observaram características semelhantes nas superfícies jateadas em seus experimentos. Nas figuras 54, 56 e 60 é bastante notável as marcas de usinagem orientadas todas numa mesma direção, provocando assim uma anisotropia na distribuição dos defeitos.

Quanto às dimensões finais dos corpos de prova, a Figura 61 ajuda a ter uma idéia da dispersão dos valores medidos, com relação à dimensão nominal. Embora a norma ASTM E 466 [52] não faça nenhuma referência às tolerâncias dimensionais dos corpos de prova, a experiência tem mostrado que desvios da ordem dos relacionados a seguir, não têm influências significativas na vida à fadiga dos materiais ensaiados. 


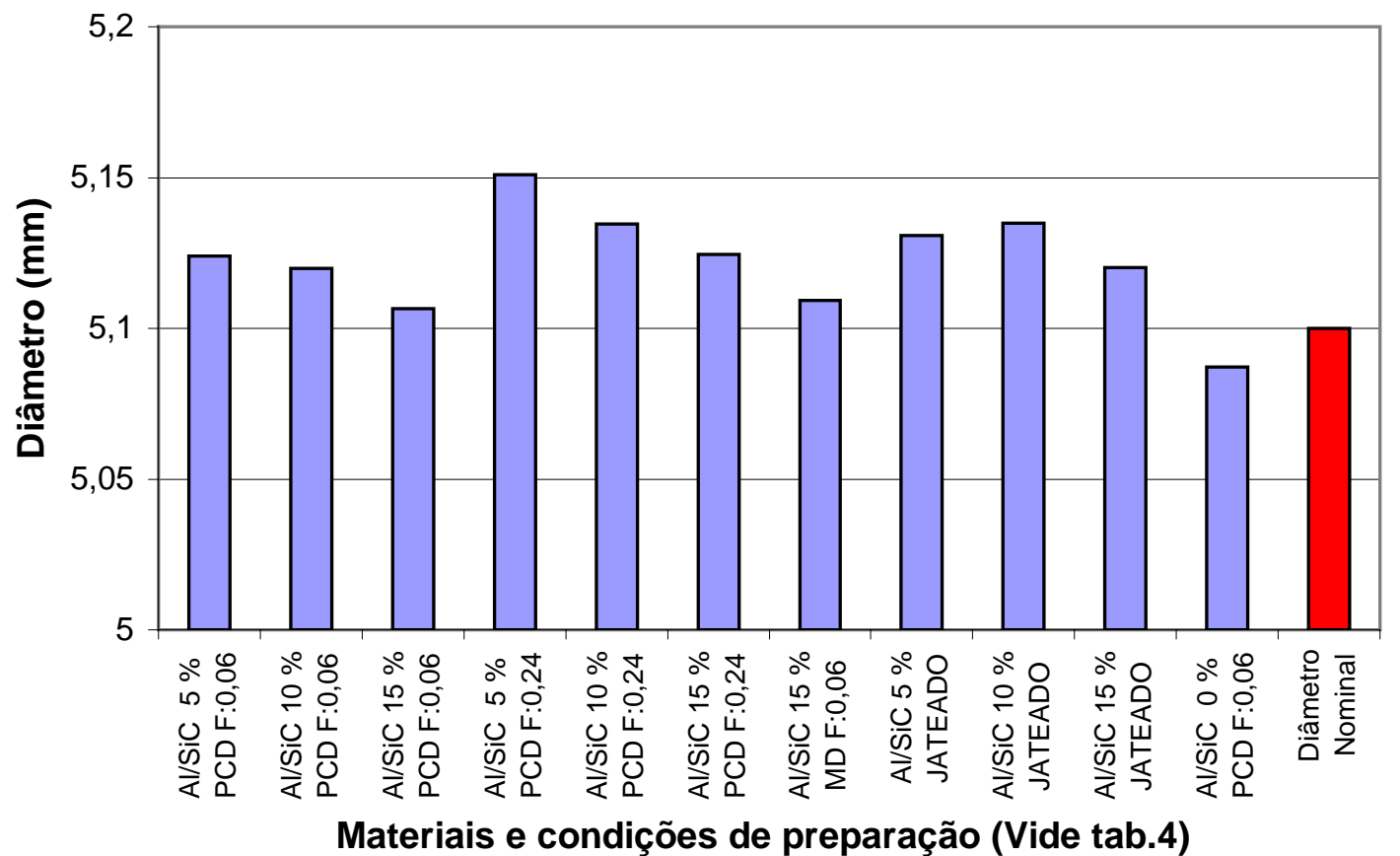

Figura 61 - Valores médios dos diâmetros finais dos corpos de prova para ensaios de fadiga.

\section{2 - Resultados dos ensaios de fadiga}

Os resultados dos ensaios de fadiga aqui apresentados foram produto de aproximadamente 3380 horas acumuladas de ensaios. Na primeira etapa serão apresentadas, analisadas e discutidas as curvas de fadiga individuais correspondentes a cada tipo de material e tipo de tratamento superficial mecânico utilizado na confecção dos corpos de prova.

Numa segunda etapa serão comparadas as curvas de fadiga apresentadas na primeira etapa, em função do material e também do tipo de tratamento superficial mecânico empregado.

As curvas de fadiga, em todos os casos, foram obtidas por regressão polinomial de primeiro grau por estar o eixo das abscissas em escala logarítimica. Entretanto, nestas condições, a regressão utilizada é equivalente à regressão linear (método dos mínimos quadrados). O software utilizado para a construção dos gráficos 
foi o Microcal Origin - versão 5.0. Os gráficos de fadiga foram feitos de acordo com as recomendações da norma ASTM E 468 [57].

Em todos os gráficos apresentados aqui achou-se conveniente não definir limites de fadiga, pois é recomendável ensaiar uma quantidade maior de corpos de prova nas proximidades desta região a fim de tornar mais precisa uma estimativa destes limites [57]. Além do mais, o método de ensaio empregado não se refere à determinação dos limites de fadiga, mas apenas a uma estimativa da curva.

De qualquer modo, os resultados que aparecem nos gráficos individuais de fadiga com uma seta vinculada, indicam continuidade da vida para valores acima de $2 \times 10^{6}$ ciclos e podem dar uma idéia, mesmo que aproximada, dos limites de fadiga para os casos em que as setas apareceram. As indicações mencionadas anteriormente não foram colocadas nos gráficos comparativos para não deixá-los muito carregados e também não foram considerados na obtenção da reta média. O gráfico individual que não apresentar indicações de continuidade de vida à fadiga, significa que todos os corpos de prova romperam a valores abaixo de $2 \times 10^{6}$ ciclos.

\subsection{1 - Curvas de fadiga individuais das condições de ensaio}

\section{utilizadas}

As figuras 62 a 72 mostram as curvas de fadiga de cada um dos lotes de corpos de prova discriminados na tabela 4, com os respectivos limites superior e inferior de confiabilidade $95 \%$. A figura 73 corresponde aos desvios padrões das curvas mencionadas anteriormente, posicionadas em ordem crescente de valores. 


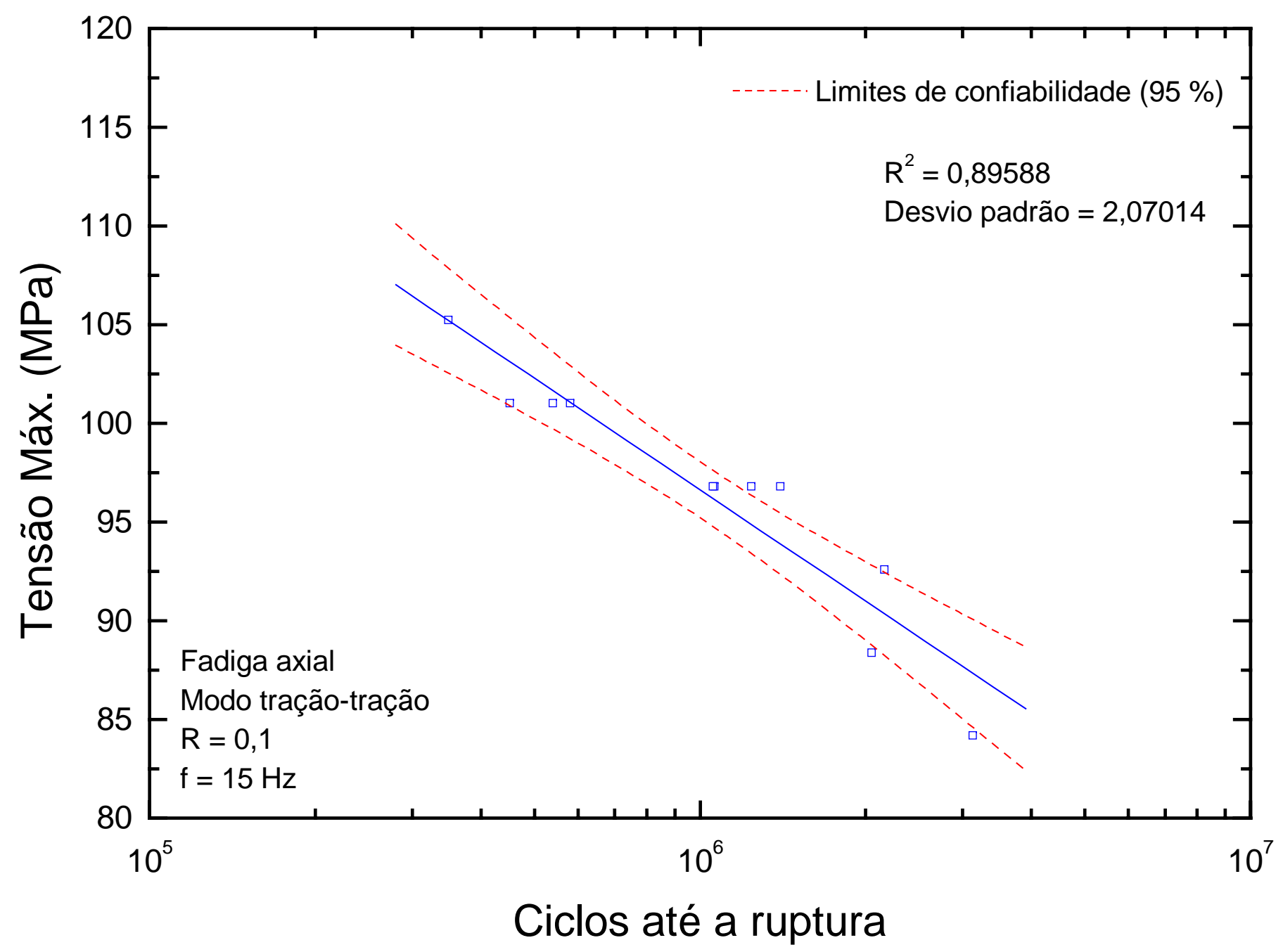

Figura 62 - Gráfico de fadiga do Al/SiC 5 \% usinado com PCD e taxa de avanço de 0,06 mm/rotação. 


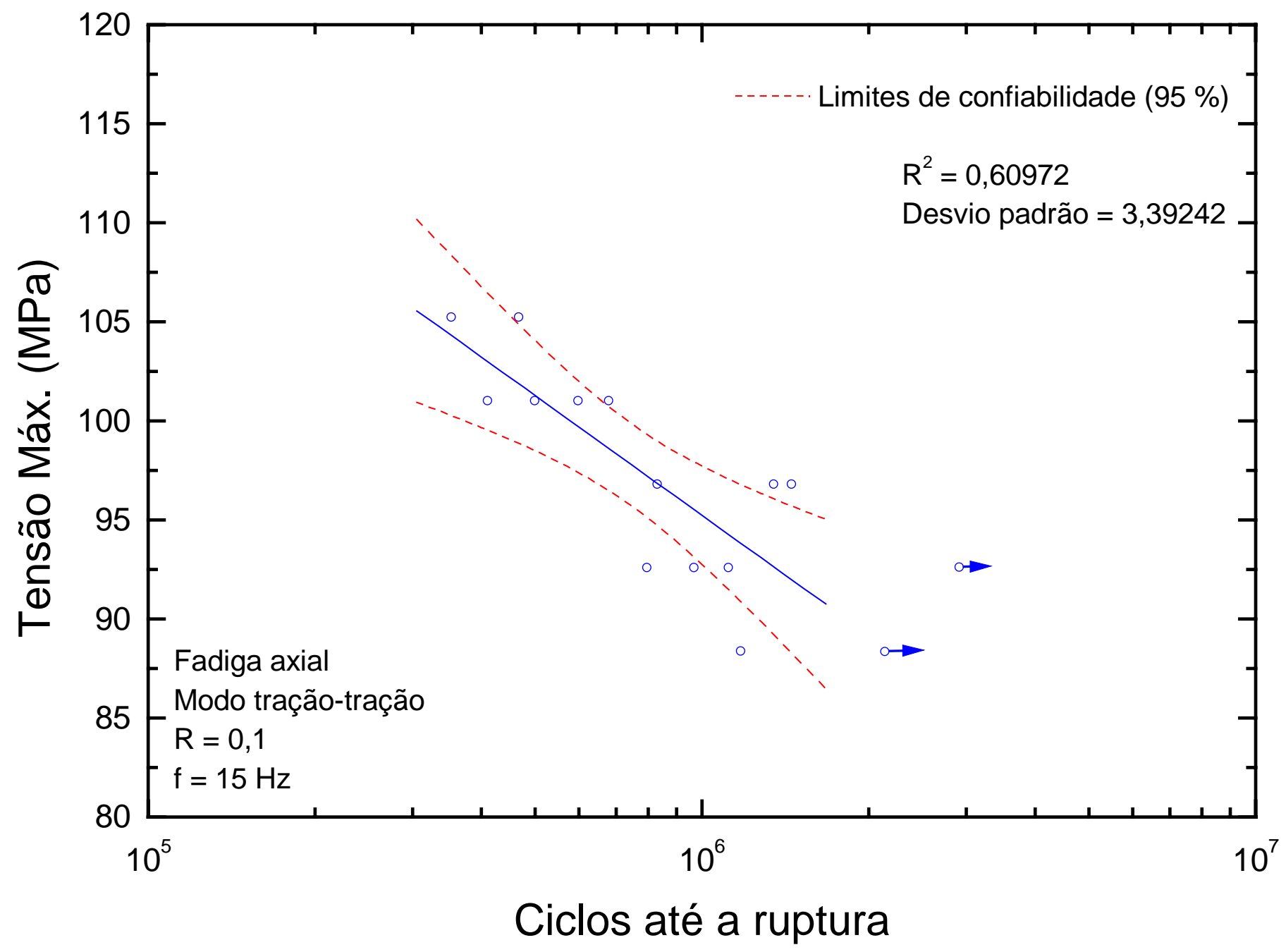

Figura 63 - Gráfico de fadiga do Al/SiC $5 \%$ usinado com PCD e taxa de avanço de 0,24 mm/rotação. 


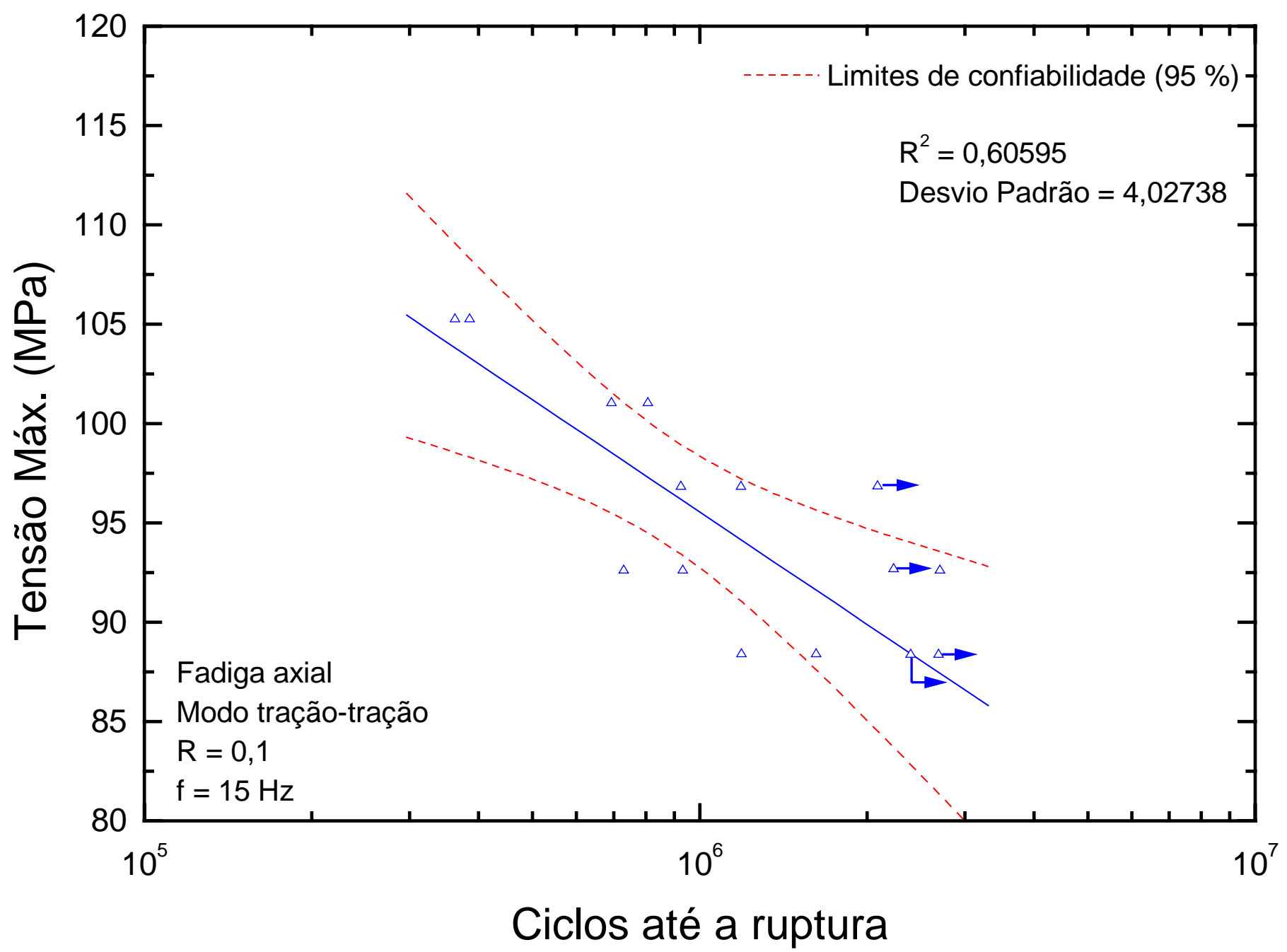

Figura 64 - Gráfico de fadiga do Al/SiC 5 \% jateado. 


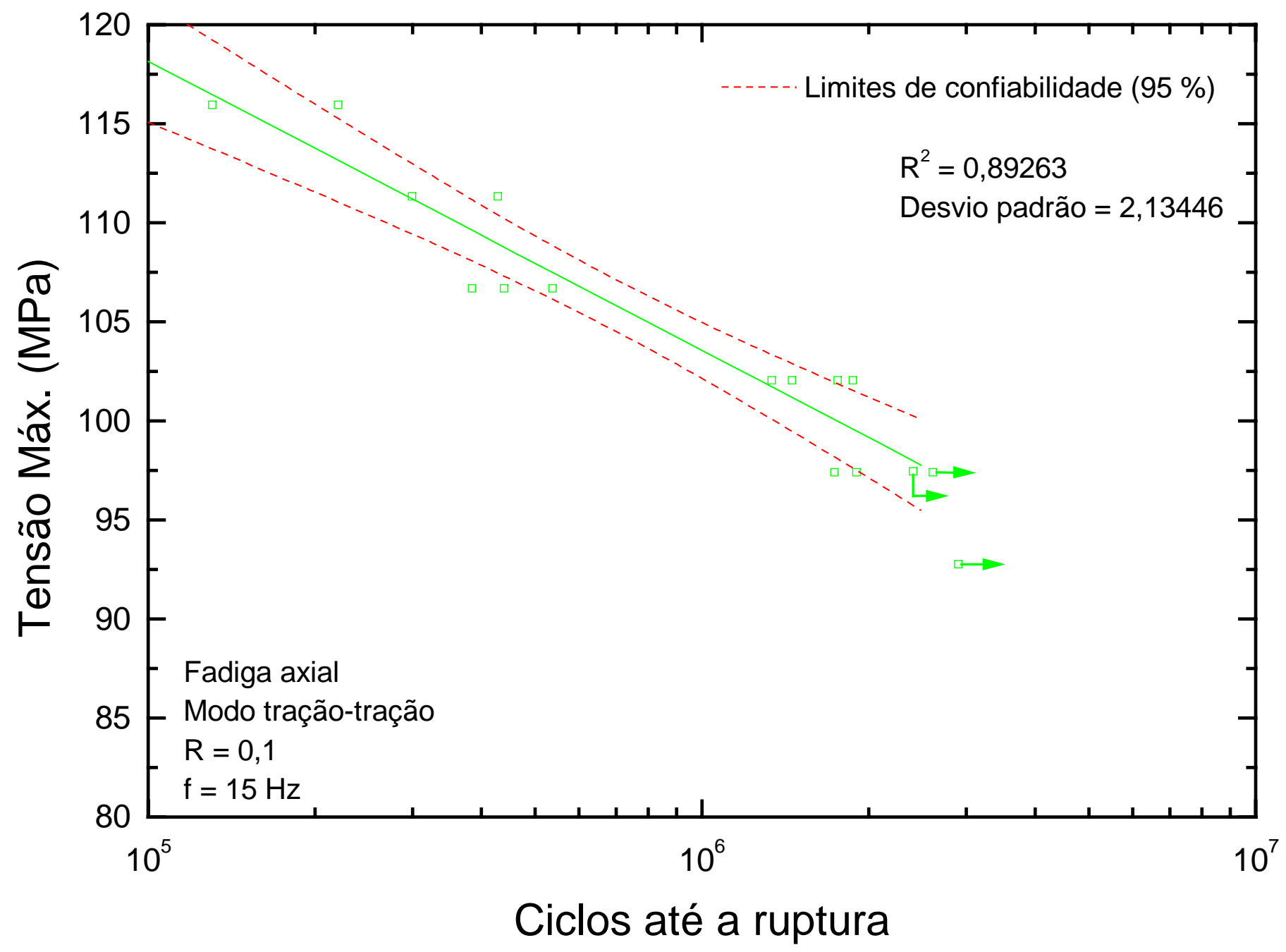

Figura 65 - Gráfico de fadiga do Al/SiC $10 \%$ usinado com PCD e taxa de avanço de 0,06 mm/rotação. 


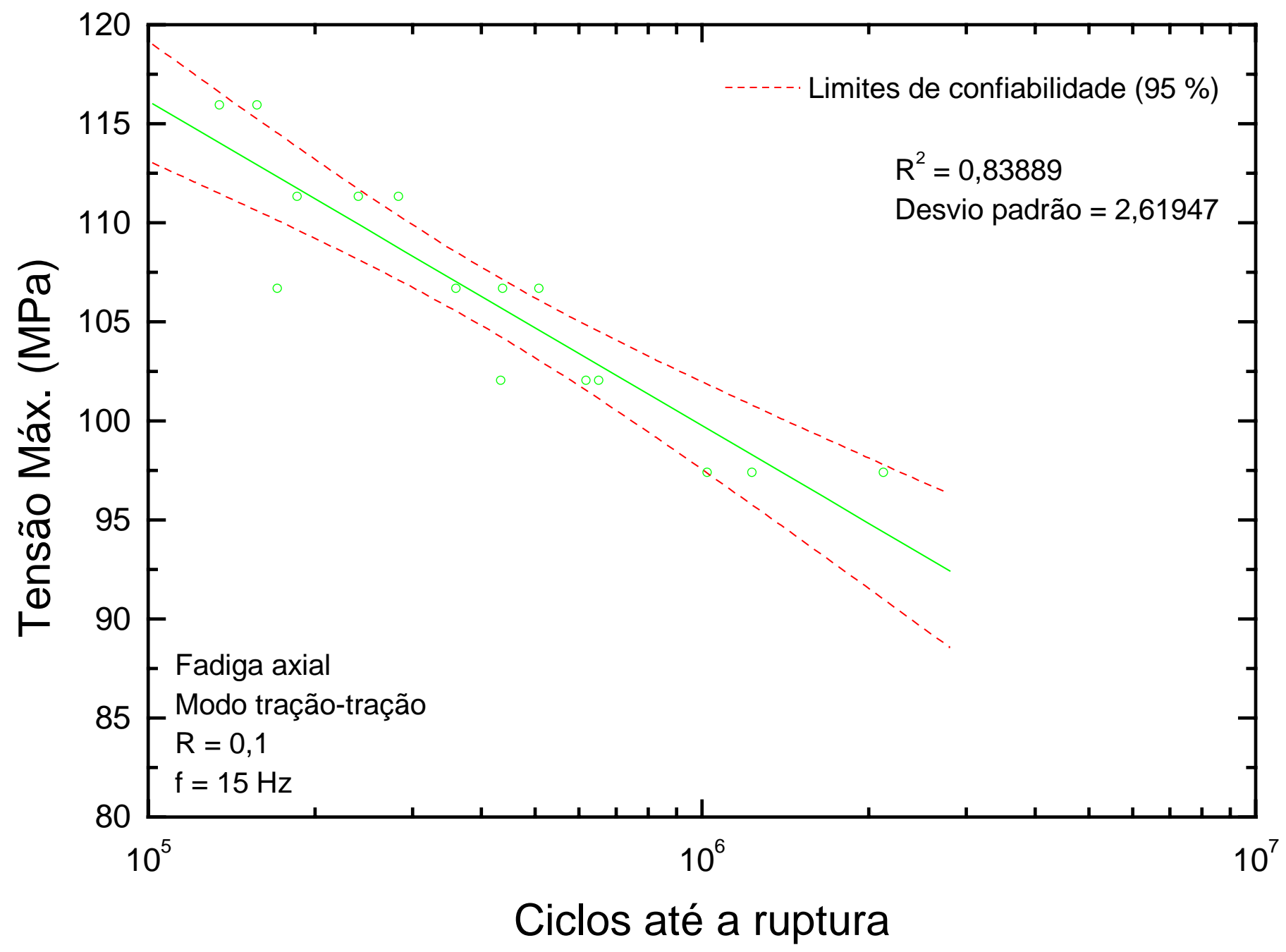

Figura 66 - Gráfico de fadiga do Al/SiC $10 \%$ usinado com PCD e taxa de avanço de $0,24 \mathrm{~mm} /$ rotação. 


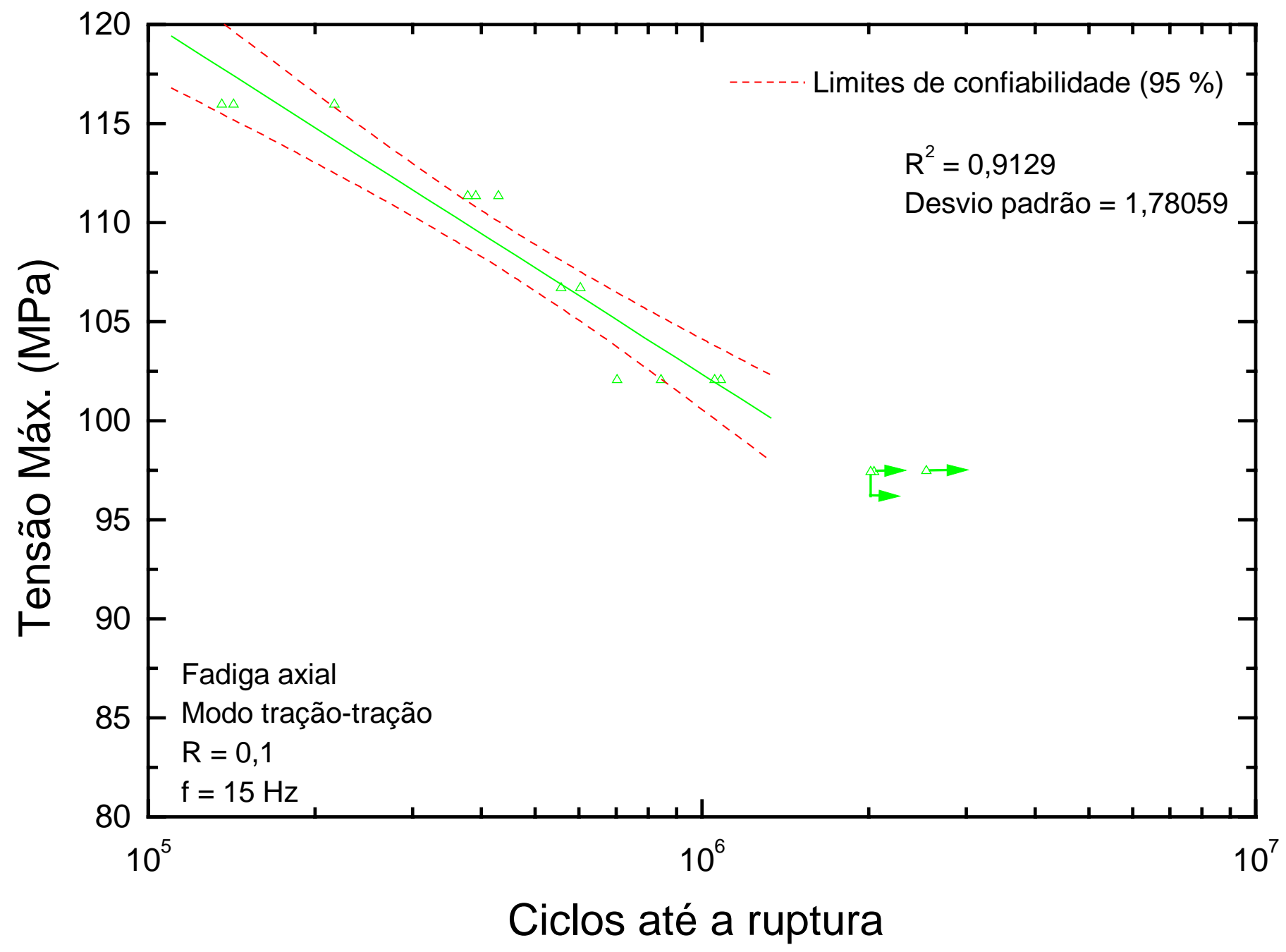

Figura 67 - Gráfico de fadiga do Al/SiC $10 \%$ jateado. 


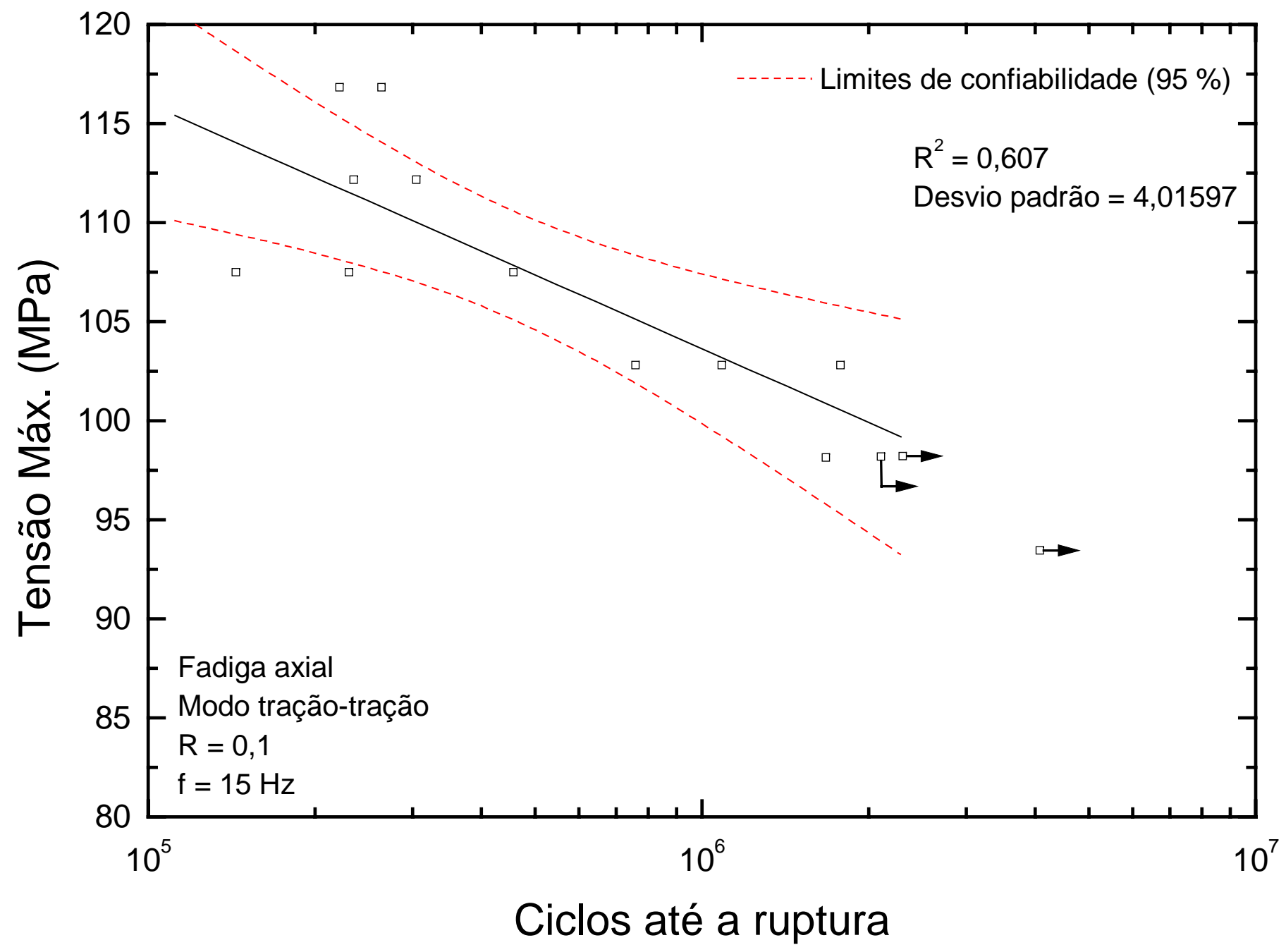

Figura 68 - Gráfico de fadiga do Al/SiC $15 \%$ usinado com PCD e taxa de avanço de 0,06 mm/rotação. 


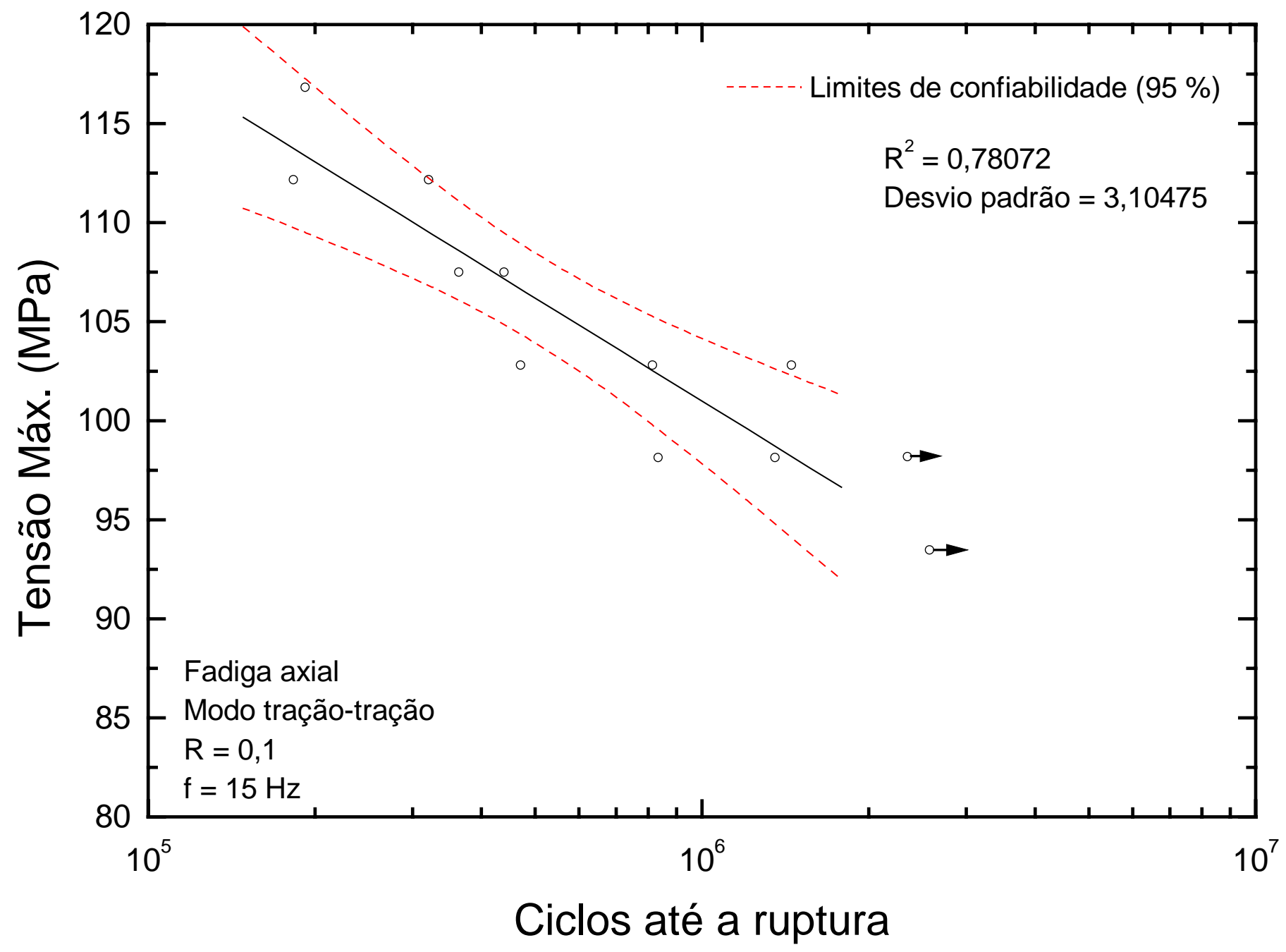

Figura 69 - Gráfico de fadiga do Al/SiC 15 \% usinado com PCD e taxa de avanço de 0,24 mm/rotação. 


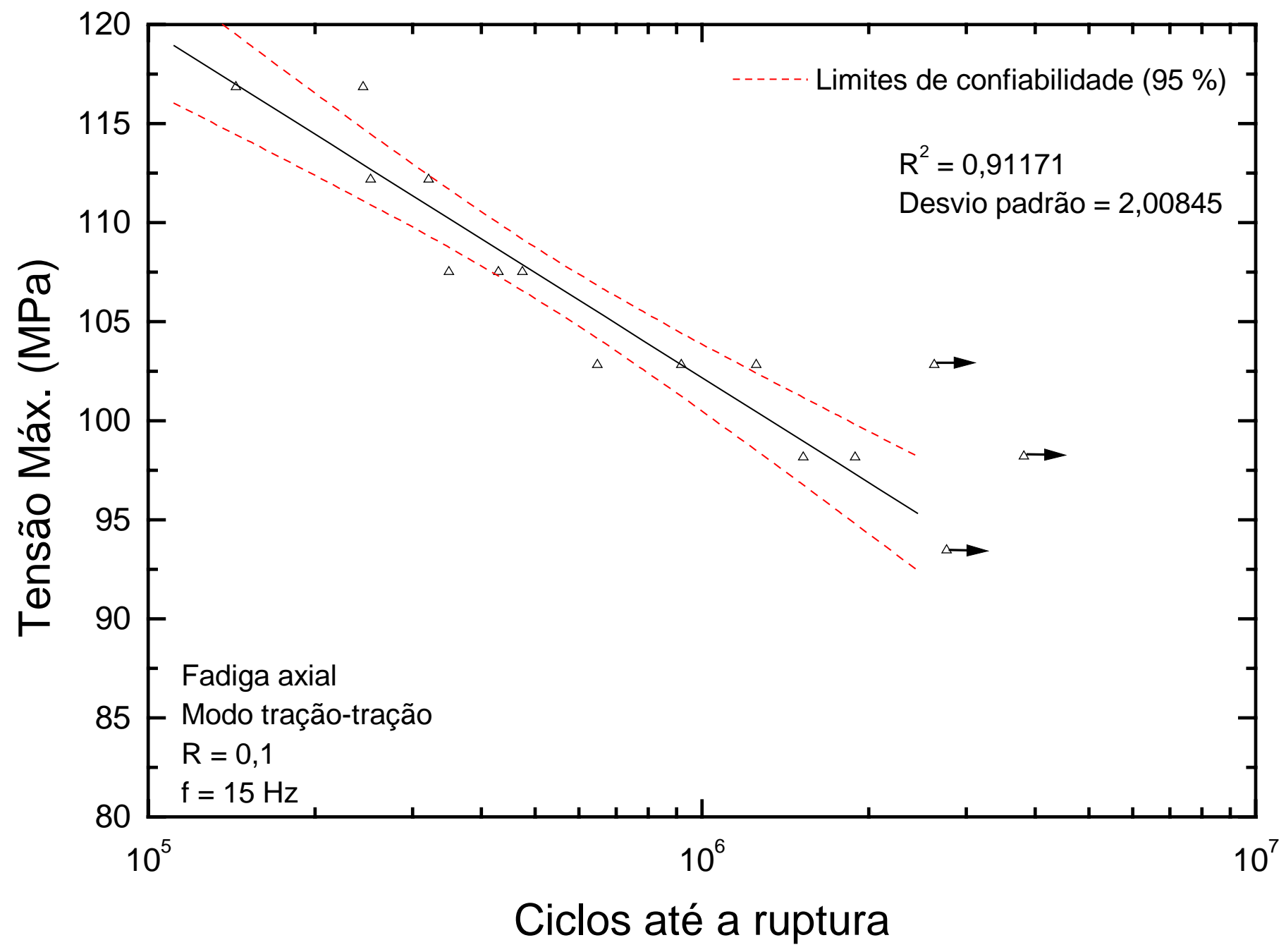

Figura 70 - Gráfico de fadiga do Al/SiC $15 \%$ jateado. 


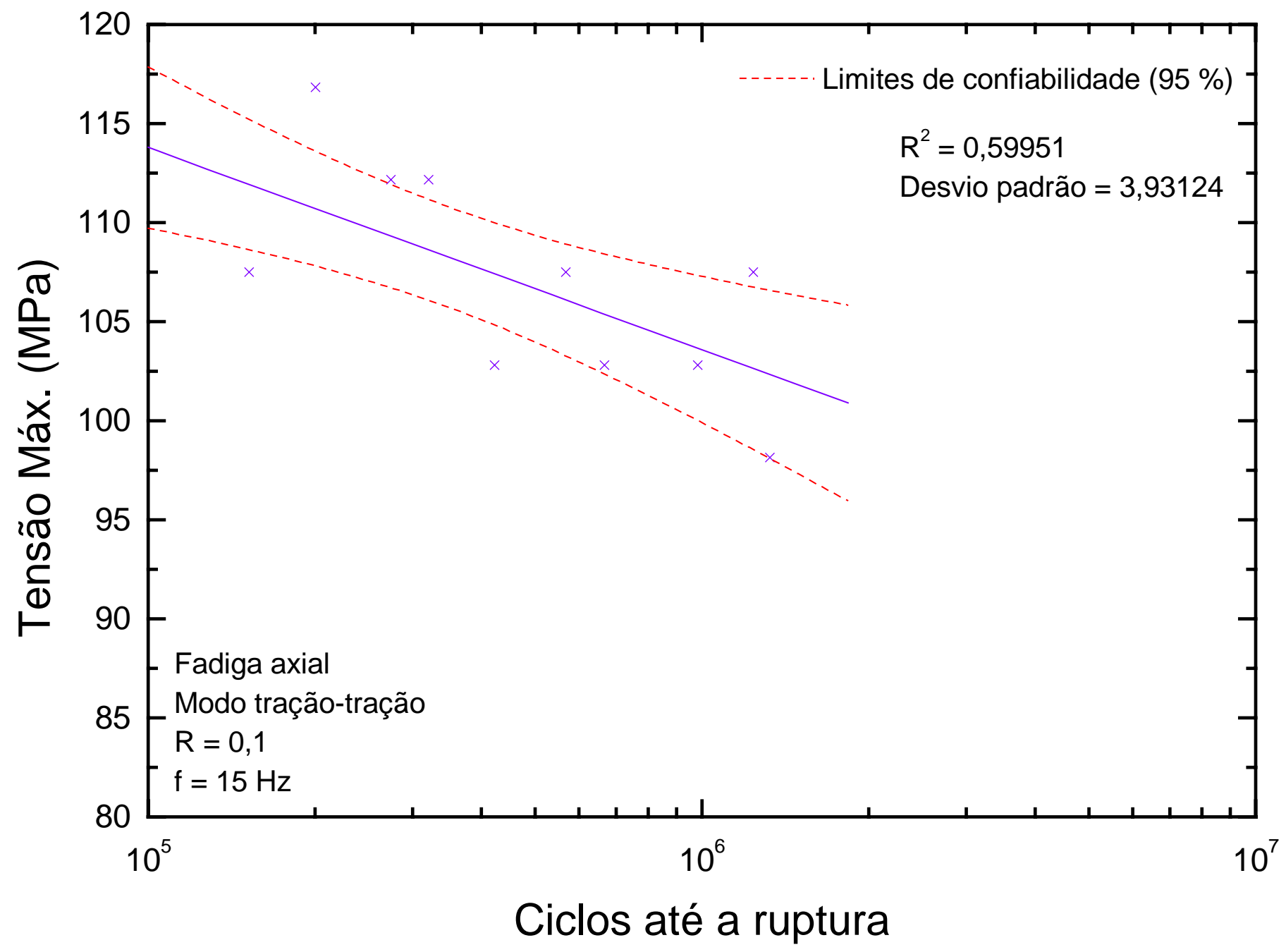

Figura 71- Gráfico de fadiga do Al/SiC $15 \%$ usinado com MD e taxa de avanço de 0,06 mm/rotação. 


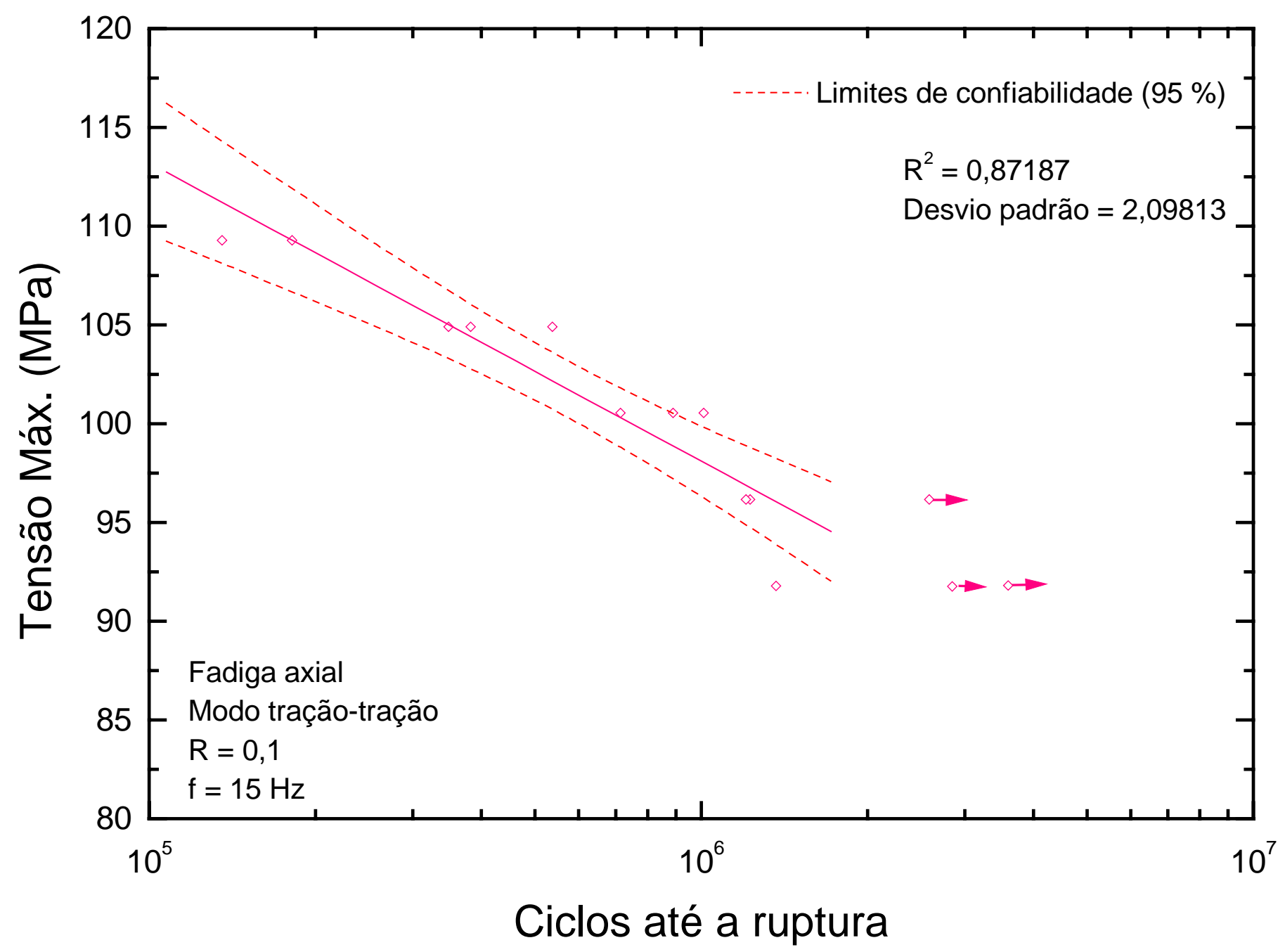

Figura 72 - Gráfico de fadiga do Al/SiC $0 \%$ usinado com PCD e taxa de avanço de 0,06 mm/rotação. 


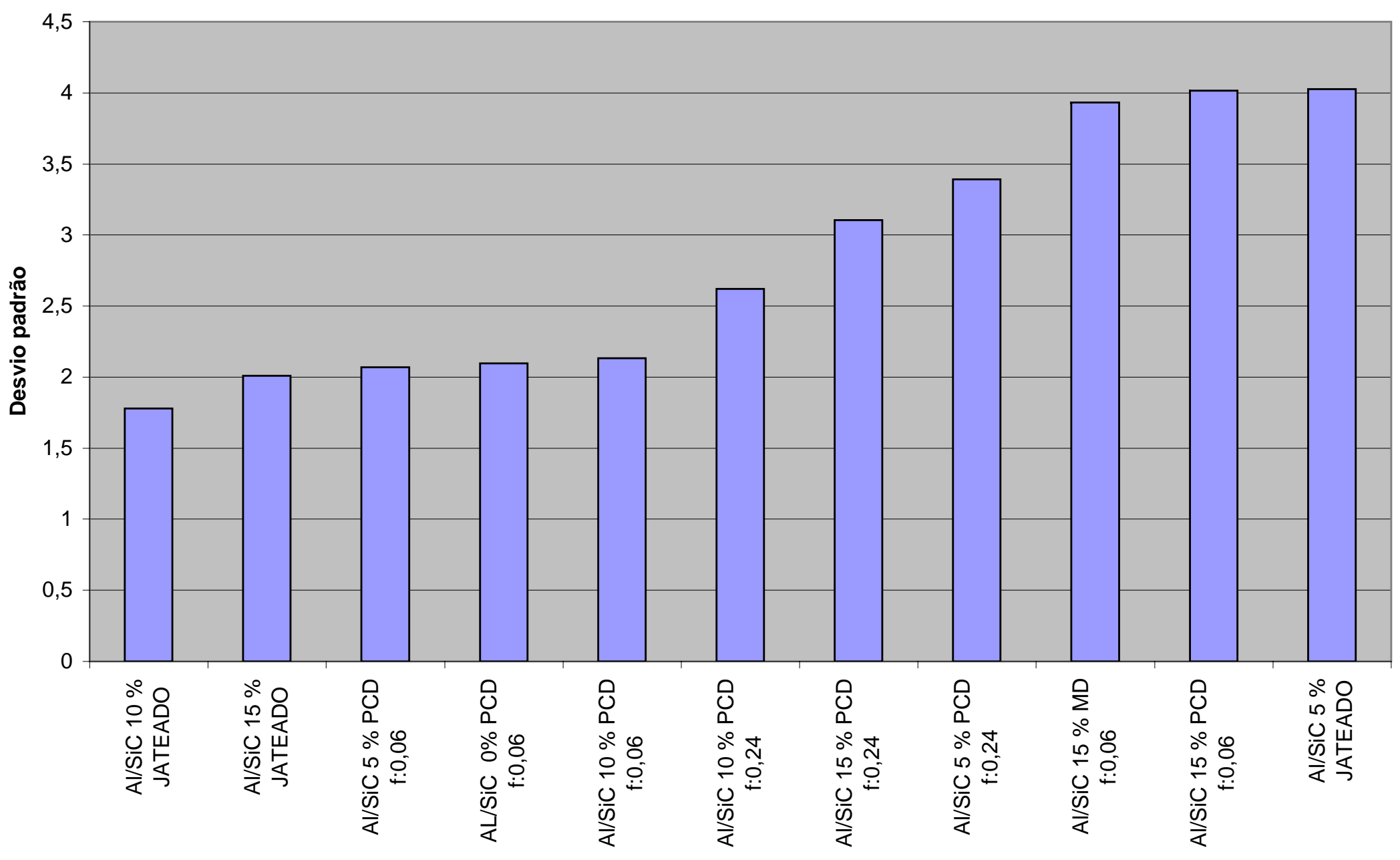

Figura 73 - Desvio padrão das curvas de fadiga obtidas (figuras 62 a 72) 
A dispersão dos resultados de fadiga pode ser associada com a maior ou menor periodicidade com que surgem e se propagam trincas de fadiga em um grupo de corpos de prova com as mesmas características, e portanto, possuem estreita relação com o grau de acabamento superficial e estrutura do material avaliado.

O desvio padrão ou mesmo as curvas de confiabilidade podem dar um indicativo de quanto é esta dispersão. O desvio padrão é um indicativo quantitativo enquanto os limites de confiabilidade, vistos diretamente no gráfico, são qualitativos. Quanto mais estreito os limites de confiabilidade e menor o desvio padrão, menor a dispersão e vice-versa.

Através do histograma da figura 73, que mostra os desvios padrões das regressões lineares obtidas nos gráficos das figuras 62 a 72, verifica-se que os materiais reforçados com $15 \%$ de $\mathrm{SiC}$ e usinados brandamente ( $\mathrm{f}=0,06 \mathrm{~mm} / \mathrm{rot}$ ), figuras 68 e 71, apresentaram desvios padrões superiores aos dos materiais com 5, 10 e $15 \%$ usinados grosseiramente com PCD ( $f=0,24 \mathrm{~mm} / \mathrm{rot})$, mostrando que nestes casos, a fração volumétrica foi a principal responsável pela grande dispersão de resultados de fadiga deste grupo de corpos de prova. A existência de maior quantidade de porosidades nestes materiais, devido à maior quantidade de reforços e, conseqüentemente, de interfaces presentes (conforme visto no sub-item 4.1.2), cria uma infinidade de possibilidades e condições para iniciação e crescimento de trincas de fadiga, que por estes motivos podem ocorrer em instantes diferenciados.

HABEL et al. [6] atribuem a dispersão de dados de vida à fadiga a diferenças nos locais de iniciação das trincas. CHAWLA, ANDRES, JONES e ALLISON [59] que estudaram uma liga de alumínio 2080 reforçada com diferentes tamanhos e frações volumétricas de SiC, associaram o alto grau de dispersão da vida à fadiga de seus experimentos com a variação do tamanho de grandes inclusões intermetálicas presentes nos materiais estudados. 
De maneira geral, os pesquisadores têm apontado como principais responsáveis pela dispersão dos resultados de fadiga, heterogeneidades na microestrutura ou na superfície dos compósitos. LLOYD [20], comenta que a considerável dispersão nos dados publicados de fadiga de compósitos, são reflexos de variações no processamento e qualidade do material.

No caso dos materiais usinados grosseiramente $(f=0,24 \mathrm{~mm} / \mathrm{rot})$, figuras 63, 66 e 69, os sulcos provocados pela ferramenta de usinagem (figura 55), parece ter contribuído para a diminuição da dispersão de resultados em relação aos reforçados com $15 \%$ e usinados brandamente $(f=0,06 \mathrm{~mm} / \mathrm{rot})$, na medida em que 0 início das trincas ficaram concentradas nestas regiões. Com relação a isso, BATHIAS [60] observou que corpos de prova brutos de fundição apresentaram limite de fadiga apreciavelmente superior aos corpos de prova de mesmo material, porém usinados. Segundo ele, incluindo variações de microestrutura, a microgeometria superficial foi a causa mais provável.

Os materiais reforçados com 5 e $10 \%$ de SiC e usinados com avanço de $0,06 \mathrm{~mm} /$ rot (figuras 62 e 65), apresentaram uma dispersão de resultados de fadiga ainda menor, que pode ser atribuída à menor quantidade de defeitos presentes nestes casos, tanto a nível microestrutural, quanto superficial. Estas características tornam estes materiais mais homogêneos com relação aos reforçados com $15 \%$ de SiC e aos usinados com avanço de $0,24 \mathrm{~mm} /$ rot e, portanto, mais homogêneos também em termos de dispersão dos resultados de fadiga.

Os materiais jateados reforçados com 10 e $15 \%$ de SiC (figuras 67 e 70), foram os que apresentaram a menor dispersão com relação a todos os demais casos. A menor dispersão de resultados, nestes casos, pode ser devida às tensões residuais compressivas inseridas na superfície dos mesmos durante o processo de jateamento, que tenderam a uniformizar e controlar o aparecimento e crescimento de trincas de fadiga. O grau do acabamento superficial não foi preponderante aqui, visto 
que apesar de terem apresentado valores comparáveis aos dos materiais usinados grosseiramente (figura 52), os desvios padrões encontrados foram os menores.

Situação completamente inversa ocorreu para o material reforçado com $5 \%$ de SiC e jateado (figura 64), que com uma superfície bastante atacada e degradada pelos efeitos do jateamento (conforme visto no item 4.1.4), apresentou o maior desvio padrão de todos os casos. Com relação a isso, LU et al. [56] também fizeram observações semelhantes. Segundo eles, o jateamento pode trazer benefícios para os compósitos de matriz metálica, entretanto, salientam que estes materiais são muito sensíveis ao estado de superfície.

A relação entre 0 tamanho das partículas de jateamento e espaçamento interpartículas do compósito pode justificar a maior degradação do material reforçado com $5 \%$ de SiC (figura 74). Para um mesmo tamanho de partículas de jateamento, o espaçamento interpartículas do material reforçado com 5 \% é maior com relação aos reforçados com 10 e 15 \% de SiC, e portanto, a matriz do compósito fica mais exposta à ação do tratamento. Como a matriz possui natureza bastante dúctil, ela tende a ser bastante agredida pelo processo. As regiões cobertas pelas partículas de reforço podem estar mais protegidas e, portanto, os danos na matriz, nestas regiões, serão menores. A distribuição de tensões residuais sobre o compósito nestas circunstâncias tenderá a ser muito heterogênea, levando a uma incidência maior de trincas de fadiga e conseqüentemente à grande dispersão de resultados.

Para os materiais jateados e reforçados com 10 e $15 \%$ de SiC, o espaçamento interpartículas é menor, com isso as partículas de jateamento não conseguiram agredir a matriz com rigor e de forma direta, uma vez que os reforços promoveram uma maior cobertura da superfície. Com isso, os danos na matriz foram menores e a distribuição das tensões residuais mais homogêneas, causando assim menor dispersão dos resultados. 


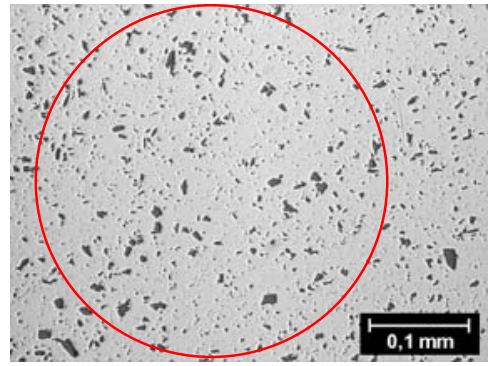

(a)

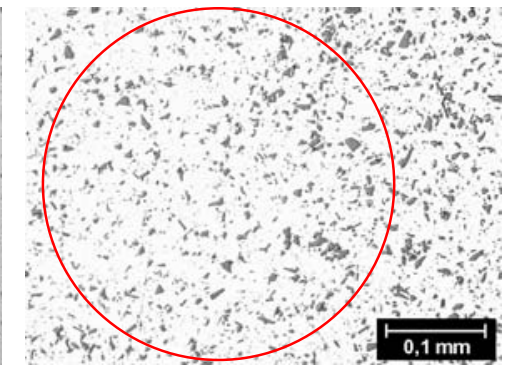

(b)

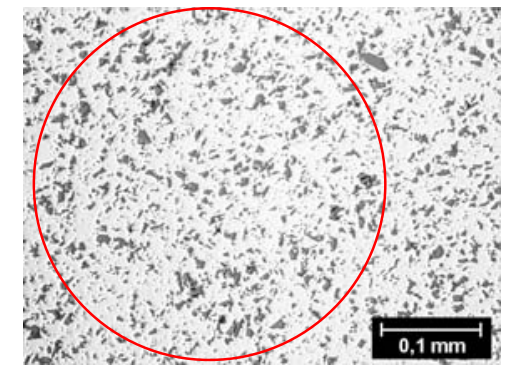

(c)

Figura 74 - Projeção do tamanho mediano de uma microesfera de vidro $(0,36 \mathrm{~mm})$ sobre a superfície de cada um dos materiais obtidos. (a) material reforçado com $5 \%$, (b) $10 \%$ e (c) $15 \%$.

\subsection{2 - Comparação entre as curvas de fadiga}

As figuras 75 a 80 mostram as curvas de fadiga das figuras 62 a 72 , agora de maneira sobreposta. Primeiramente foram comparadas as curvas de fadiga dos diversos tipos de tratamentos superficiais utilizados para cada tipo de material obtido (reforçados com 5, 10 ou $15 \%$ em volume de SiC e material de controle), figuras 75 a 77, e em seguida são comparadas as curvas dos diversos tipos de materiais obtidos para cada tipo de tratamento superficial utilizado (usinados com avanço de $0,06 \mathrm{~mm} / \mathrm{rot}, 0,24 \mathrm{~mm} / \mathrm{rot}$ ou jateados), figuras 78 a 80 . A figura 81 apresenta as declividades das curvas de fadiga, através das quais é possível fazer uma relação da sensibilidade da vida à fadiga dos materiais com a variação da carga aplicada nos ensaios. 


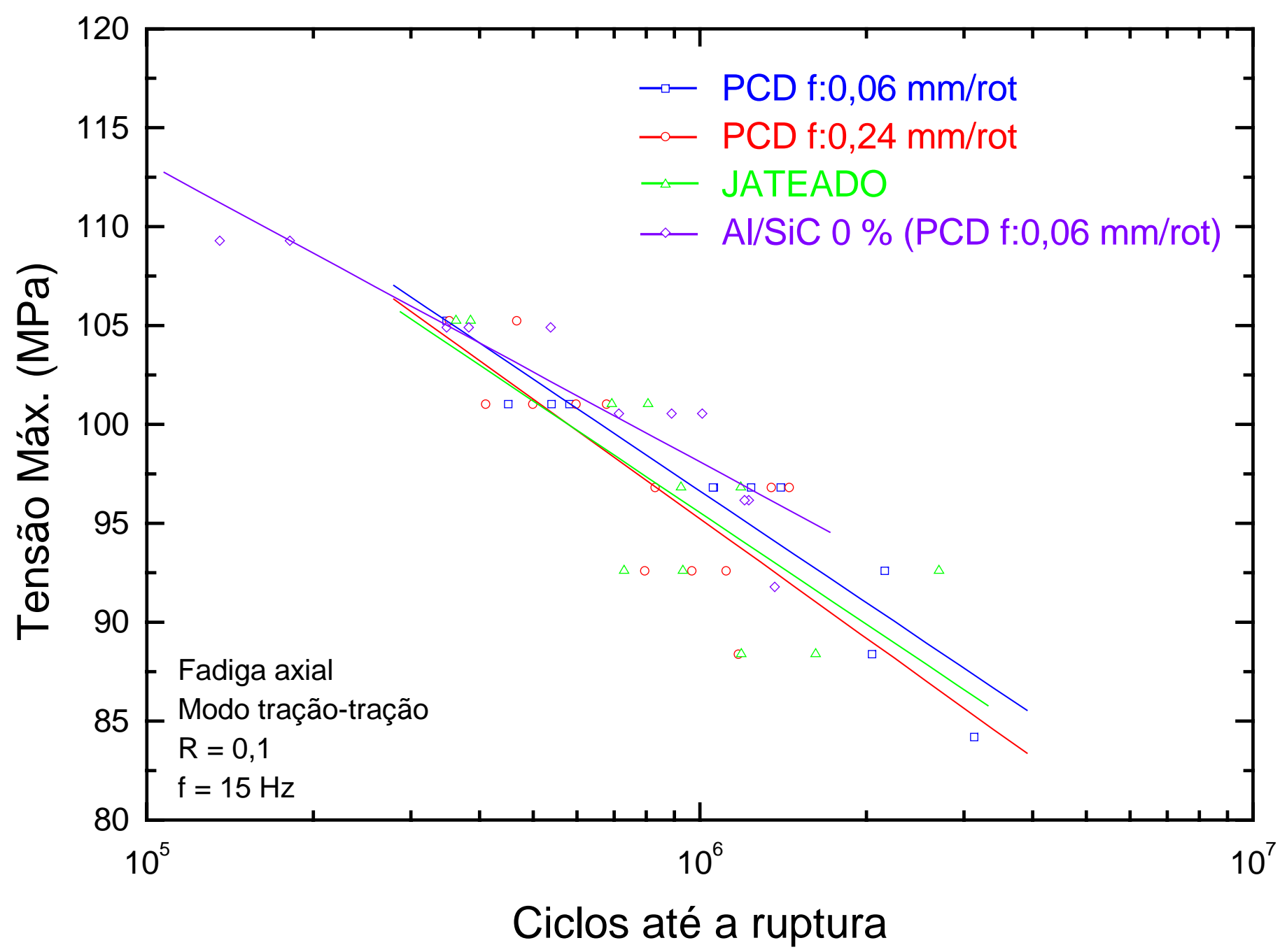

Figura 75 - Variação do comportamento à fadiga dos corpos de prova de Al/SiC 5 \% frente às condições de tratamento superficial. 


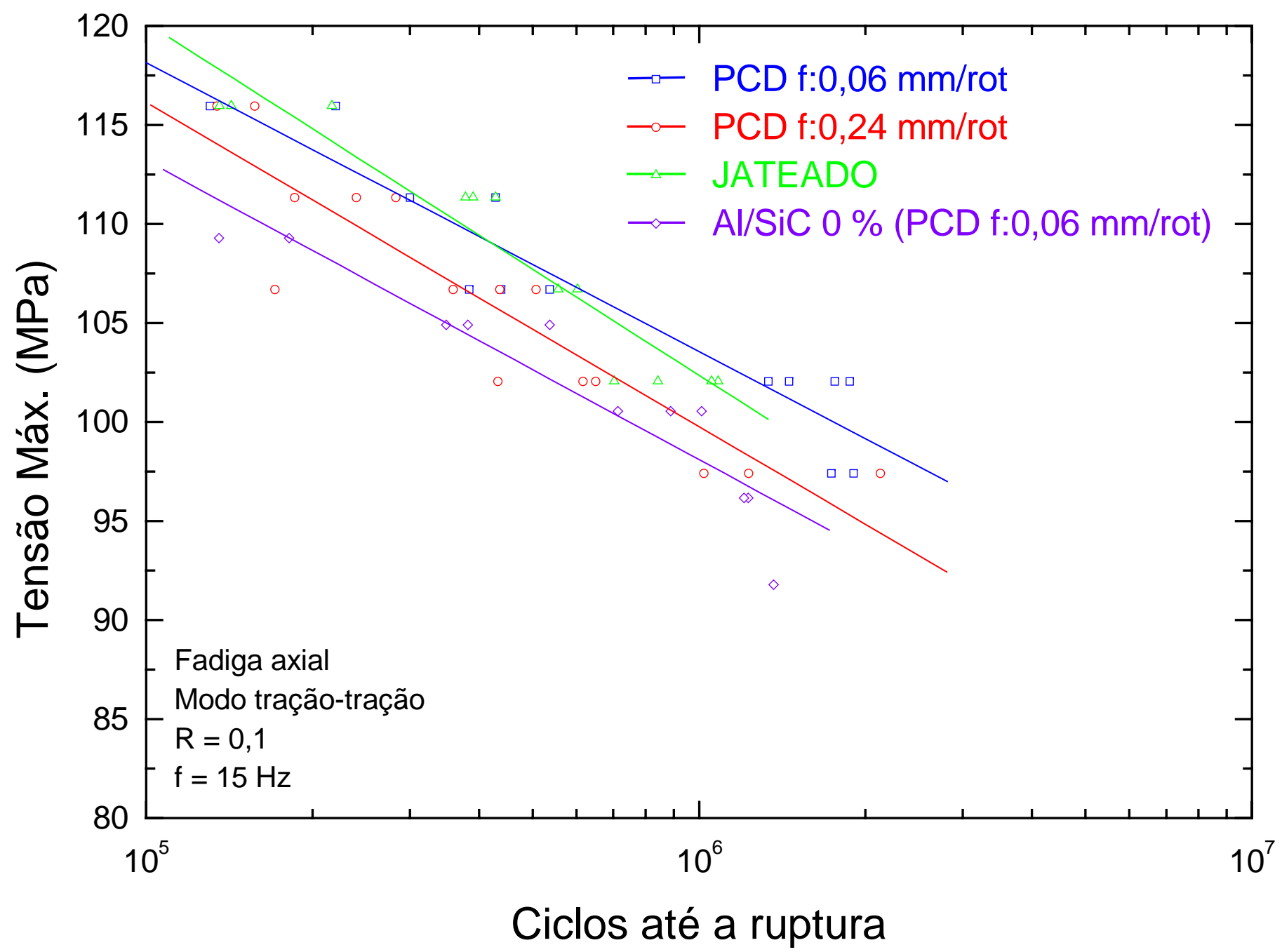

Figura 76 - Variação do comportamento à fadiga dos corpos de prova de Al/SiC 10 \% frente às condições de tratamento superficial. 


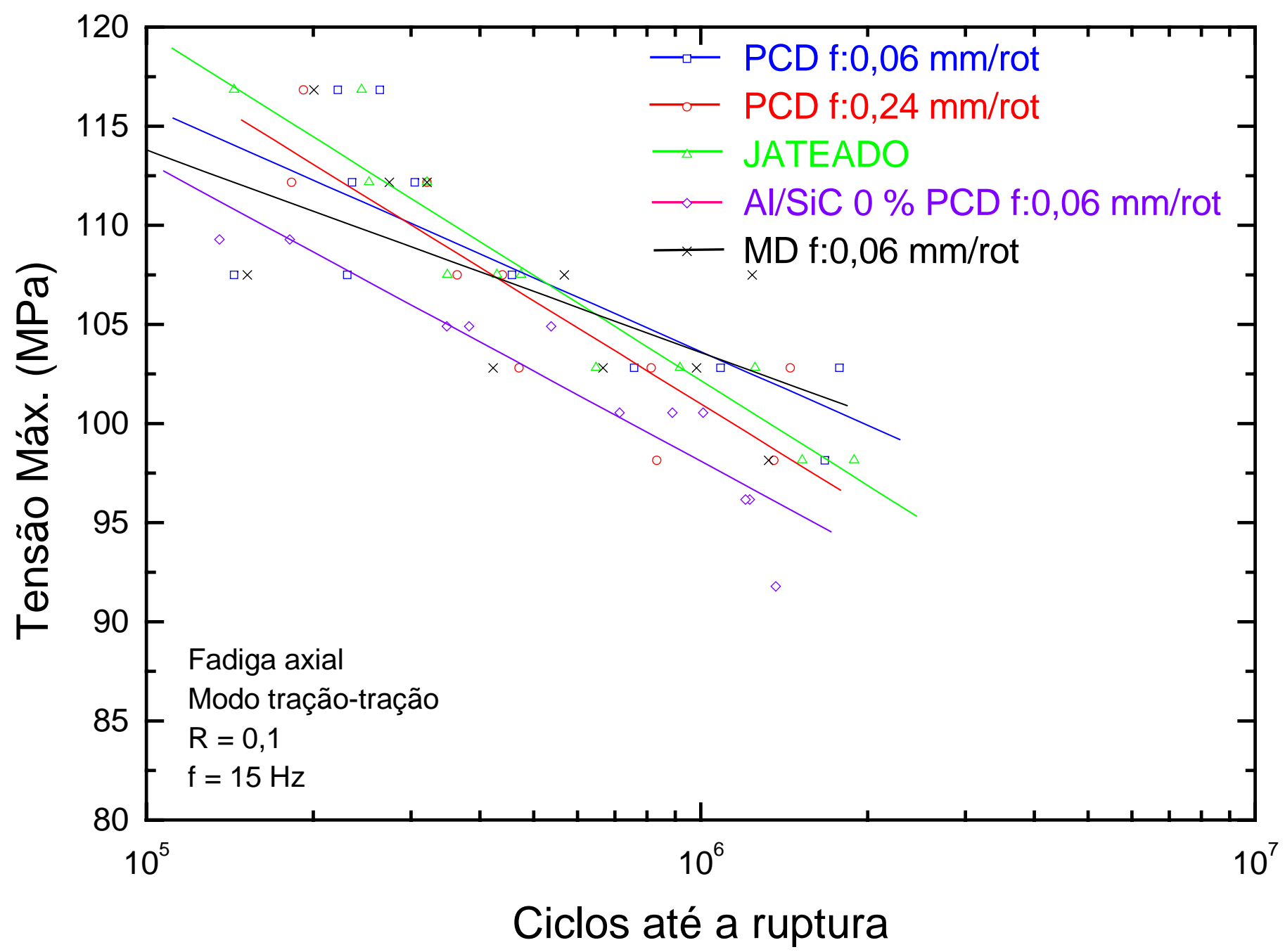

Figura 77 - Variação do comportamento à fadiga dos corpos de prova de Al SiC $15 \%$ frente às condições de tratamento superficial. 


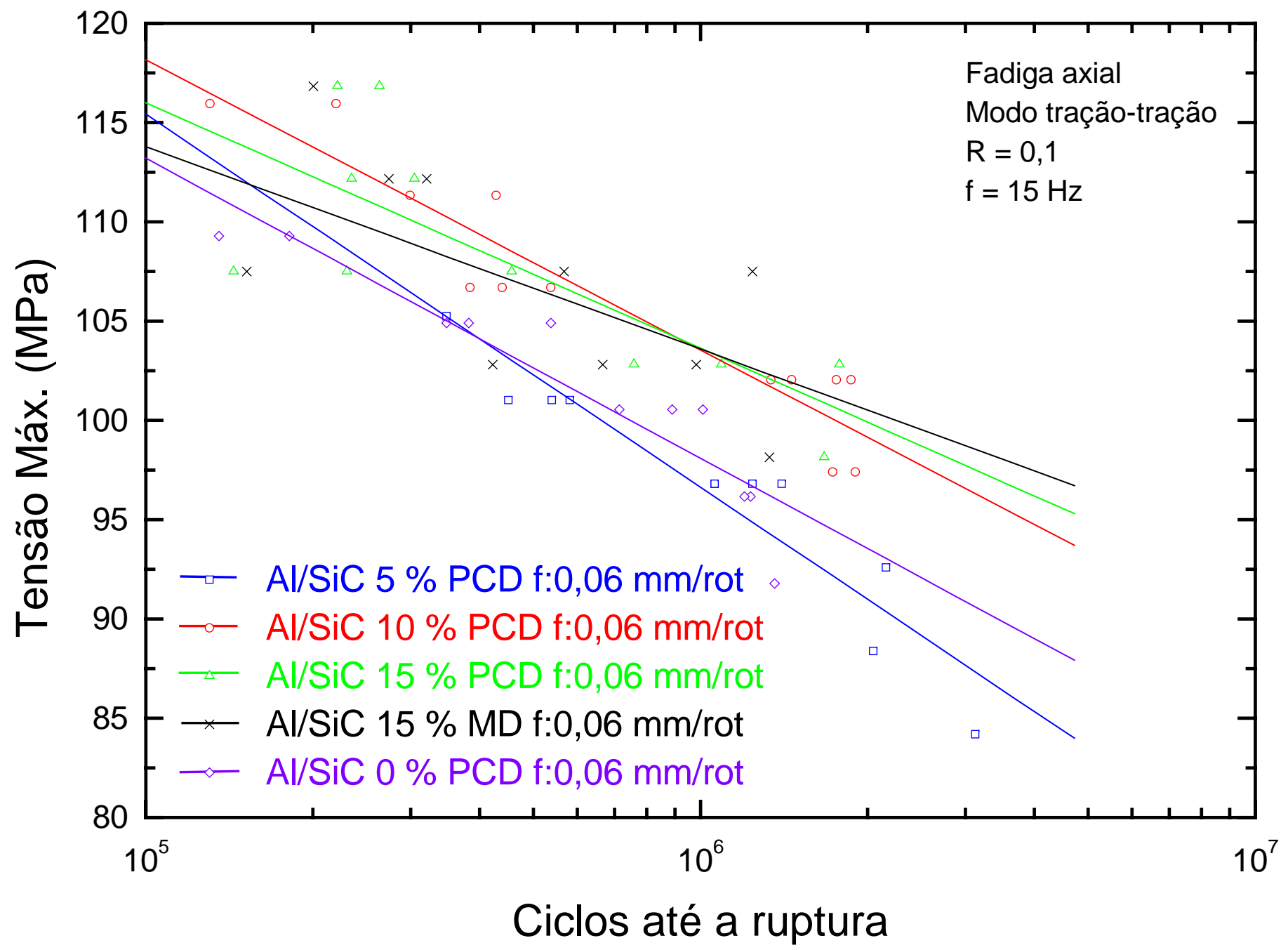

Figura 78 - Variação do comportamento à fadiga entre os diferentes materiais obtidos e usinados com $P C D$ ou MD com avanço de $0,06 \mathrm{~mm} / \mathrm{rot}$. 


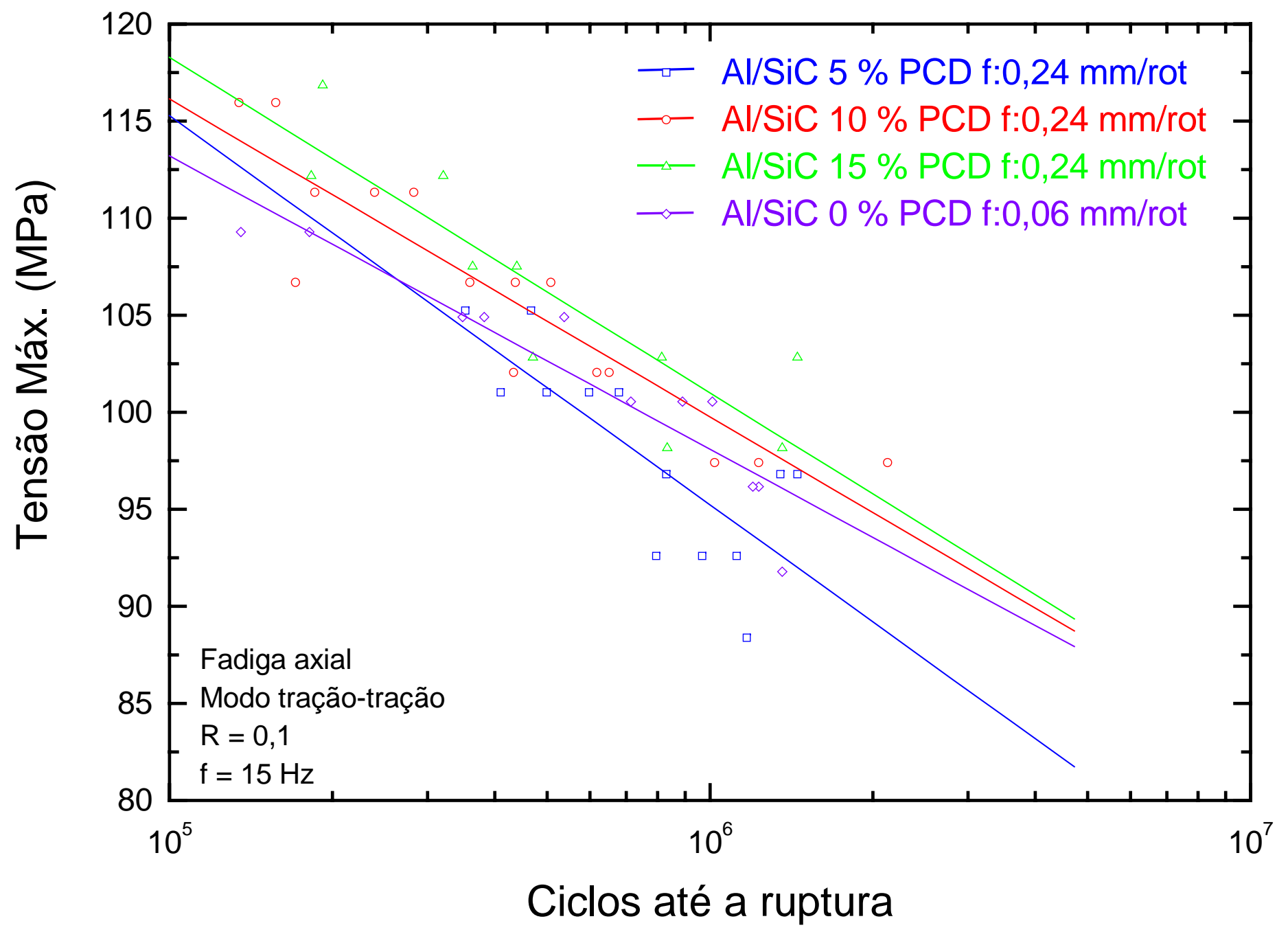

Figura 79 - Variação do comportamento à fadiga dos diferentes materiais obtidos e usinados com PCD com avanços de 0,06 ou $0,24 \mathrm{~mm} / \mathrm{rot}$. 


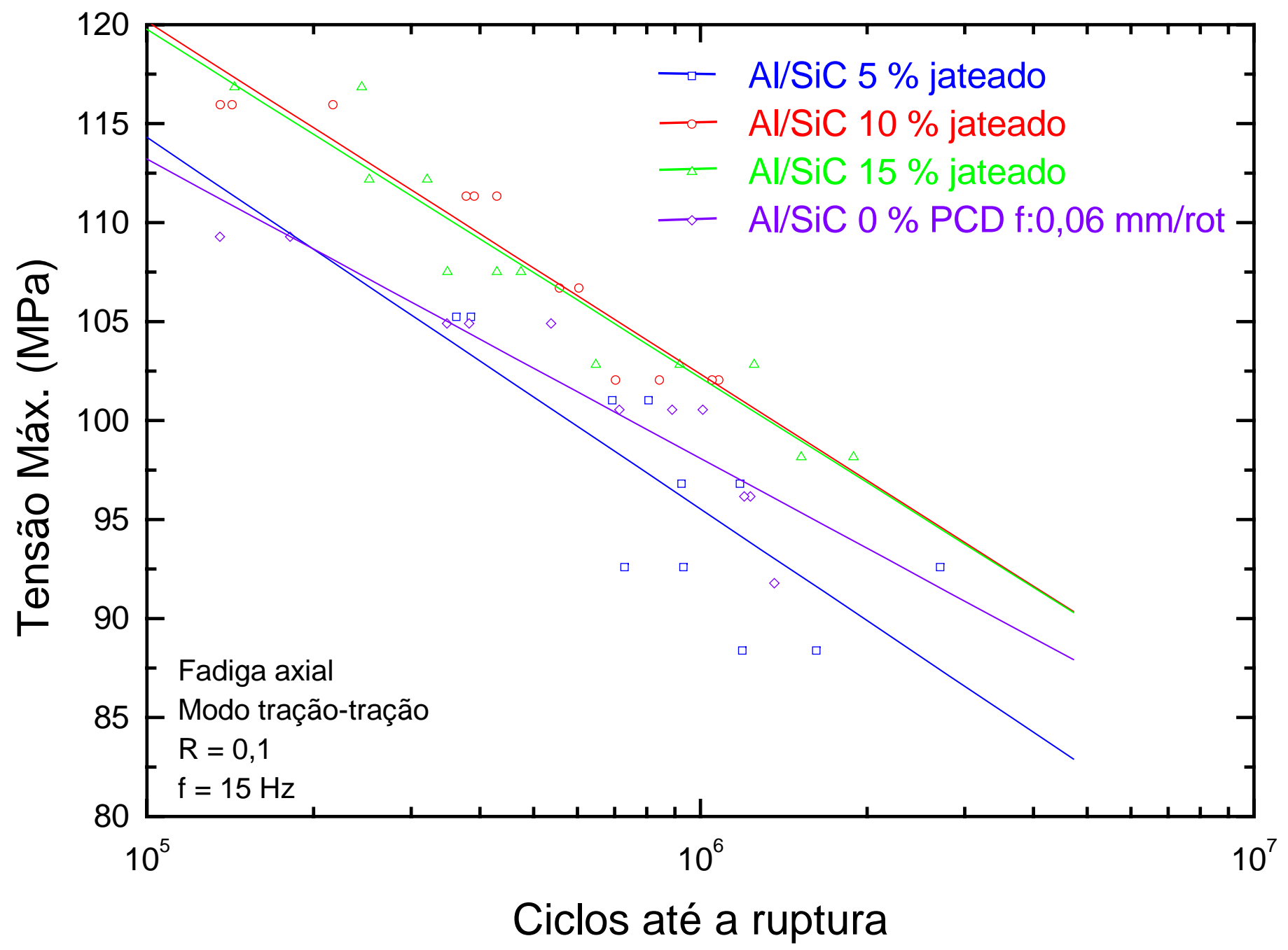

Figura 80 - Variação do comportamento à fadiga dos diferentes materiais obtidos e jateados ou usinados com $P C D$ e avanço de $0,06 \mathrm{~mm} / \mathrm{rot}$. 


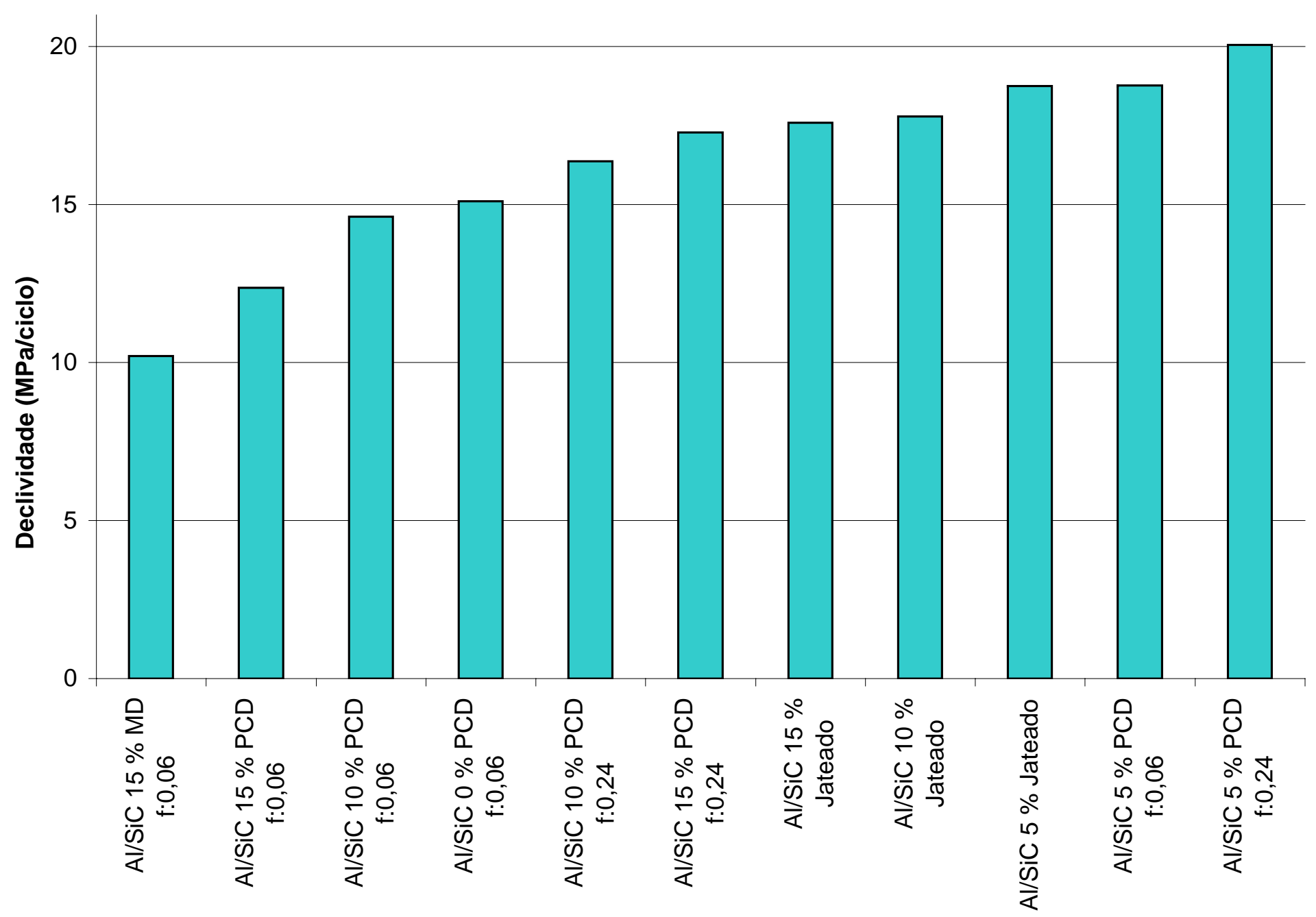

Figura 81 - Declividade das curvas de fadiga dos materiais ensaiados. 
A figura 75 mostra uma concentração bem acentuada das curvas de fadiga das condições de preparação para os materiais reforçados com $5 \%$ de SiC. Observa-se que os corpos de prova jateados apresentaram comportamento inferior aos usinados brandamente (taxa de avanço de 0,06 mm/rot) e praticamente igual aos usinados grosseiramente (taxa de avanço de $0,24 \mathrm{~mm} / \mathrm{rot}$ ). Estes resultados concordam com os obtidos por OMAM et al. [3] e BATHIAS [60], indicando que as tensões residuais inseridas no jateamento não foram capazes de compensar a superfície fortemente degradada pelo processo conforme já discutido anteriormente. O material não reforçado, neste caso, tendeu a apresentar, de maneira geral, melhor vida à fadiga com relação aos reforçados com $5 \%$ de SiC. BATHIAS [60], MASUDA et al. [40] e BONNEN et al. [5], concordam no sentido de que o limite de fadiga alcança um valor máximo entre 10 e $20 \%$ de fração volumétrica de reforço, dependendo da técnica adotada na obtenção do material. HARRIS [4] observou em seu trabalho que a vida à fadiga do material por ele estudado foi reduzida com a incorporação de fases reforçantes; o caso de HARRIS envolvia fração de reforços da ordem de $20 \%$ e portanto também pode se enquadrar nas conclusões de saturação da matriz defendidas por BATHIAS [60], MASUDA et al. [40] e BONNEN et al. [5]. HERTZBERG [42], também alerta para o fato de que o processo de jateamento altera a superfície do componente, produzindo pequenos "dimples" que podem ter efeito deletério sobre a vida à fadiga, por agirem como numerosos locais de concentração de tensão. Este estado de superfície muitas vezes pode ser contrabalanceado pelo campo favorável de tensão residual compressiva inserida pelo processo.

A vida à fadiga inferior dos materiais reforçados com $5 \%$ de SiC em relação ao material de controle, pode ser devida a dois motivos: 1 - Ao limite de escoamento destes materiais também de valor inferior ao do material de controle, uma vez que este foi a referência utilizada para definir os níveis de tensão dos ensaios de fadiga; 2 - A possíveis efeitos detrimentais que a pequena quantidade de reforços 
possa ter provocado nestes materiais, conforme discutido no sub-item 4.1.1 anteriormente. Nestas circunstâncias, o tipo de tratamento superficial mecânico adotado no processo de obtenção apresentou pouca ou insignificante influência na vida à fadiga destes materiais.

Ainda com relação aos materiais reforçados com $5 \%$, as colocações de HALL, JONES, SACHDEV [61] sobre a correlação entre a vida à fadiga e a resistência mecânica "se a resistência mecânica do compósito é maior que a resistência da liga da matriz, a vida à fadiga é maior" não se verificaram aqui. A resistência à tração dos compósitos reforçados com $5 \%$ de SiC foi ligeiramente maior do que a do material da matriz, entretanto a vida à fadiga destes foi, de modo geral, inferior.

Os materiais reforçados com 10 e $15 \%$ de $\mathrm{SiC}$ (figuras 76 e 77) apresentaram curvas de fadiga mais distribuídas, mostrando que os corpos de prova usinados com taxa de avanço de $0,06 \mathrm{~mm} / \mathrm{rot}$, concorrem com os jateados em termos de vida a fadiga. Para os corpos de prova jateados nota-se melhor vida à fadiga para tensões acima de $105 \mathrm{MPa}$ (regime de baixo ciclo) e dos usinados de maneira fina, para valores abaixo desta tensão (regime de alto ciclo). Com relação a isso BONNEN, YOU, ALLISON e JONES [62], verificaram em seus experimentos que a adição de partículas de SiC melhorou a vida a fadiga acima daquela do material não reforçado, sendo que esta melhoria foi maior próximo da região do limite de fadiga, diminuindo com o aumento dos níveis de tensão. HARRIS e YI [63], também notaram comportamento similar em seus trabalhos.

Em ambos os casos (para 10 e $15 \%$ de SiC), também não houve melhoria significativa de vida a fadiga dos corpos de prova jateados com relação aos usinados, mesmo tendo apresentado uma ligeira melhoria no grau do acabamento superficial destes, quando comparado aos reforçados com $5 \%$ de SiC. Analisando-se o grau de rugosidade dos corpos de prova jateados e usinados grosseiramente 
(Gráfico 52) é possível confirmar mais uma vez as observações de OMAM et al. [3] e BATHIAS [60], que atribuíram à degradação da superfície os efeitos pouco expressivos do jateamento nestes materiais. Nota-se que o grau da rugosidade obtido nos dois tratamentos são praticamente da mesma ordem de grandeza, mas os benefícios do jateamento sobre a vida à fadiga não são tão expressivos. Vale ressaltar, que OMAM et al. [3] utilizaram no jateamento de suas amostras, esferas de aço de 0,6 mm de diâmetro médio, enquanto que no presente trabalho foram utilizadas microesferas de vidro de $0,36 \mathrm{~mm}$ de diâmetro mediano (0,39 mm de diâmetro médio).

Os corpos de prova usinados grosseiramente (taxa de avanço de 0,24 $\mathrm{mm} / \mathrm{rot}$ ), de maneira geral apresentaram pior vida em fadiga em todos os casos. As nítidas estrias deixadas na superfície dos corpos de prova pela ferramenta de usinagem, funcionaram como fortes concentradores de tensão, cujas raízes foram pontos preferenciais para o início de trincas de fadiga (Figura 82).

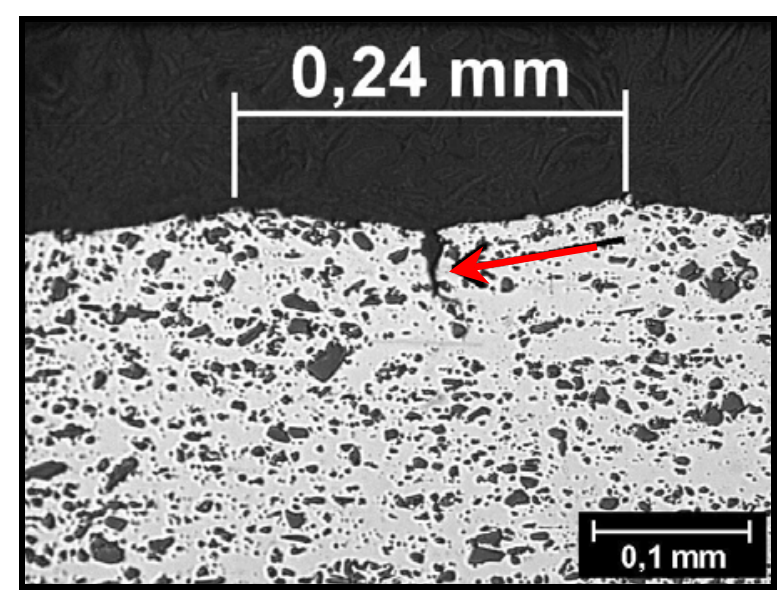

Figura 82 - Trinca originada na raiz de um sulco deixado pela ferramenta de usinagem de diamante utilizando taxa de avanço de 0,24 $\mathrm{mm} / \mathrm{rot}$.

Ainda com relação aos materiais usinados grosseiramente $(\mathfrak{f}=0,24$ $\mathrm{mm} / \mathrm{rot}$ ), além do processo em si já introduzir tensões residuais de tração na superfície que, conforme foi dito em itens anteriores, tem efeito detrimental para o material, soma-se o fato de que, durante o processo, as partículas de reforço mais superficiais 
do material tendem a ser arrancadas e arrastadas sobre o mesmo, contribuindo ainda mais para a diminuição do desempenho do material às solicitações mecânicas que the são impostas [11]. É evidente então, que com o aumento da fração volumétrica de reforços dos materiais estes danos serão maiores, e maiores também serão os efeitos detrimentais. Embora RASUL e MEGUID [58] tenham utilizado aço (817M40) em seus experimentos, eles verificaram que os níveis de tensão residual de tração aumentaram com o aumento da rugosidade superficial; assim, considerando que os materiais usinados grosseiramente (f:0,24 mm/rot) do presente trabalho apresentaram pior vida à fadiga com relação aos usinados brandamente (f:0,06 mm/rot), supõe-se que a rugosidade superficial também tenha contribuído aqui, da mesma maneira.

Nos materiais usinados grosseiramente a incidência de trincas originadas na superfície foi maior do que nos usinados de maneira fina e nos jateados. Nos materiais usinados de maneira fina, não foi possível visualizar as estrias deixadas pela ferramenta de usinagem, e portanto nestes casos, elas podem não ter sido tão críticas como no caso dos materiais usinados grosseiramente.

Os materiais usinados com metal duro (MD) e taxa de avanço de 0,06 $\mathrm{mm} /$ rot não apresentaram melhorias significativas de vida à fadiga com relação aos usinados com diamante policristalino $(P C D)$ e mesmo avanço. A menor agressão à superfície dos materiais usinados com ferramenta de metal duro apontada por JESUS FILHO e ROSSI [11] em seus experimentos com compósitos Al/FeNbC e Al/NbC, não foi verificada aqui. Isto pode ser devido a diferenças nas classes de metal duro utilizadas em cada um dos trabalhos. O metal duro utilizado no presente trabalho tem maior resistência ao desgaste do que aquele utilizado por JESUS FILHO e ROSSI.

Conforme a classificação de ABD EL-AZIM, KHALIFA e EL-AKABAWY [64], partículas de reforço com tamanho médio de $9 \mu \mathrm{m}$ são consideradas pequenas, o que, segundo suas conclusões, proporciona resistência à fadiga superior com relação ao material da matriz para frações volumétricas acima de $5 \%$. O tamanho médio das 
partículas utilizadas no presente trabalho $(7 \mu \mathrm{m})$ se enquadra na categoria de partículas pequenas, conforme a classificação de ABD EL-AZIM et al.. Entretanto, o comportamento à fadiga dos compósitos obtidos não apresentou melhorias significativas, quando comparados com o material de controle (material sem reforço). Neste caso, o comportamento dos materiais obtidos foi comparável ao de materiais constituídos por partículas classificadas por ABD EL-AZIM et al. como intermediárias (33 $\mu \mathrm{m})$, que segundo eles não apresentam efeito significativo sobre a resistência à fadiga.

Uma outra particularidade nas curvas de fadiga que pode funcionar como indicador da sensibilidade ou resposta à fadiga de um material com a variação da carga, é a declividade. Ela também pode ajudar a definir melhor a faixa de aplicação do material, uma vez conhecidos os níveis de flutuação de tensão.

Analisando-se a figura 81 nota-se que o materiais reforçados com $5 \%$ de SiC foram os que apresentaram menor sensibilidade à fadiga com a variação da carga (maior declividade da curva), para todos os tipos de tratamentos superficiais impostos, quando comparados com os materiais reforçados com 10 e $15 \%$, mostrando que a variável preponderante neste caso foi a menor fração volumétrica de reforços.

Para os materiais reforçados com 10 e $15 \%$ de $\mathrm{SiC}$, os corpos de prova usinados com taxa de avanço de 0,06 mm/rot apresentaram curvas com as menores declividades em todos os casos, e portanto, com maior sensibilidade à variação da carga. Este comportamento agora parece ter sido ditado pelo acabamento superficial mais refinado.

Os materiais reforçados com 10 e $15 \%$ de SiC e usinados grosseiramente (f:0,24 mm/rot), apresentaram pior vida à fadiga, entretanto apresentaram menor sensibilidade com a variação da carga com relação aos materiais de mesma fração volumétrica mas usinados brandamente (f: 0,06 mm/rot). 
Com a variação de 5 para $10 \%$ de reforço nos compósitos, houve um aumento na sensibilidade à fadiga para todos os tipos de tratamento. Com o aumento de 10 para $15 \%$, nota-se que esta sensibilidade (declividade da curva), permanece praticamente inalterada para os materiais usinados com $0,24 \mathrm{~mm} / \mathrm{rot}$ de avanço e para os jateados. Para os materiais usinados com avanço de $0,06 \mathrm{~mm} / \mathrm{rot}$, entretanto, houve um aumento bastante significativo desta sensibilidade.

Estas observações sobre a sensibilidade dos materiais à fadiga com a variação da carga, levam a concluir que, embora tenham apresentado vida à fadiga inferior à do material não reforçado, os materiais reforçados com $5 \%$ de $\mathrm{SiC}$ se mostraram os mais indicados para aplicações onde haja uma larga faixa de variação de tensão, pois os mesmos apresentaram as menores sensibilidades em todos os casos.

\subsection{3 - Fractografias de fadiga}

\subsubsection{1 - Trincas de fadiga}

As micrografias apresentadas através das figuras 82 a 93 foram obtidas em microscópio óptico e mostram algumas trincas encontradas na secção longitudinal dos corpos de prova fraturados por fadiga. 

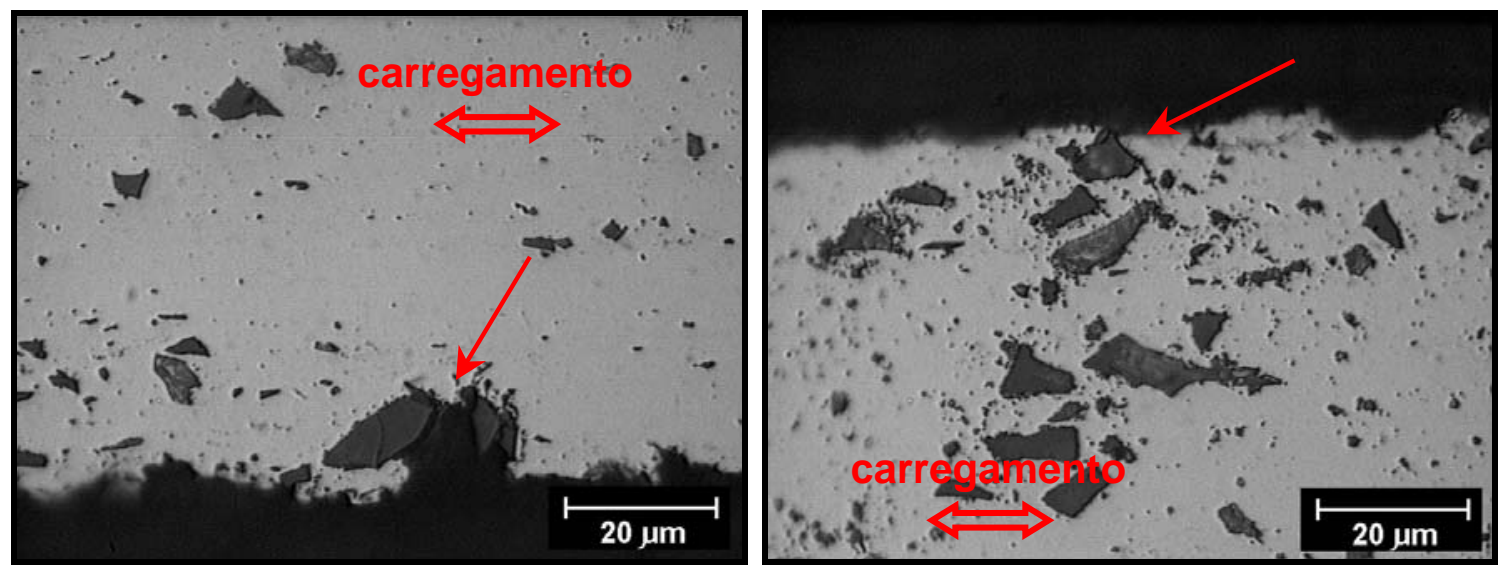

Figura 82 - Micrografia do Al/SiC $5 \%$ Figura 83 - Micrografia do Al/SiC $5 \%$ usinado com $P C D$ e f:0,06 mm/rot. A seta usinado com $P C D$ e f:0,06 mm/rot. A seta indica um local onde houve provável indica uma trinca iniciada na interface de arrancamento da partícula de reforço na uma partícula com a matriz.. usinagem.

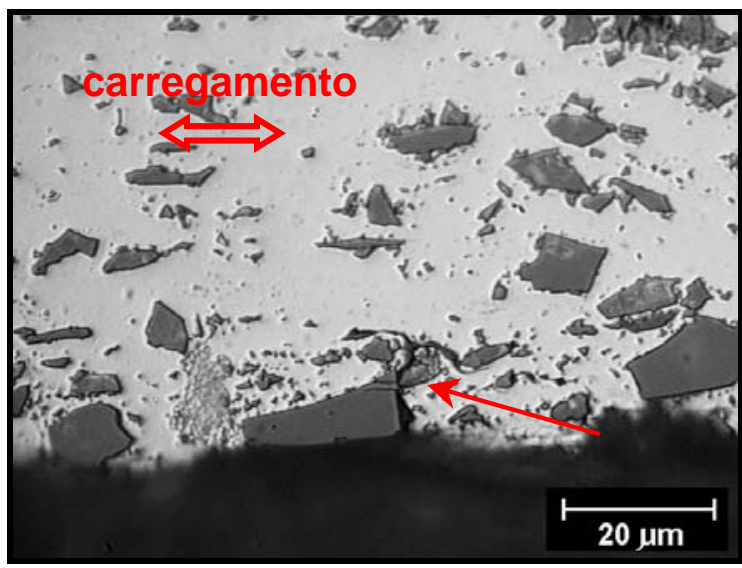

Figura 84 - Micrografia do Al/SiC $5 \%$ usinado com MD e f:0,06 mm/rot. A seta indica uma trinca iniciada próxima de uma partícula de reforço.

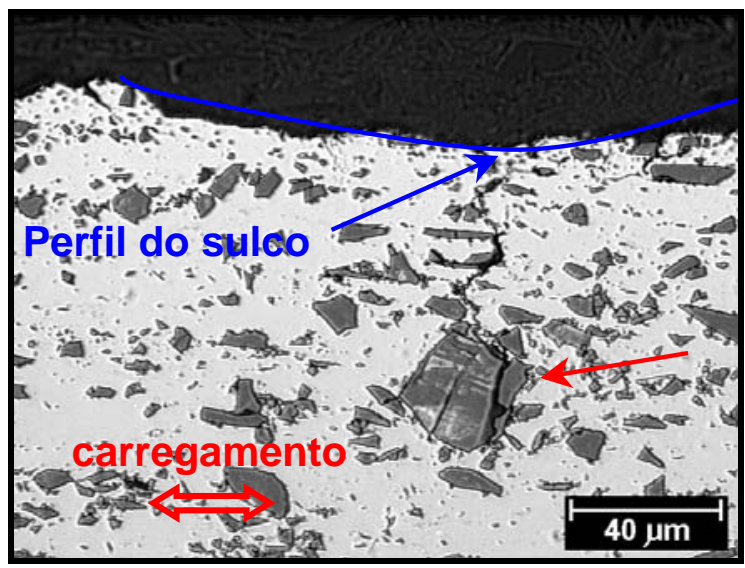

Figura 85 - Micrografia do Al/SiC 15\% usinado com PCD e f:0,24 mm/rot, mostrando uma trinca iniciada na raiz do sulco provocado na usinagem. A seta indica a provável fratura de uma partícula grande encontrada no caminho da trinca. 

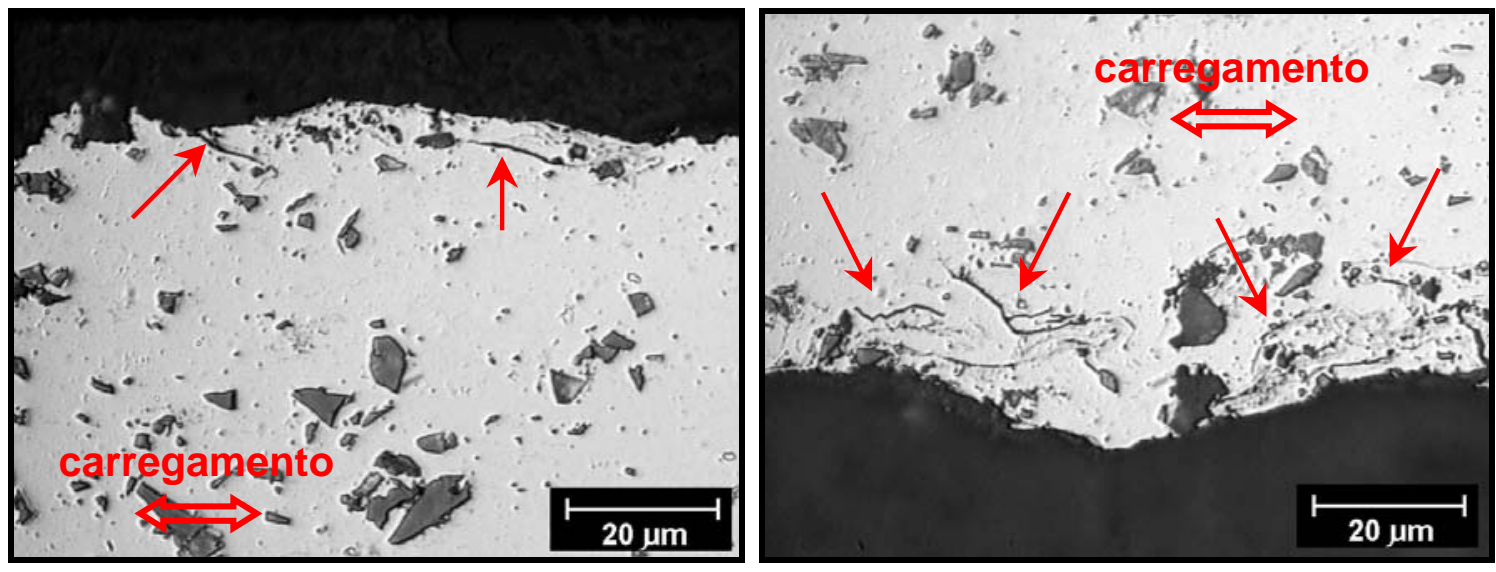

Figura 86 - Micrografia do Al/SiC $5 \%$ jateado. As setas mostram trincas se propagando de maneira subsuperficial e paralela à superfície e à direção de carregamento.

Figura 87 - Micrografia do Al/SiC $5 \%$ jateado. As setas indicam trincas surgindo e se propagando de maneira subsuperficial e paralela à superfície e à direção de carregamento.
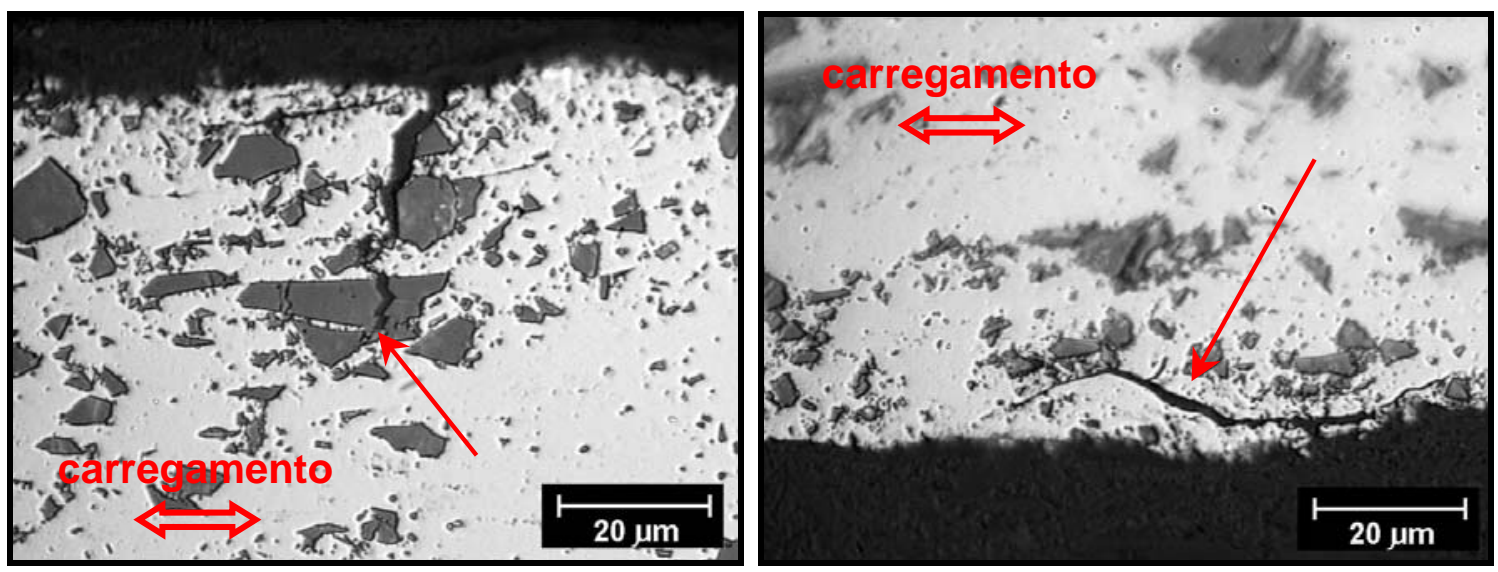

Figura 88 - Micrografia do Al/SiC $15 \%$ jateado. A seta aponta para uma trinca que partiu da superfície e pode ter propagando de maneira subsuperficial e provocado a fratura de uma partícula de paralela à superfície e à direção de SiC que encontrou no caminho. carregamento 

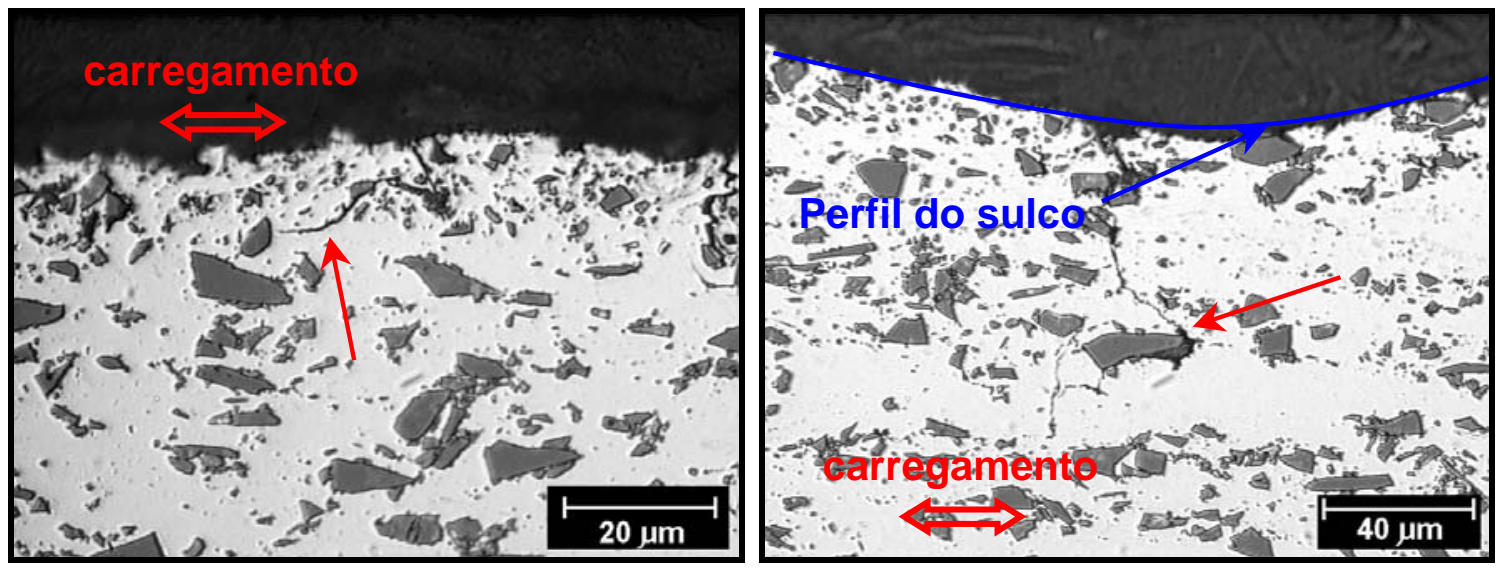

Figura 90 - Micrografia do Al/SiC $15 \%$ Figura 91 - Micrografia do Al/SiC $15 \%$ jateado. A seta mostra uma trinca se usinado com $P C D$ e f:0,24 mm/rot. A seta, propagando de maneira subsuperficial e mostra uma trinca iniciada na raiz do sulco paralela à superfície e à direção de provocado na usinagem, que caminha em carregamento. direção à extremidade de um reforço.

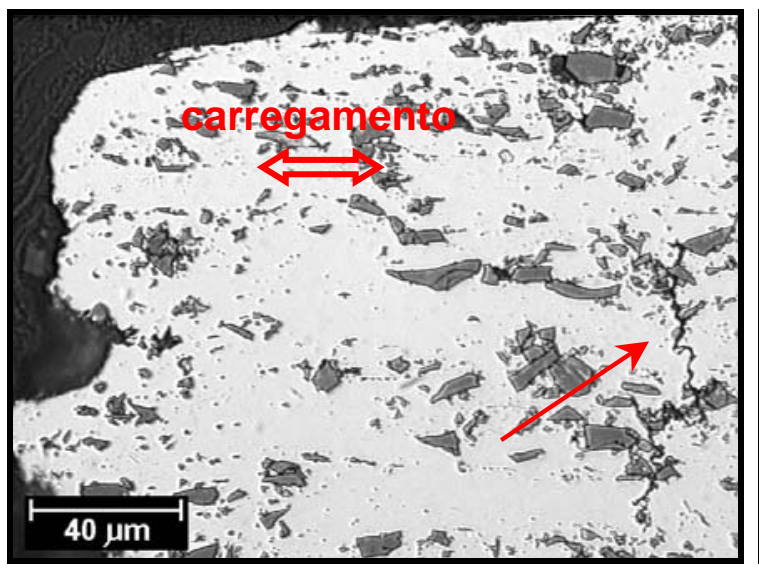

Figura 92 - Micrografia do Al/SiC $15 \%$ usinado com $P C D$ e f:0,24 mm/rot. A seta aponta para uma trinca iniciada no interior do material.

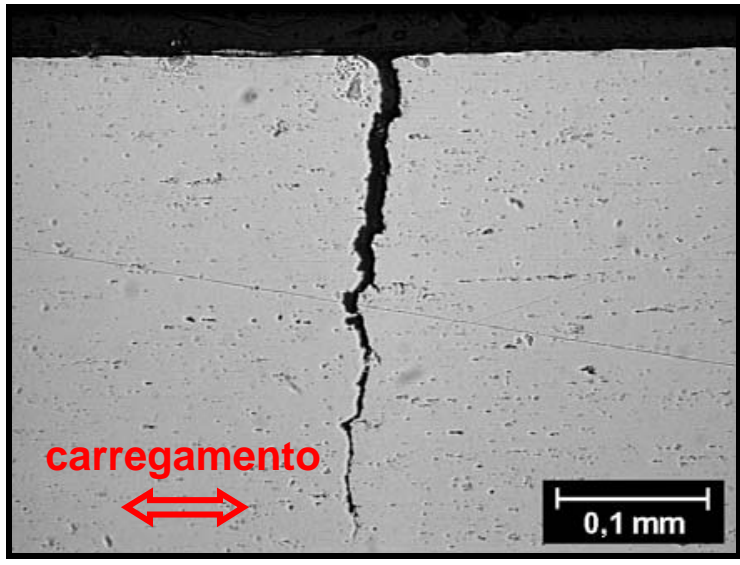

Figura 93 - Micrografia do Al/SiC $0 \%$ usinado com PCD e $\mathrm{f}: 0,06 \mathrm{~mm} / \mathrm{rot}$, mostrando a propagação de uma trinca de fadiga iniciada na superfície.

Nas micrografias de fadiga observou-se que, independentemente da fração volumétrica de reforços, nos materiais usinados brandamente (f:0,06 mm/rot), 
os pontos de iniciação de trincas foram preferencialmente em locais da superfície onde houve deslocamento ou arrancamento de partículas de reforço durante a usinagem (figura 82 e 83) ou a presença de partículas grandes de reforço (figura 84). As trincas de fadiga também surgiram em regiões onde haviam aglomeração de particulas de reforço (clusters) subsuperficialmente (figura 88).

Para os materiais usinados grosseiramente (f: $0,24 \mathrm{~mm} / \mathrm{rot}$ ), indiscutivelmente, os pontos de concentração de tensões deixados pela ferramenta de usinagem na superfície dos mesmos, foram os principais locais para o surgimento de trincas de fadiga (figuras 85 e 91).

Nos materiais jateados, como a superfície sofreu uma homogeneização macroscópica durante o processo de jateamento (conforme discutido no sub-item 4.1.4) não foi possível identificar sítios preferenciais para o surgimento de trincas. As tensões residuais inseridas e os efeitos provocados pelo jateamento na superfície dos materiais, tornaram os pontos de iniciação de trincas muito aleatórios, particulares e de difícil determinação.

Entretanto, uma particularidade curiosa somente observada nos materiais jateados (principalmente nos reforçados com $5 \%$ de SiC), pode ser vista nas figuras 86 a 90. As trincas nestes materiais apresentaram características de crescimento e propagação interessantes, ou seja, em um primeiro estágio as trincas surgiram e se propagaram superficial ou subsuperficialmente, paralelamente à superfície e à direção de carregamento. Uma explicação possível é de que estas trincas tenderam a surgir e/ou se propagar nas regiões de interface ou transição entre os níveis de tensão residual compressiva inseridos durante o jateamento e o nível de tensão residual original do material. Uma tentativa de se fazer um ataque químico seletivo para revelar os grãos da matriz e tentar distinguir esta zona de transição, foi feita, mas os resultados não foram satisfatórios. 
A figura 91 mostra uma trinca que partiu da superfície livre do corpo de prova e caminhou em direção à extremidade da partícula de SiC apontada pela seta. A geometria alongada da partícula alinhada na direção do carregamento faz com que os maiores níveis de tensão se concentrem nas extremidades da mesma, tornando-as assim, locais preferenciais para a propagação de trincas.

O caminho de propagação das trincas de fadiga nos materiais foi basicamente através da matriz (figuras 91 e 92). Em regiões com maior aglomeração de partículas de reforço as trincas de fadiga propagaram-se preferencialmente por entre elas (através da interface matriz/reforço ou apenas através da matriz - figuras 85 e 91). Embora as partículas de reforço fraturadas mostradas nas figuras 85 e 88 estejam no caminho das trincas de fadiga, não é possível afirmar que as mesmas tenham sido fraturadas por elas. Estas partículas também podem ter sido quebradas durante a fase de produção dos materiais, como por exemplo na etapa de extrusão. Nestas circunstâncias, elas podem ter funcionado apenas como agentes facilitadores para a propagação das trincas.

A figura 93 mostra uma trinca no material não reforçado (Al/SiC 0 \%). A propagação da trinca apresenta característica bem menos tortuosa e bem perpendicular à direção de carregamento, com relação aos materiais reforçados. Esta é uma característica de propagação de trincas bastante comum em materiais monolíticos.

\subsubsection{2 - Superficies de fratura}

As fractografias das figuras 94 a 99, referem-se às superficies fraturadas por fadiga de alguns corpos de prova dos materiais obtidos.

Nestas figuras, procurou-se destacar as regiões denominadas de "zonas de fadiga". Nestas regiões, é onde aparecem, crescem e se propagam as primeiras trincas de fadiga. A superfície restante, corresponde à parcela do material que rompeu 
de maneira rápida quando as trincas e os danos de fadiga, limitados na "zona de fadiga", atingiram uma proporção tal, que o material não pôde mais suportar os esforços e então falhou de maneira catastrófica.

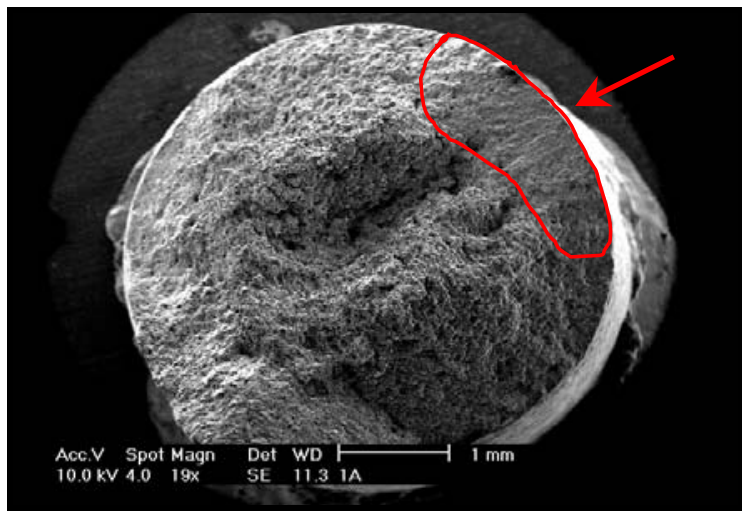

(a)

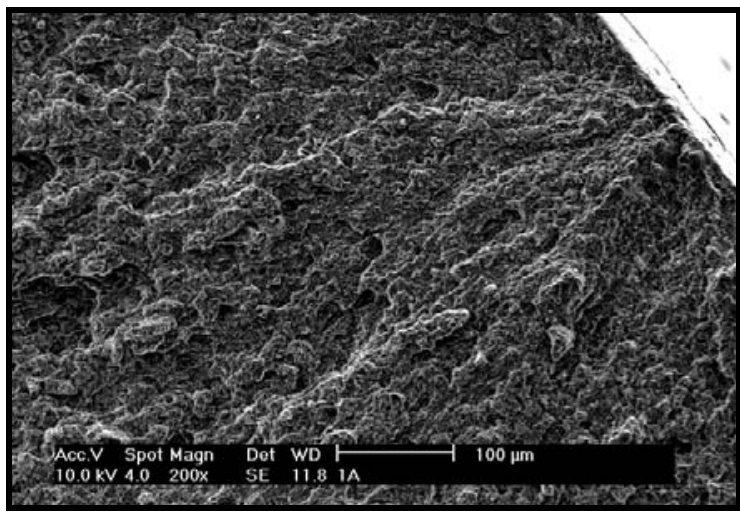

(b)

Figura 94 - Superfícies de fratura do Al/SiC $5 \%$ usinado com PCD e f:0,06 mm/rot (a) Visão geral da superfície com destaque para a zona de fadiga delimitada em vermelho; (b) Detalhe do ponto de início da trinca indicado pela seta na figura a.

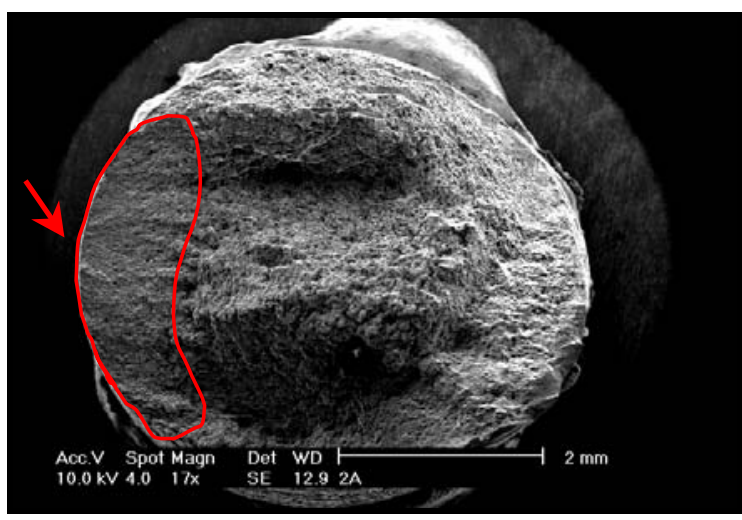

(a)

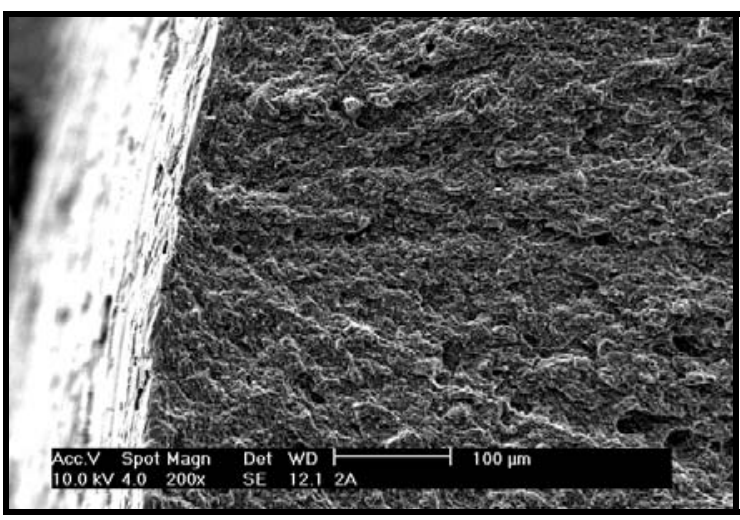

(b)

Figura 95 - Superfícies de fratura do Al/SiC $5 \%$ usinado com PCD e f:0,24 mm/rot (a) Visão geral da superfície com destaque para a zona de fadiga delimitada em vermelho; (b) Detalhe do ponto de início da trinca indicado pela seta na figura a. 


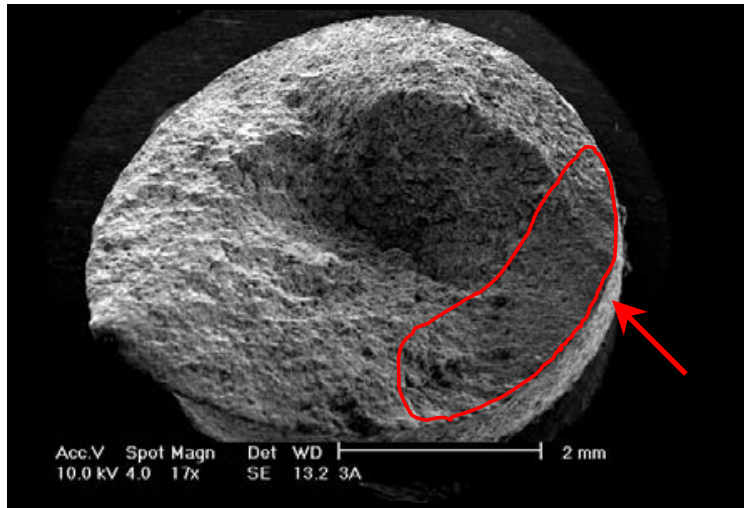

(a)

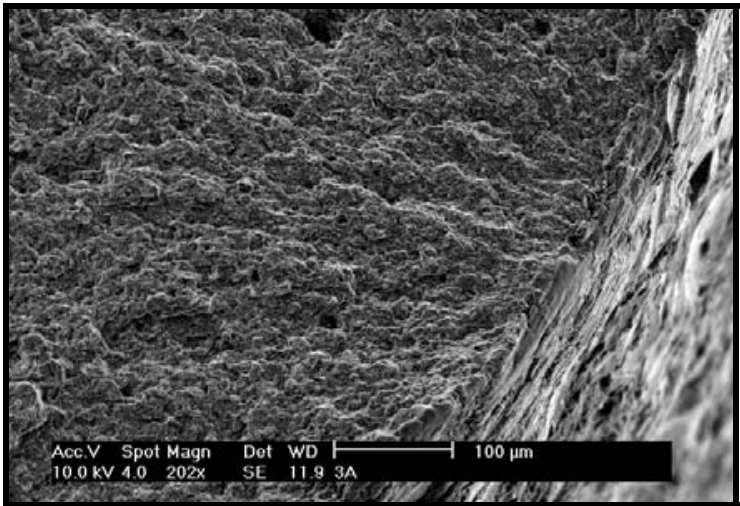

(b)

Figura 96 - Superfícies de fratura do Al/SiC $5 \%$ jateado. (a) Visão geral da superfície com destaque para a zona de fadiga delimitada em vermelho; (b) Detalhe do ponto de início da trinca indicado pela seta na figura a.

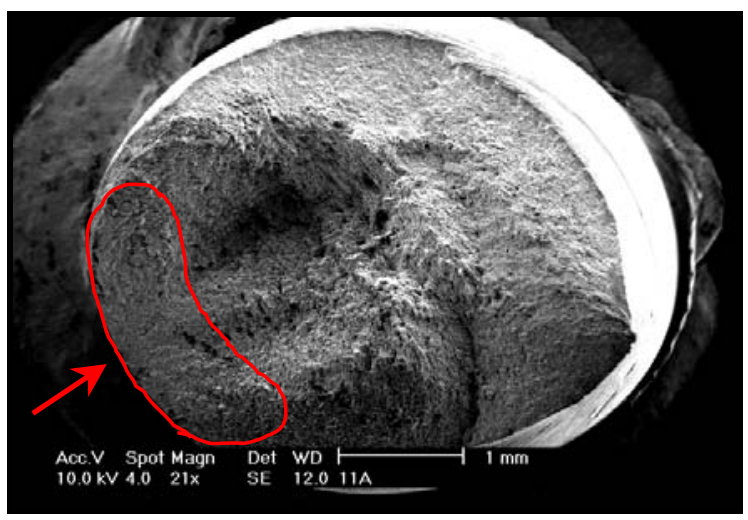

(a)

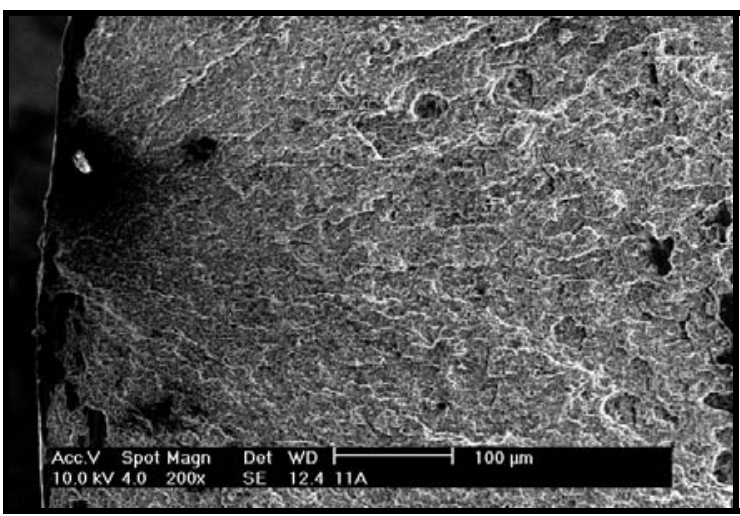

(b)

Figura 97 - Superfícies de fratura do Al/SiC $0 \%$ usinado com PCD e f:0,06 mm/rot (a) Visão geral da superfície com destaque para a zona de fadiga delimitada em vermelho; (b) Detalhe do ponto de início da trinca indicado pela seta na figura a.

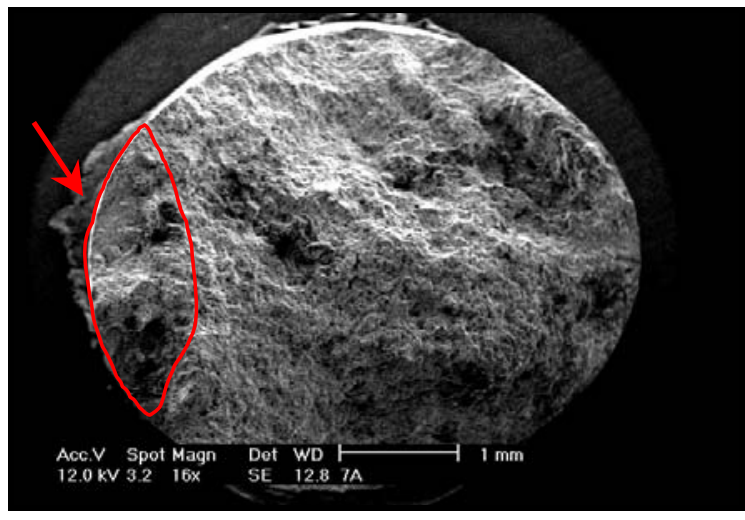

(a)

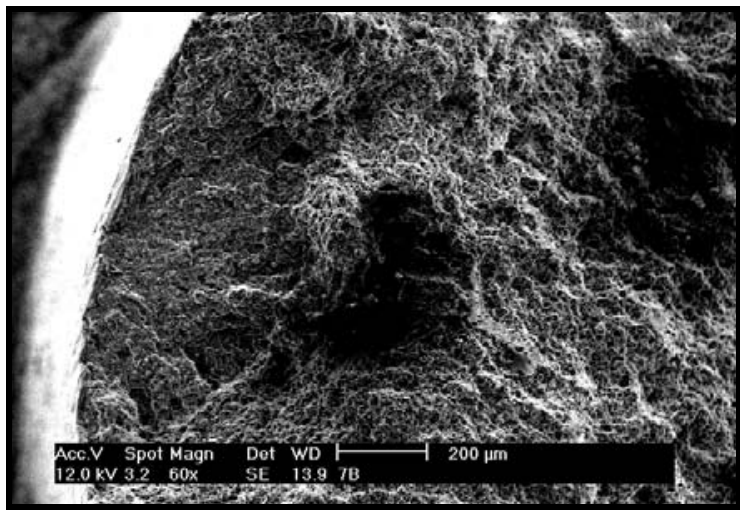

(b)

Figura 98 - Superfícies de fratura do Al/SiC $10 \%$ usinado com PCD e f:0,24 mm/rot (a) Visão geral da superfície com destaque para a zona de fadiga delimitada em vermelho. (b) Detalhe do ponto de início da trinca indicado pela seta na figura a. 


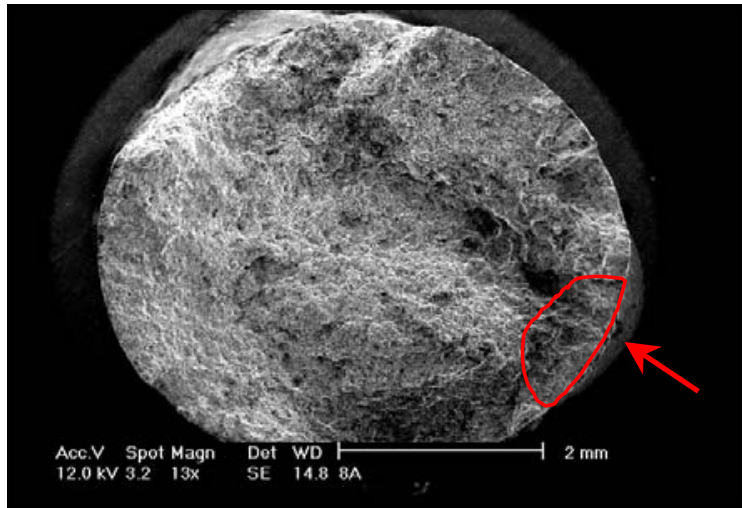

(a)

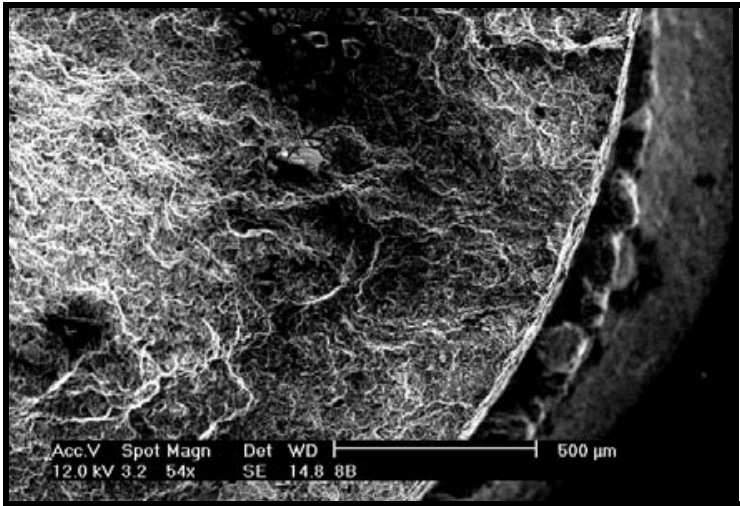

(b)

Figura 99 - Superfícies de fratura do Al/SiC $15 \%$ usinado com PCD e f:0,24 mm/rot (a) Visão geral da superfície com destaque para a zona de fadiga delimitada em vermelho; (b) Detalhe do ponto de início da trinca indicado pela seta na figura a.

A figura 99, corresponde a um compósito reforçado com $15 \%$ de SiC.

Este material apresenta um comportamento mais frágil que os demais. Por este motivo a "zona de fadiga" possui uma área muito menor com relação aos demais materiais.

As fraturas de fadiga normalmente tiveram origem na superfície do corpo de prova ou próxima dela, com exceção do caso onde houve aglomeração de alumínio puro, como será visto mais a frente, no sub-item 4.2.3.4, figura 104. NIEH, LESUER e SYN [65] também observaram esta característica nas superfícies fraturadas da liga de alumínio 6090 reforçada com $25 \%$ de partículas de SiC. Nos trabalhos de HALL et al. [61] as trincas de fadiga também iniciaram normalmente em defeitos ou particularidades localizadas na superfície do corpo de prova ou perto dela.

Nas fractografias observadas aqui, não foi possível visualisar ou identificar estrias de fadiga na matriz do compósito. LI e ELLYIN [66] também não conseguiram visualizá-las em seus experimentos com compósitos de matriz de Al 6061 reforçados com $20 \%$ em volume de $\mathrm{Al}_{2} \mathrm{O}_{3}$.

YU, YUAN, WANG e SUI [67] também não encontraram estrias de fadiga nas superfícies fraturadas dos corpos de prova ensaiados em seus experimentos. Ainda alertam para a grande dificuldade que os compósitos apresentam 
para o reconhecimento e identificação da origem das trincas de fadiga que levam o material à falha.

\subsubsection{3 - Aspecto transversal das fraturas de fadiga}

As figuras 100 a 103 mostram o aspecto transversal das fraturas de fadiga nos materiais obtidos. O tipo de tratamento superficial adotado na preparação da superfície dos corpos de prova não teve influência sobre o aspecto das fraturas, sendo o principal responsável, nestes casos, a própria microestrutura de cada material.

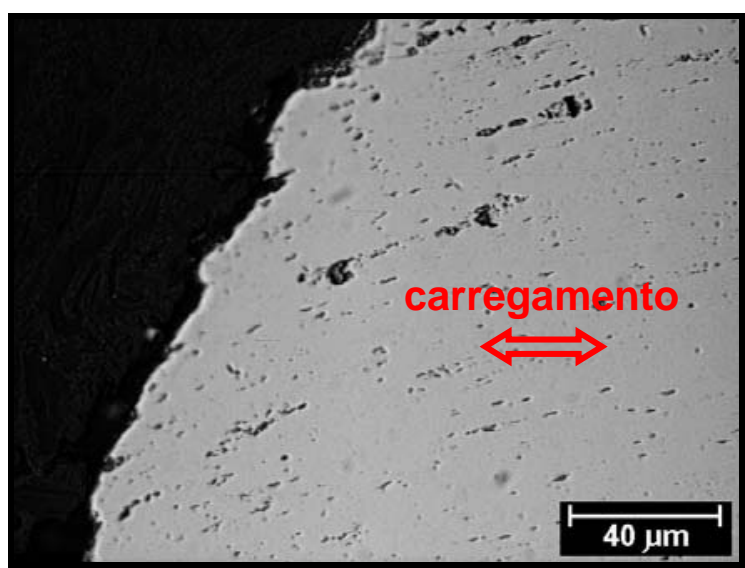

Figura 100 - Micrografia óptica mostrando o aspecto transversal da fratura de fadiga do Al/SiC $0 \%$.

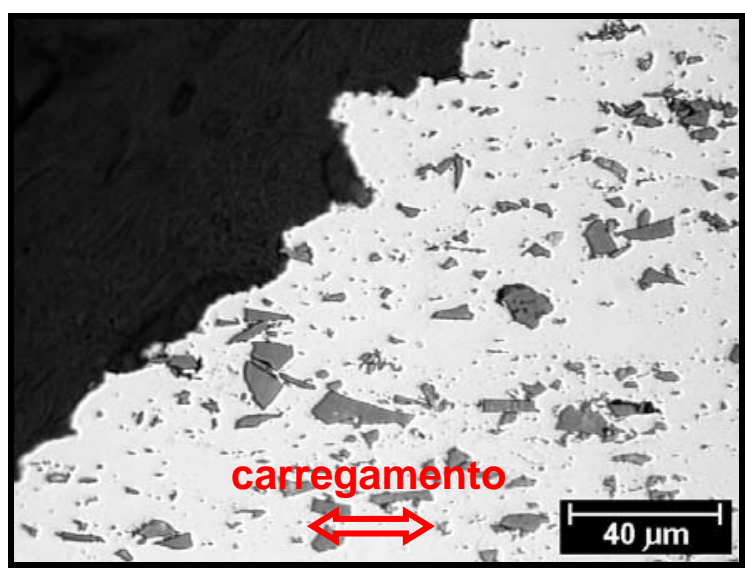

Figura 102 - Micrografia óptica mostrando o aspecto transversal da fratura de fadiga do $\mathrm{Al} / \mathrm{SiC} 10 \%$.

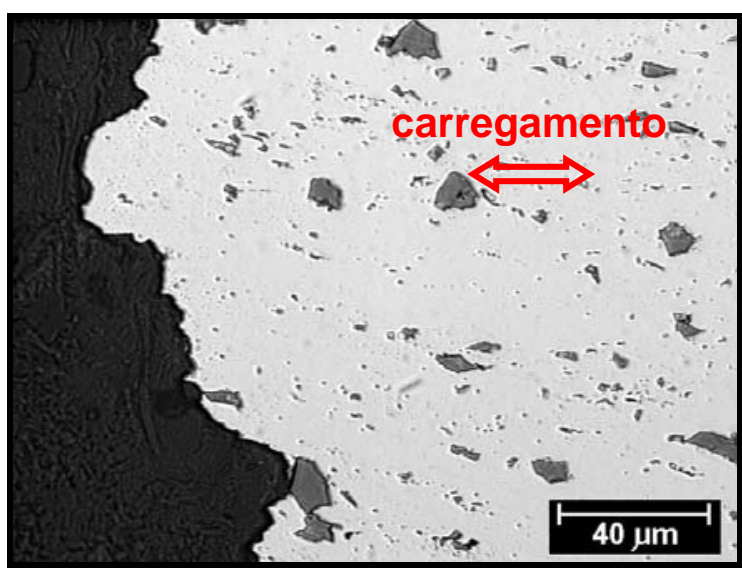

Figura 101 - Micrografia óptica mostrando o aspecto transversal da fratura de fadiga do Al/SiC $5 \%$.

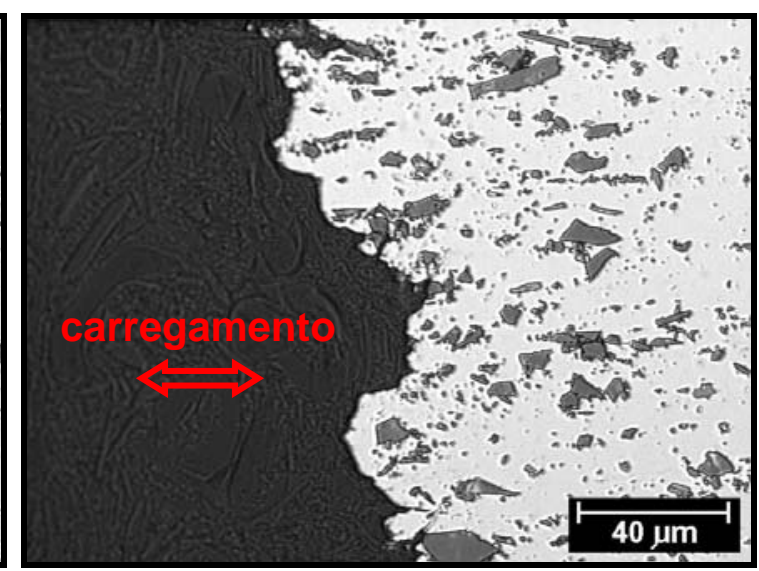

Figura 103 - Micrografia óptica mostrando o aspecto transversal da fratura de fadiga do Al/SiC $15 \%$. 
Analisando-se qualitativamente as fractografias anteriores, nota-se um aumento crescente de irregularidades nos perfis das fraturas com o aumento da fração volumétrica de reforços. Isto se deve provavelmente à diminuição crescente da ductilidade do compósito com o aumento da fase reforçante. Além disso, com o aumento de reforços, a fratura tende a se propagar de maneira mais tortuosa provocando mais irregularidades. LI, TIAN, HAN, KANG e WANG [68] também notaram este comportamento em seus experimentos, quando correlacionaram a rugosidade da superfície de fratura, com as propriedades de fadiga dos compósitos.

\subsubsection{4 - Falhas precoces.}

Para os corpos de prova que romperam com vida em fadiga abaixo de valores mais ou menos esperados, notou-se a presença de defeitos macroscópicos bastante visíveis nas superfícies fraturadas, que levaram os mesmos a falharem precocemente. As figuras 104 e 105, mostram duas fraturas de corpos de prova que romperam prematuramente.

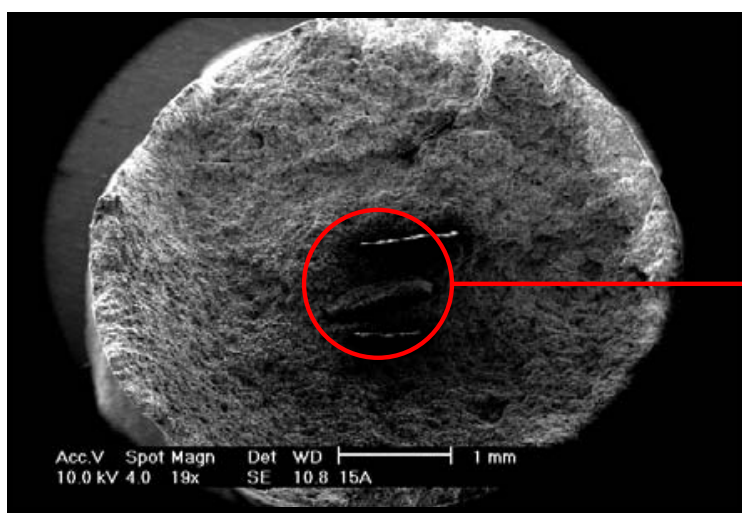

(a)

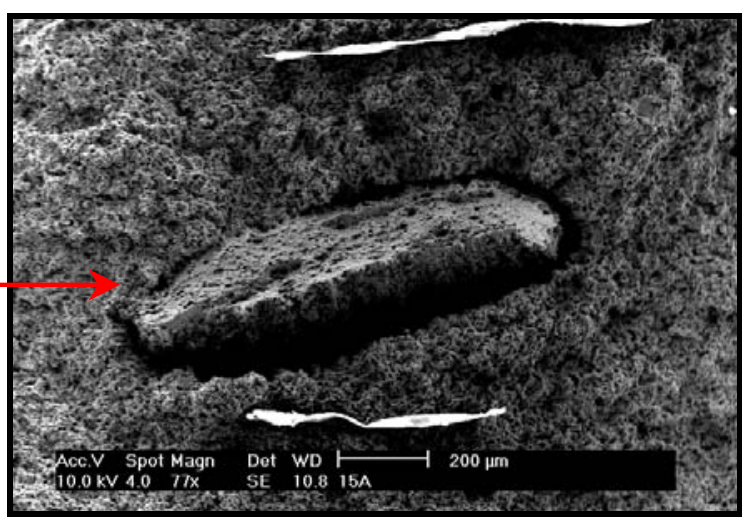

(b)

Figura 104 - Superfície fraturada do Al/SiC $5 \%$ usinado com PCD e avanço de 0,06 $\mathrm{mm} / \mathrm{rot}$, mostrando um defeito (aglomeração de alumínio) no interior do material que levou a uma falha precoce do corpo de prova. (a) Vista geral do defeito; (b) Detalhe do defeito. 


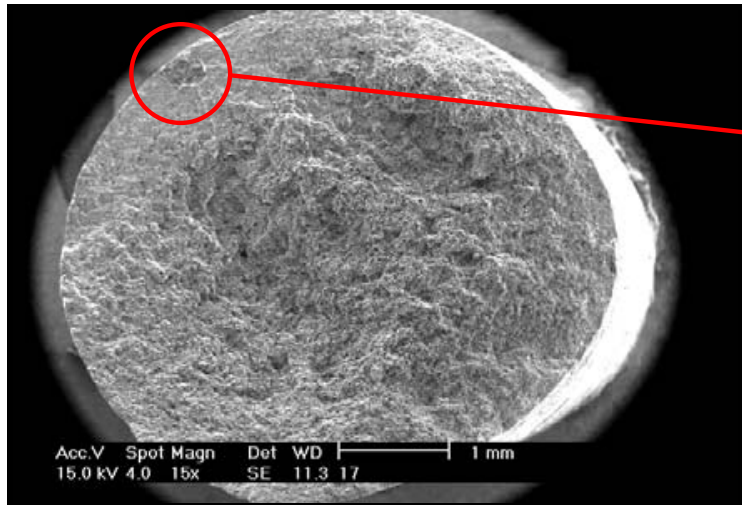

(a)

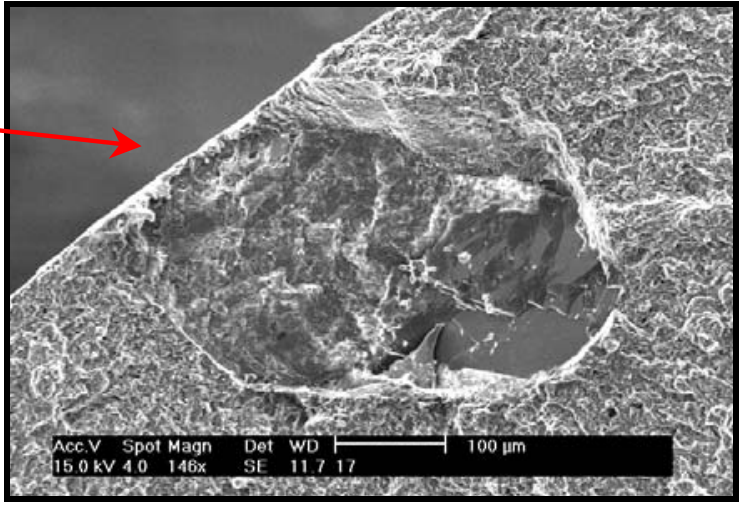

(b)

Figura 105 - Superfície fraturada do Al/SiC $15 \%$ usinado com MD e avanço de 0,06 $\mathrm{mm} / \mathrm{rot}$, mostrando um defeito (aglomeração de alumínio) no interior do material que levou a uma falha precoce do corpo de prova. (a) Vista geral do defeito; (b) Detalhe do defeito.

A figura 104 mostra um corpo de prova reforçado com $5 \%$ de SiC, usinado com PCD e taxa de avanço igual a $0,06 \mathrm{~mm} / \mathrm{rot}$. Este corpo de prova rompeu com 960 mil ciclos quando se esperava uma vida em torno de 2,2 milhões de ciclos. A fractografia revelou um veio de alumínio puro ao centro do corpo de prova que provocou a falha precoce do mesmo. Uma análise química feita por EDAX (figura 106) no microscópio eletrônico de varredura, confirmou a presença de alumínio puro na região realçada na figura.

$\mathrm{Na}$ fractografia da figura 105 nota-se a presença de uma partícula grande de SiC próxima da superfície do corpo de prova que provocou a falha precoce do mesmo. Este corpo de prova rompeu com 222 mil ciclos quando se esperava alcançar uma vida em torno de 1,3 milhões de ciclos. É facilmente observável nesta figura o aspecto de fratura por clivagem da partícula, que é uma característica de fratura muito comum em materiais frágeis.

Estes dois corpos de prova foram os únicos que apresentaram claramente características e evidências de falha precoce e representam cerca de apenas $1 \%$ do total de corpos de prova ensaiados. 


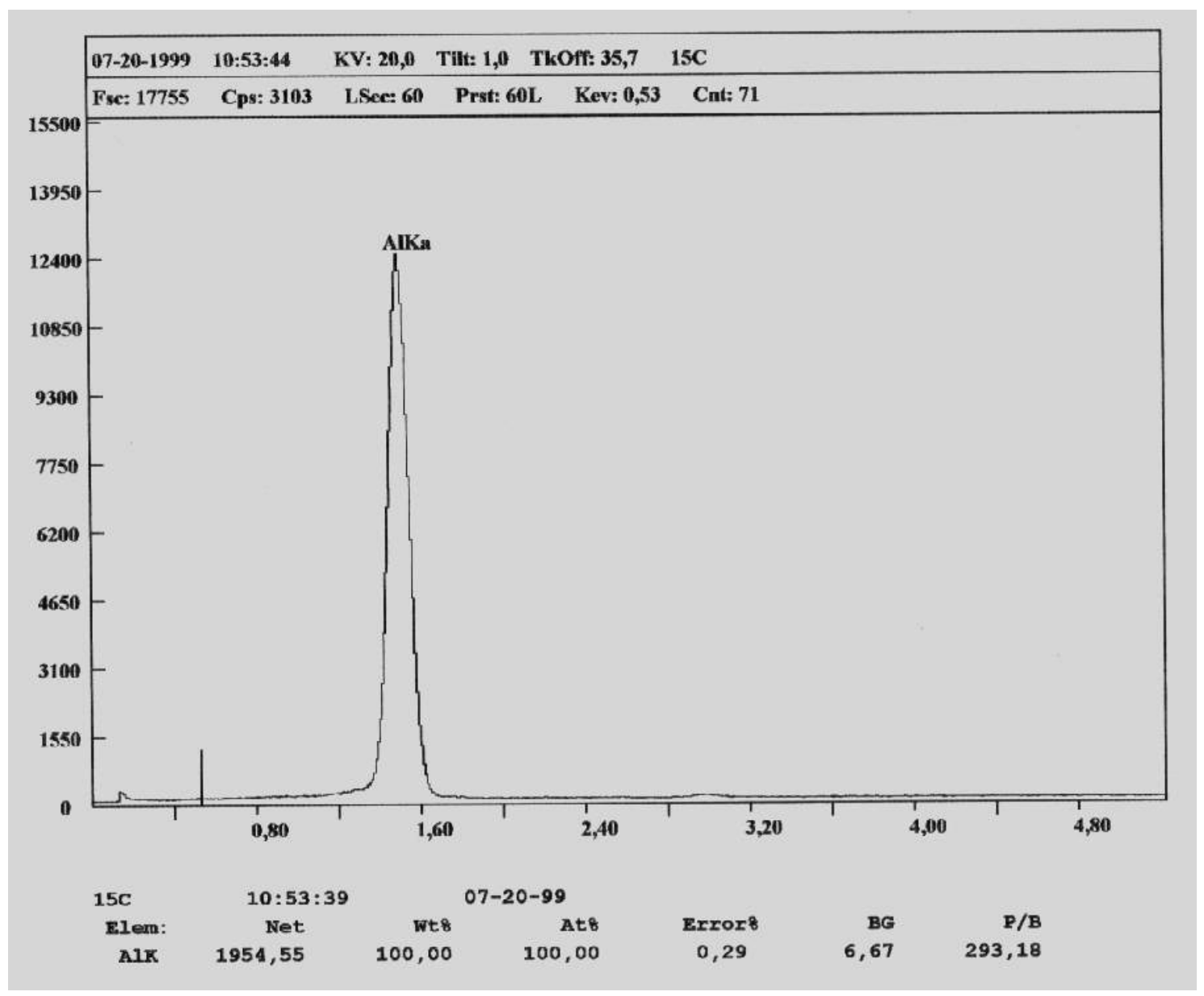

Figura 106 - Análise química feita por EDAX no microscópio eletrônico de varredura, da região realçada da fractografia mostrada na figura 104. A análise acusou a presença de alumínio puro na região realçada da figura 104. 


\section{CONCLUSÕES}

$\checkmark$ Os materiais reforçados com $5 \%$ de SiC apresentaram vida à fadiga inferior ao do material de controle (material não reforçado com $\mathrm{SiC}$ ) para todos os tipos de tratamentos superficiais mecânicos utilizados. Este comportamento pode ser devido à baixa fração volumétrica de reforços ou ao menor limite de escoamento destes materiais.

Para os materiais reforçados com 10 e $15 \%$ de SiC, a vida à fadiga dos corpos de prova usinados com taxa de avanço de $0,06 \mathrm{~mm} /$ rot concorreu com os jateados; mostrando que o processo de jateamento, nas condições em que foi realizado, não produziu efeitos benéficos satisfatórios sobre a vida à fadiga destes materiais.

$\checkmark$ Os materiais usinados com taxa de avanço de $0,24 \mathrm{~mm} /$ rot apresentaram a pior vida à fadiga em todos os casos. As raízes dos sulcos provocados pela ferramenta de usinagem sobre a superfície destes corpos de prova, funcionaram como fortes concentradores de tensão tornando-se pontos preferenciais para o aparecimento de trincas de fadiga.

$\checkmark$ Os materiais usinados com metal duro (MD) e avanço de $0,06 \mathrm{~mm} / \mathrm{rot}$ não apresentaram diferenças de vida à fadiga com relação aos usinados com diamante (PCD) e mesma taxa de avanço. O metal duro utilizado, que possui melhores propriedades ao desgaste, foi o provável responsável por este comportamento.

$\checkmark$ Os materiais reforçados com $5 \%$ de SiC e jateados apresentaram resultados de fadiga com o maior desvio padrão de todos os casos porque a superfície dos corpos de prova foi muito agredida e degradada pelos efeitos do processo. 
$\checkmark$ Os materiais reforçados com $5 \%$ de SiC, embora tenham apresentado vida à fadiga inferior à do material não reforçado, se mostraram os mais indicados para aplicações onde haja uma larga faixa de variação de tensão, pois os mesmos apresentaram menor sensibilidade à fadiga com a variação da carga (maior declividade da curva de fadiga), com relação aos demais materiais.

$\checkmark$ A seleção adequada do conjunto de variáveis no processo de jateamento é muito importante para garantir que os benefícios oriundos das tensões residuais compressivas, sejam capazes de superar o estado de superfície deixado por ele e com isso possa proporcionar benefícios positivos e expressivos em termos de melhoria das propriedades mecânicas. 


\section{SUGESTÕES PARA TRABALHOS FUTUROS}

- Pesquisar ataques químicos que revelem com nitidez os contornos de grão da matriz destes compósitos, para tentar visualizar a influência que os diferentes tratamentos mecânicos têm sobre eles a nível subsuperficial.

- Estudar o comportamento mecânico destes materiais sujeitos a diferentes condições e intensidades de jateamento.

- Avaliar o comportamento à fadiga de compósitos com matriz de alumínio AA-1100 e frações volumétricas entre $5 \%$ e $10 \%$ de SiC, afim de se verificar qual o limite mínimo de reforço necessário para promover a melhoria das propriedades dinâmicas, em relação ao material não reforçado .

- Avaliar o comportamento à fadiga de compósitos com matriz de alumínio AA-1100, obtidos por outras rotas de produção. 


\section{REFERÊNCIAS BIBLIOGRÁFICAS}

(1)MATTHEWS, F. L.; RAWLINGS, R. D. Composite Materials: Engineering and Science. Chapman e Hall, $1^{\text {st }}$. Edition, 1994.

(2)KUMAI, S.; KING, J. E.; KNOTT, J. F. Fatigue in SiC-particulate-reinforced aluminium alloy composites. Materials Science and Engineering, A146, p. 317-326, 1991.

(3)OMAM, C. N.; LU, J.; LIEURADE, H. P.; FLAVENOT, J. F. Endurance à la fatigue des composites à matrice métallique. Matériaux e Techniques, n. 5-6, p. 915, 1995.

(4)HARRIS, S. J.; Cast metal matrix composites. Materials Science and Technology, v. 4, p. 231-239, march, 1988.

(5)BONNEN, J. J.; ALLISON, J. E.; JONES, J. W. Fatigue behavior of a $2 x x x$ series aluminum alloy reinforced with $15 \mathrm{vol}$ pct $\mathrm{SiC}_{\mathrm{p}}$. Metallurgical Transactions $\boldsymbol{A}$, v. 22A, p. 1007-1019, may, 1991.

(6)HABEL, U.; CHRISTENSON, C. M.; ALLISON, J. E.; JONES, J. W. Fatigue behavior of a 2080 Al/SiC composite. Metal Matrix Composites, v. 2, p. 596-604, 1995.

(7)QUIGLEY, O.; MONAGHAN, J.; O'REILLY, P. Factors affecting the machinability of an $\mathrm{Al} / \mathrm{SiC}$ metal-matrix composite. Journal of Materials Processing Technology, n. 43, p. 21-36, 1994.

(8)STUCKY, M.; RICHARD, M. Influence of surface quality on fatigue behavior of AlSi7Mg type alloys. Materials Science Forum, v. 217-222, p. 1389-1394, 1996.

(9)SHARP, P. K.; CLAYTON, J. Q.; CLARK, G. The fatigue resistance of peened 7050T7451 aluminium alloy-repair and re-treatment of a component surface. Fatigue Fract. Engng Mater. Struct., v. 17, n. 3, p. 243-252, 1994.

(10)TAYLOR, D.; CLANCY, O. M. The fatigue performance of machined surfaces. Fatigue Fract. Engng Mater. Struct., v. 14, n. 2-3, p. 329-336, 1991.

(11)JESUS FILHO, E. S.; ROSSI, J. L. Surface finishing and damage in metal matrix composite machining. Materials Science Forum, v. 299-300, p. 416-423, 1999.

(12)METALS HANDBOOK. Failure, analysis and prevention. Ed. 9, v. 11, p. 102-135.

(13)DEGARMO, E. P.; BLACK, J. T.; KOHSER, R. A. Materials and Processes in Manufacturing, eighth edition, Prentice Hall, 1997. 
(14)STERNOWSKY, S. B.; DONNELL, G. O.; LOONEY, L. Effect of particle size on the mechanical properties of SiC particulate reinforced aluminium alloy AA6061. Key Engineering Materials, v. 127-131, p. 455-462, 1997.

(15)TAYA, M.; ARSENAULT, R. J. Metal Matrix Composites. Pergamon, ed. 1, 1989.

(16)HULL, D. An Introduction to Composite Materials. Cambridge University Press, 1981.

(17)DIETER, G. E. Mechanical Metallurgy. McGraw-Hill International Editions, third edition, 1986.

(18)CLYNE, T. W.; WITHERS, P. J. An introduction to Metal Matrix Composites. Cambridge University, 1993.

(19)SRIVATSAN, T. S.; SUDARSHAN, T. S.; LAVERNIA, E. J. Processing of discontinuously-reinforced metal matrix composites by rapid solidification. Progress in Materials Science, v. 39, p. 317-409, 1995.

(20)LLOYD, D. J. Particle reinforced aluminium and magnesium matrix composites. International Materials Reviews, v. 39, n. 1, p. 1-23, 1994.

(21)KREIDER, K.G. Metallic Matrix Composites. Academic Press, v. 4, 1974.

(22)SRIVATSAN, T.S.; IBRAHIM, I. A.; MOHAMED, F. A.; LAVERNIA, E. J. Processing techniques for particulate-reinforced metal aluminium matrix composites. Journal of Materials Science, n. 26, p. 5965-5978, 1991.

(23)AMBROZIO FILHO, F.; GOLDENSTEIN, H.; GONÇALVES, M.; ROSSI, J. L.; SOUZA, R. M.; YOSHIMURA, H. N. Desenvolvimento de compósitos de matriz metálica. Metalurgia \& Materiais, v. 52, n. 452, p. 248-252, 1996.

(24)APPLIED RESEARCH LABORATORY AT PENN STATE UNIVERSITY - Web Page. www.arl.psu.edu/areas/spraymetform/spraymetform.html ,march 2, 2000.

(25)EDSER, C. Healthy growth continues for PM conrods. Metallurgical Powder Report, november, pp.16-17, 1998.

(26)MANGIN, C.; ISAACS, J. A.; CLARK, J. P. MMCs for automotive engine applications. JOM - Jounal of the Minerals, Metals and Materials Society, Vol. 46, June, pp. 49-51, 1997.

(27)HUNT JR, W. H. Consultants' corner. The International Journal of Powder Metallurgy, Vol. 35, n. 2, pp. 23-25, 1999.

(28)JESUS, E. R. B. Obtenção, usinagem e desgaste de materiais compósitos de matriz metálica processados via metalurgia do pó. Dissertação de Mestrado IPEN / USP -1998. 
(29)COLLINS, J. A. Failure of Materials in Mechanical Design. Jonh Wiley \& Sons, second edition, 1993.

(30)CHIAVERINI, V. Tecnologia Mecância. Estrutura e Propriedades. Processos de Fabricação. V. 1, 2. ed. EDUSP e McGraw-Hill, 1986.

(31)SURESH, S. Fatigue of Materials. Cambridge University, 1994.

(32)BOYER, H. E. Atlas of fatigue curves. AMERICAN SOCIETY FOR METALS, Ohio, 1986.

(33)KOCANDA; S. Fatigue Failure of Metals. Sijthoff \& Noordhoof International Publishers, Vol. 1, 1978.

(34)METALS HANDBOOK. Failure, analysis and prevention, Eighth edition, pp. 95125, 1975.

(35)FUCHS, H. O.; STEPHENS, R. I. Metal Fatigue in Engineering, Jonh Wiley \& Sons, 1980.

(36)HWANG, W.; HAN, K. S. Statistical study of strength and fatigue life of composite materials. Composites, v. 18, n. 1, p. 47-53, 1987.

(37)ASTM E 739-91 STANDARD PRACTICE FOR STATISTICAL ANALYSIS OF LINEAR OR LINEARIZED STRESS-LIFE (S-N) AND STRAIN-LIFE ( $\varepsilon-N)$ FATIGUE DATA.

(38)KUMAI, S.; HU, J.; HIGO, Y.; NUNOMURA, S. Effects of dendrite cell size and particle distribution on the near-threshold fatigue crack growth bahavior of cast Al-SiCp composites. Acta Metallurgica, Vol. 44, n. 6, pp. 2249-2257, 1996.

(39)LIU, X. C.; BATHIAS, C. Fatigue behavior of $\mathrm{Al}_{2} \mathrm{O}_{3}$ short fibre reinforced aluminium alloy. Fatigue Fract. Engng. Mater. Struct., Vol. 15, n. 11, pp. 1113-1123, 1992.

(40)MASUDA, C.; TANAKA Y. Fatigue properties and fatigue fracture mechanisms of SiC whiskers or SiC particulate-reinforced aluminium composites. Journal of Materials Science, n. 27, pp. 413-422, 1992.

(41)SHANG, I. K.; YU, W.; RITCHIE, R. O. Role of silicon carbide particles in fatigue crack growth in SiC-particulate-reinforced aluminum alloy composites. Materials Science and Engineering A, 102, pp. 181-192, 1988.

(42)HERTZBERG, R. W. Deformation and Fracture Mechanics of Engineering Materials. 3. ed., Jonh Wiley \& Sons, 1989.

(43)FORREST, P. G.; Fatigue of Metals. Pergamon Press, 1962.

(44)BLACK, S. C.; CHILES, V.; LISSAMAN, A. J.; MARTIN, S. J. Principles of Enginnering Manufacture, third edition, Arnold, 1996. 
(45)MARCONDES, F. C. A História do Metal Duro - Sandvik - $1^{a}$ edição, Unida Artes Gráficas e Editora Ltda, 1990, pp. 27-28.

(46)SHOT PEENING TERMINOLOGY - Web Page.

www.shotpeening.com/shot_peening_terminology.htm , march 2, 2000.

(47)NOYAN, I. C.; COHEN, J. B. Residual Stress - Measurement by diffraction and interpretation, Springer-Verlag, 1987.

(48)AGOSTINHO, L. O.; ROdRIGUES, A. C. S.; LIRANI, J. Tolerâncias, Ajustes, Desvios e Análise de Dimensões. Edgard Blücher Ltda, 1977.

(49)NBR 6405 - Rugosidade das Superfícies - ABNT - Associação brasileira de normas técnicas, Jan. 1988.

(50)MOURISCO, A. J. - Preparação e caracterização de compósito de matriz de alumínio 1100 com partículas de SiC por metalurgia do pó. Dissertação de Mestrado - IPEN / USP -1995.

(51)DIN 50125 - Ensaios de Materiais Metálicos - Corpos de prova de tração Diretrizes para a execução - Versão traduzida para o português - 1976.

(52)ASTM E 466 - 96 STANDARD PRACTICE FOR CONDUCTING FORCE CONTROLLED CONSTANT AMPLITUDE AXIAL FATIGUE TESTS OF METALLIC MATERIALS.

(53)BARAGETTI, S.; GUAGLIANO, M. Influence of low-intensity shot peening on the fatigue strength of an Al/Al2O3 composite material. Fatigue \& Fracture of Engineering Materials \& Structures, 21, pp. 717-726, 1998.

(54)CHERNENKOFF, R. A.; MOCARSKI, S.; YEAGER, D. A. Increased fatigue strength of powder forged connecting rods by optimised shot peening. Powder Metallurgy, Vol. 38, Nº 3, pp. 196-200, 1995.

(55)COUTURIER, L.; LIEURADE, H. P.; FLAVENOT, J. F.; LU, J. Comportement en fatigue de composites à matrice aluminium. Mécanique Industrielle et Matériaux, Vol. 50, Nº 3, pp. 116-121, septembre, 1997.

(56)LU, J.; MIEGE, B.; FLAVENOT, J. F.; THERY, S. Study on the effect of the surface treatment on the residual stress gradient in silicon carbide (SiC) reinforced aluminum metal matrix composites. Journal of Composites Technology \& Research, Vol. 12, № 4, pp. 232-238, 1990.

(57)ASTM E 468-90 STANDARD PRACTICE FOR PRESENTATION OF CONSTANT AMPLITUDE FATIGUE TEST FOR METALLIC MATERIALS.

(58)RASUL, T.; MEGUID, S. A. Machining residual stresses. Materials Science and Technology, Vol. 12, pp. 445-449, May, 1996. 
(59)CHAWLA, N.; ANDRES, C.; JONES, J. W.; ALLISON, J. E. Effect of SiC volume fraction and particle size on the fatigue resistance of a $2080 \mathrm{Al} / \mathrm{SiCp}$ composite. Metallurgical and Materials Transactions A, volume 29A, pp. 2843-2854, november, 1998.

(60)BATHIAS, C. A review of fatigue of aluminium matrix reinforced by particles or short fibers. Materials Science Forum, Vols. 217-222, pp. 1407-1412, 1996.

(61)HALL, J. N.; JONES, J. W.; SACHDEV, A. K. Particle size, volume fraction and matrix strength effects on fatigue behavior and particle fracture in 2124 aluminum-SiCp composites. Materials Science and engineering, A183, pp. 69-80, 1994.

(62)BONNEN, J. J.; YOU, C. P.; ALLISON, J. E.; JONES; J. W. Fatigue behavior of discontinuouly reinforced aluminum matrix composites. Fatigue 90, Honolulu, Hawaii, USA, 15-20 july 1990, pp. 887-892.

(63)HARRIS, S. J.; YI, G. The fatigue characteristics of 8090 reinforced with silicon carbide particulate. Sixth International Aluminium-Lithium Conference, Garmisch - Partenkirchen - Germany, pp. 663-669, 7-11 october, 1991.

(64)ABD EL-AZIM, A. N.; KHALIFA, T. A.; EL-AKABAWY, A. A. Mechanical properties of A356/particle metal matrix composites. Processing and Fabrication of Advanced Materials VI, pp. 543-556, 1998.

(65)NIEH, T. G.; LESUER, D. R.; SYN, C. K. Tensile and fatigue properties of a 25 vol $\%$ SiC particulate reinforced $6090 \mathrm{Al}$ composite at $300^{\circ} \mathrm{C}$. Scripta Metallurgica et Materialia, Vol. 32, Nº 5, pp. 707-712, 1995.

(66)LI, C.; ELLYIN, F. Fatigue damage and its localization in particulate metal matrix composites. Materials Science and Engineering, A214, pp. 115-121, 1996.

(67)YU, W.; YUAN, J.; WANG, Z.; SUI, Q. Characteristics of Fatigue in a SiC Reinforced Aluminium Alloy. Chin. J. Met. Sci. Technol., Vol. 5, pp. 279-283, 1989.

(68)LI, X. W.; TIAN, J. F.; HAN, N. L.; KANG, Y.; WANG, Z. G. Quantitative study of correlation between fracture surface roughness and fatigue properties of SiC/Al composites. Materials Letters, 29, pp. 235-240, 1996. 
APÊNDICE 1 
PROGRAMA DE USINAGEM (CNC) DOS CORPOS DE PROVA DE FADIGA SENTIDO DE USINAGEM: DA DIREITA PARA A ESQUERDA

\begin{tabular}{|c|c|c|c|c|c|c|}
\hline $\mathrm{N}$ & G & $x$ & Z & $\mathrm{I}, \mathrm{F}, \mathrm{T}, \mathrm{S}$ & $\mathrm{K}, \mathrm{M}, \mathrm{L}$ & OBS: \\
\hline N05 & & & & & M29 & \\
\hline N10 & & & & & M39 & \\
\hline $\mathrm{N} 15$ & & & & T0101 & & \\
\hline $\mathrm{N} 20$ & G50 & & & S3980 & & \\
\hline $\mathrm{N} 25$ & G96 & & & S150 & & \\
\hline N30 & G00 & & $\mathrm{Z} 70$ & & & \\
\hline N30 & G00 & $\mathrm{X} 16$ & & & M14 & \\
\hline N35 & G01 & $\times 10,6$ & & $F(*)$ & & \\
\hline $\mathrm{N} 40$ & G01 & & Z-2 & & & \\
\hline N45 & G00 & $\mathrm{X} 12,2$ & & & & \\
\hline N50 & G00 & & $Z 51,744$ & & & \\
\hline N55 & G02 & $\times 9,430$ & $Z 41,5$ & R38,635 & & \\
\hline $\mathrm{N} 60$ & G01 & & $Z 25,5$ & & & \\
\hline N65 & $\mathrm{G} 02$ & $\mathrm{X} 12,2$ & $Z 15,256$ & R38,635 & & \\
\hline N70 & G00 & & $Z 53,105$ & & & \\
\hline N75 & $\mathrm{G} 02$ & $\times 8,664$ & $Z 41,5$ & $\mathrm{R} 39,018$ & & \\
\hline $\mathrm{N} 80$ & G01 & & $\mathrm{Z} 25,5$ & & & \\
\hline N85 & G02 & $\mathrm{X} 12,2$ & $Z 13,895$ & $\mathrm{R} 39,018$ & & \\
\hline $\mathrm{N} 90$ & G00 & & Z54,334 & & & \\
\hline N95 & G02 & $\times 7,898$ & $Z 41,5$ & $\mathrm{R} 39,401$ & & \\
\hline N100 & G01 & & $\mathrm{Z} 25,5$ & & & \\
\hline N105 & $\mathrm{G} 02$ & $\mathrm{X} 12,2$ & $Z 12,666$ & $\mathrm{R} 39,401$ & & \\
\hline N110 & G00 & & $Z 55,466$ & & & \\
\hline N115 & $\mathrm{G} 02$ & $\times 7,132$ & $Z 41,5$ & $\mathrm{R} 39,784$ & & \\
\hline N120 & G01 & & $Z 25,5$ & & & \\
\hline N125 & G02 & $\times 12,2$ & $Z 11,534$ & $\mathrm{R} 39,784$ & & \\
\hline N130 & G00 & & $Z 56,522$ & & & \\
\hline N135 & $\mathrm{G} 02$ & $\times 6,366$ & $Z 41,5$ & $\mathrm{R} 40,167$ & & \\
\hline N140 & G01 & & $\mathrm{Z} 25,5$ & & & \\
\hline N145 & G02 & $\times 12,2$ & $\mathrm{Z} 10,478$ & $\mathrm{R} 40,167$ & & \\
\hline N150 & G00 & & $Z 57,518$ & & & \\
\hline N155 & G02 & $\times 5,600$ & $Z 41,5$ & $\mathrm{R} 40,55$ & & \\
\hline N160 & G01 & & Z25,5 & & & \\
\hline N165 & G02 & $\times 12,2$ & $Z 9,482$ & $\mathrm{R} 40,55$ & & \\
\hline N170 & G00 & & $\mathrm{Z} 70$ & & & \\
\hline N175 & G00G42 & $\mathrm{X} 10,2$ & & & & \\
\hline N180 & G01 & & $Z 55,692$ & & & \\
\hline N185 & G02 & $\times 5,1$ & $Z 41,5$ & $\mathrm{R} 40,8$ & & \\
\hline
\end{tabular}




\begin{tabular}{|c|c|c|c|c|c|c|}
\hline $\mathrm{N} 190$ & $\mathrm{G} 01$ & & $\mathrm{Z} 25,5$ & & & \\
\hline $\mathrm{N} 195$ & $\mathrm{G} 02$ & $\mathrm{X} 10,2$ & $\mathrm{Z} 11,308$ & $\mathrm{R} 40,8$ & & \\
\hline $\mathrm{N} 200$ & $\mathrm{G} 01$ & & $\mathrm{Z}-2$ & & & \\
\hline $\mathrm{N} 205$ & G00G40 & $\mathrm{X} 100$ & & & & \\
\hline N210 & G00 & Z100 & & & & \\
\hline N255 & & & & & M30 & \\
\hline
\end{tabular}

( * ) - Foi utilizada uma taxa de avanço de $0,24 \mathrm{~mm} /$ rot para um acabamento grosseiro e $0,06 \mathrm{~mm} /$ rot para acabamento fino.

PROGRAMA DE USINAGEM (CNC) DOS CORPOS DE PROVA DE FADIGA SENTIDO DE USINAGEM: DA ESQUERDA PARA A DIREITA

\begin{tabular}{|c|c|c|c|c|c|c|}
\hline $\mathrm{N}$ & $G$ & $x$ & $Z$ & $\mathrm{I}, \mathrm{F}, \mathrm{T}, \mathrm{S}$ & $\mathrm{K}, \mathrm{M}, \mathrm{L}$ & OBS: \\
\hline N05 & & & & & M29 & \\
\hline $\mathrm{N} 10$ & & & & & M39 & \\
\hline N15 & & & & T0101 & & \\
\hline $\mathrm{N} 20$ & G50 & & & S3980 & & \\
\hline $\mathrm{N} 25$ & G96 & & & S150 & & \\
\hline N30 & G00 & & $Z-2$ & & & \\
\hline N30 & G00 & $\times 13$ & & & M14 & \\
\hline N35 & G01 & $\times 10,6$ & & $F(*)$ & & \\
\hline $\mathrm{N} 40$ & G01 & & $\mathrm{Z} 70$ & & & \\
\hline $\mathrm{N} 45$ & G00 & $\mathrm{X} 12,2$ & & & & \\
\hline $\mathrm{N} 50$ & G00 & & $Z 15,256$ & & & \\
\hline N55 & G03 & $\times 9,430$ & $Z 25,5$ & R38,635 & & \\
\hline $\mathrm{N} 60$ & G01 & & $Z 41,5$ & & & \\
\hline N65 & G03 & $\mathrm{X} 12,2$ & $Z 51,744$ & $\mathrm{R} 38,635$ & & \\
\hline N70 & G00 & & Z13,895 & & & \\
\hline N75 & G03 & $x 8,664$ & Z25,5 & R39,018 & & \\
\hline N80 & G01 & & $Z 41,5$ & & & \\
\hline N85 & G03 & $\mathrm{X} 12,2$ & $Z 53,105$ & R39,018 & & \\
\hline N90 & $\mathrm{G} 00$ & & Z12,666 & & & \\
\hline N95 & $\mathrm{G} 03$ & $\times 7,898$ & $Z 25,5$ & R39,401 & & \\
\hline N100 & G01 & & $Z 41,5$ & & & \\
\hline N105 & G03 & $\mathrm{X} 12,2$ & Z54,334 & R39,401 & & \\
\hline N110 & G00 & & Z11,534 & & & \\
\hline N115 & G03 & $\times 7,132$ & $Z 25,5$ & R39,784 & & \\
\hline N120 & G01 & & $Z 41,5$ & & & \\
\hline N125 & $\mathrm{G} 03$ & $\mathrm{X} 12,2$ & $Z 55,466$ & R39,784 & & \\
\hline N130 & G00 & & $Z 10,478$ & & & \\
\hline N135 & G03 & $\times 6,366$ & $Z 25,5$ & $\mathrm{R} 40,167$ & & \\
\hline N140 & G01 & & $Z 41,5$ & & & \\
\hline
\end{tabular}




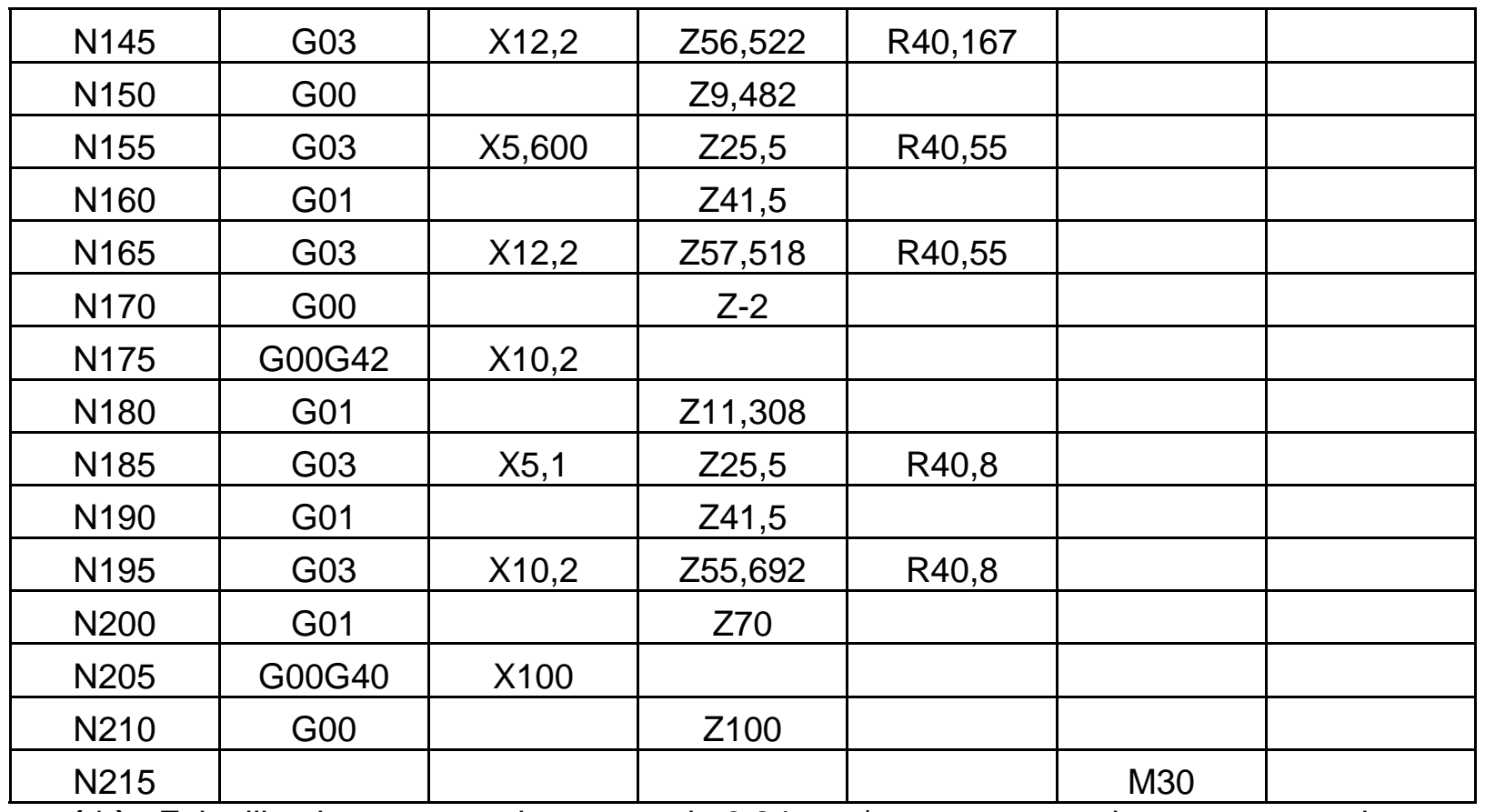

( * ) - Foi utilizada uma taxa de avanço de $0,24 \mathrm{~mm} /$ rot para um acabamento grosseiro e $0,06 \mathrm{~mm} /$ rot para acabamento fino. 